\title{
Die Urkundensammlung
}

\section{am K. B. Nationalmuseum zu München.}

Von

M. J. Neudegger, K. Reichsarchivrat.

Die Urkundensammlung am K. B. Nationalmuseum in München ist nicht von grösserem Umfang aber von gediegenem weitreichenden und vielseitigen Inhalt. Das beigegebene „Chronologische Verzeichnis" und das ihres "Inhalts" erhärten dies in Kurzem hinsichtlich Zeitumfangs (1141-1839), Gegenstande, Herkunft und geographischer Verbreitung.

Die Anlegung von Urkundensammlungen in Museen neben anderen „Werken unserer Väter" ist durchaus gerechtfertigt, denn es ist ihre "Aufgabe, darnach zu streben, ein Gesamtkulturbild der früheren Jahrhunderte zu bieten, und es müssen sonach Urkunden, Siegel, Münzen usw. vertreten sein, um die jeweilige Zeitperiode zu illustrieren " (Gutachten des Nat.-Mus. vom 6. März 1875). Es sind früher von staatlichen Archiven, denen die Bewahrung der Landesurkunden obliegt, Bedenken gegen das Anlegen paralleler Sammlungen in Museen erhoben worden. Dem wurde von letzteren entgegnet, dass ihnen ingleichen entsprechende Sammlung von Gemälden, Drucken, Münzen und Medaillen etc. abgesprochen werden könnte. Es ergibt sich, dass es auf die Gattung von Urkunden ankommt, die in Museen gezeigt werden können, und dass es genügt, da 
nur kleinere charakteristische Sammlungen, streng auf den $Z$ weck beschränkt, zusammenzustellen. Berühmte Staats- und historische Akten dürfen also als Ausstellungsobjekte in Museen richt gesucht werden; dagegen ist kein Mangel an Proben von Schriftwerken und schriftlichen Beurkundungen, die nicht streng und allein in Archiven aufbewahrt werden müssen. Unter diesem Gesichtspunkte betrachtet ist die Auswahl des Münchener Nationalmuseums bei der verhältnismässig geringen Zahl von 294 Urkunden eine zutreffende und höchst entsprechende. Fast alle Verhältnisse des öffentlichen, staatlichen wie kommunalen, kirchlichen wie laischen, des privaten rechtlichen wie wirtschaftlichen Lebens kommen durch geeignete Beurkundungen zur anschaulichen Darstellung: ein Buch der Kulturgeschichte ist hier vor uns aufgeschlagen.

Die Darstellung der Schriftentwicklung ist als nächster Zweck beinahe vollständig erreicht: Ihre Clironologie erstreckt sich von Mitte des 12. Jahrhunderts') nahezu lückenlos über sieben Jahrhunderte, ihr geographischer Kreis sichert eine Vergleichung der Schriften von nahezu Mitteleuropa. Auf das heutige Bayern entfällt der grössere Teil, auf Territorien ausserhalb Bayerns ein Fünftel der Urkunden (welch' letztere durch Sternchen * zur rascheren Orientierung gekennzeichnet sind). Mangels Beigabe von Schriftabbildungen mag auf die Werke solcher an den verschiedenen Münchener Bibliotheken und Archiven hingewiesen werden.

Wie Kunst- und Handwerkserzeugnisse so geben auch Schrift- und Sprachformen den jeweiligen Charakter der Zeit - Höhepunkte und Verfallszeiten - wieder. Die nähere Untersuchung der Schriftentwicklung und des Beurkundungswesens gehört in das wissenschaftliche Gebiet der Paläographie und Diplomatik; bezügliche Erörterungen wurden hier, wo der Zweck zunächst Orientierung ist, weggelassen; nur mag zur vorliegenden Spezialsammlung führend der allgemeine Hinweis dienlich sein, dass mit dem 17. Jahrhundert, besonders seit dem dreissigjährigen Krieg und mit dem zunehmenden Akten- und Prozesswesen die bisherigen klaren, charaktervollen Schrift-, Beurkun-

1) Das Vorhandensein einiger $\mathrm{K}$ a is erurkunde $\mathrm{n}$ (seit Karl d. Gr.) wäre erwünscht; es befindet sich aber ein grosser Selekt solcher am Reiohsarchiv in München. 
dungs- und Sprachformen sich lockern und allmählich auflösen (Zu vgl. No. 1 u. 2 gegen 203, 287). Bis in die neuere Zeit ist die äussere Form der alten feierlichen Urkunden fast nur mehr in sogenannten „Diplomen“ erhalten (Zu vgl. im „Verz. des Inhaltes" unter IV die Adels- und Wappenbriefe, unter IX die Diplome des Schul- und Gelehrtenwesens, persönlicher Ehrenbezeugungen, der Gewerbs- und Geburtsatteste). - Nur einige Stiicke der Sammlung, wohl Beigaben zu Geschenken, erscheinen überzählig. - Unecht ist nur eine Urkunde (No. 6), die aber als Beispiel, wie nach zweihundert Jahren ein Original nachzuahmen versucht wurde, belehrendes Interesse bietet.

Dass manche Stücke dieser Sammlung eine wertvolle Bereicherung für Landesarchive bilden und systemgemäss in deren Obhut gehören würden, ist zuzugeben, kann aber den Besitz des königlichen Nationalmuseums nicht schmälern; vielmehr ist dieser Umstand der nächste Anlass der Erschliessung dieser Urkunden im Rahmen der "Archival. Zeitschrift". - Die Regesten (Auszüge) wurden nach Massgabe des Raumes und gemeingültiger UUbung, inhaltlich mit Berücksichtigung des kulturgeschichtlichen Zweckes der Sammlung hergestellt; daher schliesst sich u. a. die Ausdrucksweise gerne jener der Urkunden und den entnommenen Originalstellen an.

Eine eingehende materielle Besprechung hauptsächlicher, merkwürdiger oder wissenschaftlich bemerkenswerter Stücke konnte hier, ausser durch Andeutung, nicht Aufgabe sein; letztere bestand, wie bereits bemerki, in der erstmaligen, ein Repertorium ersetzenden Inventarisation, und man wollte besonders der Spezialforschung und-Anzeige Jener nicht vorgreifen, die den einzelnen Urkunden je nach Ort oder Inhalt oder durch frühere Arbeiten besonders nahe stehen (zu vgl. No. $1-\bar{\tau}$ usw.); vorgearbeitet hat ihnen aber der Verfasser durch das chronologische Gegenstands- und das Orts- und rechtssystematische Inhaltsverzeichnis.

Zur äusseren Statistik ist noch zu bemerken, dass von den Urkunden 121 mit Hänge-Siegeln, No. 39 und 142 je mit 10, No. 74 noch mit 37 versehen sind. Das älteste Hänge-Siegel datiert von 1213, das jüngste von 1839. - In 6 Urkunden ron verschiedenen mittelalterlichen niederländischen bezw. niederdeutschen Sprachidiomen unterscheidet sich die Schrift wenig 
von süddeutschen (No. 18, 29, 36, 39, 110, 150). - Die hier älteste Urkunde in deutscher Sprache rührt vom Jahre 1324 (No. 19); die deutschen Urkunden sind in den Regesten gekennzeichnet durch Einleitung des Originaldatums Init "Gegeben" oder "Geschehen", die lateinisch en mit "Datum" oder "Actum". - Jenen Urkunden, die durch ihre Herkunft oder ihre Ausstattung ansehnlicher erscheinen, wurden ihre Masse (in Centim.) beigefügt, wobei die erste Verhältniszahl die Breite oder Horizontale der zum Lesen vorliegenden Urkunde angibt, die zweite die Höhe oder Vertikale ohne die Plica.

Die Urkundensammlung wird zu Jedermanns Einsicht im sehenswerten Bibliotheksale des Nationalmuseums verwahrt.

\section{Chronologisches Verzeichnis der Urkunden.}

Die mit "bezeichneten Urkunden sind als nichtbayerische, jene olıne dieses Zeichen als bayerischo zu betrachten.

1. - 1141. 1143. Hochstift Würzburg-StiftZell, Güterschenkung.

*2. -- 1157, Jan. 24. Erzstift Magdeburg - Mons serenus (Lauter(1156, Nov. 30) berg, heute Petersberg bei Halle a S.); Gründung u. Erweiterung durch Markgraf Konrad von Meissen.

3. - 1213, Mai 29. Stadt Regensburg - Tausch von Gütern an der Bachkirchstrasse.

4. - 1233, März 25. (jraf v. Bogen u. Kloster Windberg - Kirchen zu Viechtach u. Schütenhofen.

5. - - Aug. 8. Hochstift Wiirzburg - Guiter der Grafen v. Botenlauben zu Tulbe.

6. - - - Graf v. Bogen u. Kloster $W^{r}$ ind berg - Güter zu Niederhermanstorf $u$. Waarenzug über die Donau.

* 7. - 1235, April 4. Pap s t Gregor IX - Indulgenzbulle für Kloster Heckebach.

8. - 1240, Aug. 30. Bayern, Herzog Otto d. E. - Schenkung Bogen'scher Guiter an Kluster Windherg.

9. - 1246. - - Kloster Schwarzach u. Pfarrei Kitzingen Die Kinder B.'s von Langheim.

10. - 1261, April 13. Hochstift Wurzburg - Kloster Michelfeld, päpstl. Bestätigung seiner Konstitution.

-11. - 1283, Aug. 19. Erzstift K öl n - Orden der Karmeliter, Indulgenz.

12. - 1284, Dez. 10. Hochstift Wü r z bu rg - Minoriten das., Indulgenz.

*13. - 1286. - - Orden der Karmeliter - Indulgenz.

14. - 1297, April 11. Papst Bonifazius VIII - Indulgenz für die Marienkirche in Kelheim. 
15. - 1297, Mai 3. Burggraf zu Nürnberg - Güter der Deutschherrn zu Obernzenn.

* 16. - 1303, Okt. 21. Herzog v. Kärnthen u. Tirol -- Abgabenfreiheit des Kreuzklosters zu Trient.

17. - 1305, Aug. 17. Kloster Holzkirchen - Kirche zu Neubrunn, Stift Fulda u. Deutschherrn.

* 18. - 1315, März 12. Herzog v. Braunschweig - Lehen der Mühle (1350) vor Braunschweig.

19. - 1324, Mai 19. Kloster Prüfening - Pfarrei Hohenschambach.

20. - 1325, Jan. 5. Stadt Bamberg - Familien Zollnor u. Auf soss, Erbe.

- 21. - - Juli 1. Erzstift Köln - Karmeliter, Indulgenz.

22. - 1327, Mai 5. Herzoge v. Bayern - Stadt Kelheim haftet für einen Totschlag.

23. - 1337, Juni 30 . Bamberg, Stadtgerichtsbrief - Stiftung zum Katharinenspital das.

24. - 1338, März 6. Herzog v. Bayern - Steuer der Stadt Kelheim.

25. - 1345, Jan. 16. Ka i 8 er Ludwig d. B. - Privilegien-Erneuerung für Kelbeim.

- 1350, März 12. Herzog v. Braunschweig - siebe No. 18.

26. - 1353, Mai 1. Hochst. Ba mberg - Päpstl. Indulgenz fur Bamberger Kirohen.

-27. - 1361, Mai 10. Tirol - Schwaighof zu Bruneck, Lehen.

28. - - Sept. 23. Bamborg, Stadtgerichtsbriof - Stiftung zu St. Jakob das.

*29. - 1381, Nov. 12. Herzog v. Jülich-Berg - Privileg für Bielefeld.

30. - 1391, Jan. 18. v. Paulstorfer - Hof zu Haselbach i. O. Pf.

31. - 1396, Juni 22. Bamborg, Papst-Bulle - Die Güter des Katharinenhospitals das.

- 32 - 1400, Dez. 23. Salzburg, Papstbulle - Goorgskapelle, Indulgenz.

33. - 1402, Febr. 26. W ürzburg - Lehen derer vom Stein das.

*34. - 1405, Mai 18. Rottweil -. Stiftung zur Frauenkapelle das.

35. - - Dez. 22. Hochst. B a mberg - Grundstuicke in der Mark zu Kreutschach.

-36. - 1408, Dez. 11. Gel de rn - Sticke v. Lichtenhorst, Gut zu Didam bei Doesburg.

37. - 1424, Mai 13. Hochst. B a mberg, Kellereigerichtsbrief Zehent zu Neuses.

38. - 1427, Juli 11. Herzoge v. Bayern - Anerkennung hzgl. bayer. Urkunden.

*39. - 1430. Nor. 27. Geldern (Cleve) - Kloster Sleenhorst bei Doesburg.

40. - 1432, Juni 4. Hochst. Wü zzburg - Hassiurt, Mühle das.

41. - 1435, Juni 27. Hochst. Ba mberg - Stadt u. Bischof, Fehde.

42. - 1436, Jan. 15. Stift Banz - Kesholz, Liohtenstein'eches Lehen. 
-43. - 1437, Dez. 17. Erzstift Mainz - Kloster Seligenstadt, beraubt seitens Gelnhausen.

44. - 1439. März 27. Hochst. Bamberg, Landgerichtsbrief - v. Zollner zu Herzogenaurach.

45. -- 1440, Jan. 31. Hochst. B a mberg, Urkunden des Hofgerichts, (1425, Febr. 27.) des Kellergerichts u. der "heimlichen Froischöffen“ (1440, Jan. 7.) das., Güter des Siechenhauses St. Anton betr.

* 46. - 1441. Febr. - Papst Felix V - Bulle über die Verwaltung des Franziskanerklosters zu Basel.

47. - 1444, Jan 8. Stadt Kelheim - Benefizium bei der Gottesacker-Kapelle.

48. - 1447 , Febr. \& Stadt B a m berg - Jährlicher Weinzins eines Bürgers.

49. - - Sept. 7. Stadt München - Anwesen der Astaler.

-50. - - Nov.20/27. Kaiser Friedrich - Wappenverleihung.

51. - 1450). April 20. Bamberg, Stadtgerichtsbrief - Kloster hl. Grab, Güter.

52. - 14503, Jan. 10. Hochst Bamberg - Grundvermarkung bei Obernheide.

53. - 1454, Febr. 18. Markgr. zu Brandevburg u. Burggr. zu Nürnberg - v. Zollner zu Herzogenaurach, Bestallung.

54. - - Mai 26. Nürnberg - Familien Zollner, Tetzel u. Grundherr, Lehen.

55. - 1456, Febr. 1. Markgr. zu Brandenburg u. Burggr. zu Nürnberg - v. Zollner, Dienstbrief.

56. - 1457, Juni 16. Bamberg, Stadtgerichtsbrief - Das elıem. Frauenhaus; Baumeister Vorcheimer.

57. - 1458, Okt. 20. Stadt München - Fraúenkirche, Meister Hans u. Kloster Tegernsee.

58. - 1460, Febr. 21. Kloster Miinster-Schwarzach - Zehent zu Feuerbach.

59. - 1461, Jan. 25. v. Freyberg - Familiengeschichte; briefl. Nachrichten aus der Febde.

60. - 1467, Mai 25. Hochst. Bamberg - Truchsesse zu Pommersfelden.

61. - 1469, Mai 25. Stadt Ochsenfurt - Domkap. Würzburg'sche Ratsordnung.

62. - - Nov. 29. Nürnberg, Stadtgerichtsbrief - Grundstïcke zu Neuses.

*63. - 1472, Dez. 1. Papst Sixtus IV - Diözese Lüttich, Pfarrei Ainbreleux.

64. - 1474, Juni 17. Stadt Nördlingen - Geburtsbrief.

65. - 1475, Febr.21. Bayern u. Brandenburg - Herzog Christoph u. die polit. Lage.

66. - - März 3. Stadt Mìnchen - Stiftung zur Peterskirche.

67. - 1476, April 26. Stadt Günz burg - Geburtsbrief.

68. - 1479, Jan. 23. B a m berg - St. Jakob, Güterzins. 
69. - 1485, Dez. 31. Stadt Augsburg - Geburtsbriof.

70. - 1487, Juli 30. Kurfürst zu Sachsen - Unterleiterbach, Lehen der Zollner.

i1. - - Nov. 28. Hochst. Bamberg, Hofgerichtsbrief - Stift St. Martin und die Steinmüble zu Bamberg.

72. - 1488, Juni 17. Hochst. Bamberg, Hofgerichts-Schied8spruch Zehent zu Litzendorf.

73. - - Juni 20. Hochst. Bamberg - Spital zu St. Anton, Satzungen.

74. - 1489, Juli 14. Bay yern - Ritterbund der Löwler; Gründung u. Satzungen.

75. - 1493, Jan. 12. Kloster Reichenbach - Güter zu Eppendorf.

76. - - Aug. 14. v. Hutten u. v. Rudecken - Reichslehen, Familiengeschichte.

77. - 1495, Jan. 26. Bayern, Herzog Georg - Stadt Rain u. die 18 Städte-Stiftung.

-78. - 1498, Mai 12. Cle ve - Kanonikat an der Dorukirche zu Utrecht.

79. - - Aug. 14. Hochst. Wü r z burg - Wasserrecht zu Feigendorf.

80. - 1499, April 23. Stadt Regensburg, Schultheissengericht Familien Zeller u. Gräfenreuter.

81. - - Dez. 10. Hochst. Regensburg - Errichtung der Pfarrei Affecking.

82. - 1501, Mai 24. Stadt Sohongau - Geburtsbrief.

83. - 1502, Juni 13. Nürnberg, Stadtgericht - Stift Bamberg. u. v. Zollnersche Lehen.

-84. - - Sept. - England unter König Heinrich VIl - Graf v. Suffolk, Thronprätendent, auf der Flucht in Deutschland.

-85. - 1506, Jan. 30. Salzburg, erzbisch. Hofgericht - Geburtsbriof.

86. - - April 24. Pollinger von Fronperg - Familiengeschichte.

87. - - Juli 2人. Hochet. Würzburg - Lelien der Zollner zu Arenstein.

88. - 1507, März 9. Stadt Ochsenfurt - Geburtsbrief.

89. - 1509, Okt. 8. Pfleggericht Trostberg - Geburtsbrief.

*90. - 1511, Aug. 7. Stadt St. Gallon - Geburtsbrief.

91. - 1514, März 26. Markt Burgebrach - Mühlrecht zu Obernhatmansbach.

*92. - 1515. Sept. 13. Graf zu Hanau-Lichtenberg - v. BerwangEchter, Familiengesch.

93. - 1517, April 4. Hochst. Bamberg - Sautter v. der Scherr, Hauptmannsbestallung.

94. - 1518, Nov. 6. Stadt Has 8 fu r t - Erb-Fleischbank.

95. - 1519, März 14. Hochst. Eichstätt, Landvogtei - Geburtsbrief.

96. - 1523, März 31. Zell ingen. Dorfgericht - Geburtsbrief.

*97. - 1526, Mai 18. Stadt Hall (bei Innsbr.) - Geburtsbrief.

*98. - 1527, Febr. 7. Stadt Es a lingen - Geburtsbrief.

99. - 1528, März 20. Stadt Landsberg a. L. - Geburtsbrief.

Archivalisuhe Zeitschrift. Neue Folge XII. 
100. - 1530, Juni 20. v. Freudenberg u. v. Ullersdorf - Gïter zu Haselbach i. O. Pf.

101. - - Sept. 30. Stadt Münchon - Ewiggeldbrief.

102. - 1531, Jan. 6. Kloster Ebrach - Seelenmesse-Stiftung der Zollner v. Brandt.

103. - 1532, Nov. 16. A schaffenburg - Vikarie bei St. Peter u. Alexander.

104. - 1533, Dez. 9. Dorf Schlioht u. Mühle zu Schönlind i. O. Pf.

* 105. - 1537. - - Schrift proben einer fürstl. Kanzlei.

106. -- 1538, Aug. 16. Stadt Leipzig - Schuldbeitreibung zu Bamberg.

107. - 1541, Fobr. 22. Hochst. B a mberg - Hauptmannsbestallung.

108. - - Juli 2. Stadt Memmingen - Geburtsbrief.

109. - - Juli 29. v. Zollner zu Bamberg - Ehevertrag mit Hartlieb v. Walsporn.

* 110. - - Nov. 19. Cleve-Geldern - Verlassenschaft der Camphausen zu Berg u. Schulenburg

*111. - 1542, Sept. 19. Erzst. Salz burg - Zunftordnung der Ziminerleute in Salzburg.

112. - 1544, Dez. 16. Hochst. Bamberg - Vidimus betr. Familie Zollner v. Brandt.

113. - 1545, Dez. 31. Hochst. Bamberg - Familie Zollner v. Brandt.

114. -- 1547, Sept. 20. Hochst. Würzburg - Lehen der Haller u. Zollner von Bamberg zu Miihlhausen.

*115. - 1548. Okt. 15. Markt Ri $\operatorname{Rd}-$ v. Mägerl'sche Spitalstiftung.

116. - 1549, April 2y. v. Streitberg u. v. Zollner - Lehon zu Staffelstein.

- 117. - 15̃̄o, Juli 28. J. Kneller, Comes palat. - Wappenbrief für Lauser.

118. - - Nov. 11. Eschenau, Dorfgericht - Geburtsbrief.

119. - 1554, März 16. Ka i s e Karl V-Wappenverleihungan Ph. Diennst.

* 120. - 1555, Nov. 1. Kaiser Karl V - Immunität der Familie Melchior Schedel.

121. -- 1556. Febr. 15. Stadt M ünchen -- Ewigzins-Kauf.

* 122. -- - Juli 26. Ni ed erlande - Erbschaftsauseinandersetzung, Familiensache.

123. - 1560, Fobr. 3. Hochst. Ba m berg - v. Künsberg, Hauptmannsbestallung.

124. - - Juli 22. v. Rotenhan u.v. Zollner - Lehen zu Mirsbach.

125. - 15 52 , Febr. 7. Hoohst. Ba m berg - v. Künsberg, Hauptmannsbestallung.

126. - 1563, Juni. Kloster Rottenbuch - Güterwechsel.

127. - - Nov. 15. v. Werdenstein - Wittum der Ursula v. W.

128. - 1564, Aug. 14. Hochst. Würz bu rg - v. Zollnersche Lehen zu Mühlhausen.

129. - - Dez. 24. v. Zollner, Hofrat zu Bamberg - Testament.

130. -- 1565. - - Herzog zu Sachsen - v. Zollnersches Lehen zu Arnstein. 
* 131. - 1570, Sept.10. Geldern -- Güter im Amt Brenefelt.

132. - - Nov. 20. Stadt München - Ewiggeld.

* 133. - 1571, Dez. 20. Ka iser Maximilian II - Wappenbrief für W. Thirnhaimer.

- 134. - 1573, April 15. Ka iser Maximilian II - Wildschutz bei W. Neustadt.

135. - - Sept. 18. B ayern, Herzog Albrecht - Buchdrucker Berg; das Werk des Th. Sury.

136. - 1575, März 20. Hochst. Bamberg - Zollner'sches Lehen zu Bieschberg.

* 137. - 1579. Juli 5. Hochschule Padua ... Promotion eines Doctor jur. utr.

138. - - Okt. 1. Hochst. Bamberg - Wieslehen an der Furt Schmalnohe i. O. Pf.

139. - 1580, März 2. Pfleggericht Raubenlechsberg - Der Sperberhof.

140. - - Mai 20. Kloster Schäftlarn - Grundstückverkauf.

* 141. - 1581, April 19. Kaiser Rudolph II - Kommando zu Canisa.

142. - 1582, März 18. Nouburg a. D. - Heiratsvertrag zwischen Sturmfeder zu Oppenheim u. Smullings zu Zevenar.

143. - - Juni 24. Hofmark Mü $\mathrm{ll}$ ch d orf - Geburtsbrief.

- 144. - - Sept. 6. Ka iser Rudolph II - Wappenverleihung an die Fam. Probst.

* 145. - - Sept. 6. Kaiser Rudolph II - Wappenverleihung an die Fam. Probst.

146. - 1583, März 18: Landgericht A m b erg - Anwesensübergabe zu Schlicht.

147. - - April 23. Hochstift Bamberg - N. Stumpf, Hauptmannsbestallung.

148. - 1585, Jan. 10. v. Rotenhan u. v. Zollner, Lehen zu Mirsbach.

149. - - März 27. Stadt München - A. Vetter von der Lylgen, bayer. Rat.

- 150. - - Juli 26. Cleve - Erbteilung zu Zeuenar zwischen Sturmfeder u. Spirink.

- 151. - - Sept. 16. Lrzherzog zu Österreieh - Wappen der Familie Hanibal.

152. - 158i, Jan. 6. Hochst. Bamberg - Schmidt, HauptmannsLestallung.

153. - - Febr. 9. Stadt Kitzingen - Geburtsbrief.

154. - - Sept. 16. Amt Buchloe - Grundatückverkauf.

* 155. - 1588, Febr. 22 . v. Feilitzsch - Schuld an v. Rodtschitz.

156. - - Dez. 31. v. Streitberg zu Burggrub - v. Zollnersche Belehnung.

157. - 1589, Jan. 12. Gericht H o hen burg - Geburtsbrief.

158. - 1590, Juli 6. Markt Siegenburg - Geburtsbrief.

159. - 1592, Sept. 25. Lerchenfelder zu Schwandorf - Fin Gut zu Krondorf. 
160. - 1593, Aug. 28. P. Mclissus, Comes pal. - Wappen für die Fam. Hofmann aus Crailsheim.

161. - 1595, April 4. Stadt Abensberg - Anwesensverkauf.

162. - - Okt. 6. R. St. Nürnberg u. Ulm - Verpflegung der Kreiskriegskontingente in Ungarn.

163. - 1596, Juni 21. v. Paumgarten zu Hohenschwangau, Comes pal. - Wappen für die Fam. Stauer.

164. - - Aug. 2. Schlicht bei Amberg - Familie Rothkäppel, Heiratsvertrag.

165. - 1599, Mai 11. Hochst. Bamberg - Familie Stieber, Lehen zu Adelsdorf.

166. - 1600, Okt. 24. Hofmarksgericht S e efeld - Geburtsbrief.

167. - 1601, Febr. 24. v. Pa umgarten, Comes palat. - Wappen der Fam. Geüger.

168. - - März 20. Hochst. Bamberg - Rothkäppel, Lehen zu Schmalenohe.

169. - 1602, Febr. 13. v. Rabenstein u. Rabeneck - Lehen der Zolluer v. Brandt.

170. - 1606, Febr. 15. Stadt Kichstätt - Geburtsbrief

171. - - April 11. Stadt Mühldorf - Hausverkauf.

172. - - Dez. 30. Bayern, Herzog Ferdinand -- Dankschreiben.

173. - 1607, Jan. 3. Bayern, Herzog Wilhelm V - Dankschreiben.

174. - 1608, April 9. Stadt München - Ewiggeld.

175. - - April 19. Stadt München - Jahrmesse-Stiftung bei St. Peter.

176. - 1609, März 20. Hochst. Bamberg, Landgerichtsbrief -- Familie v. Zollner u. Sartory.

177. - - Mai 7. Stieber zu Aisch - Zollner v. Brandt, Lehen.

178. - 1610, Mai 1 Landgericht A m berg - Geburtsbrief.

179. - - Juli 22. Kaiser Rudolph II - Adels- u. Wappenbrief für die Fam. Reichart.

180. - 1611, März 20. v. Rabenstein u. Rabeneck - Lehen der Zollner v. Branàt.

*181. - - April 30. v. Wodich zu Köln - v. Schonebeck auf Broeler Hof, Rente.

182 - 1612, Febr.22. Hochst. Ba mberg - Gründung des Jesuitenkollegiums zu Bamberg.

183. - 1613, Aug. 9. Stadt Berneck - Geburtsbrief.

184. - 1615, Jan. 2. Herzogin zu Sa chsen Dorothea Maria - Glückwurisch.

* 185. - - Okt. 24. Kaiser Mathias - Prozess der Stadt St. Georgen. 186. - 1621, Nov. 17. v. Streitberg zu Ahorn - v. Zollnersche Belehnung.

187. - 1622, Okt. 2. Regierung Burghausen - Lehen Ranzenberg, Verkauf.

188. - 164, Juni 26. Regierung Burghausen - Bayer. Beutellehen Ranzenberg. 
189. - 1624, Nor 19. Landgericht Burglengenfeld - v. Spiring, Hirschbichel'er Wald.

190. - 1625, Juni 21. Pfleggericht Rain - Grundstück zu Tödting.

* 191. - - Juli 18. Stadt Lin z - Geburtsbrief.

192. - 1628, Aug 17. Kloster Michaelsberg - Zollner v. Brandt, Belehnung.

193. - 1629, Juni 15. Kaiser Ferdinand II - Adelsbrief für die Fam Frobenius.

194. - - Juni 30. Hofmark Scheibelsgrub - v. Nothaft'sche Sölde.

195. - - Okt. 30. Markt Wolfratshausen - Geburtsbrief.

196. - 1630. Mai 14. Grafen zu Ött ingen - Zollner v. Brandt, Lehen Staffelstein.

197. - - Aug. 3. Stadt Mün chen - St. Peter, Ewiggeld.

- 198. - - Okt. 18. Kaiaer Ferdinand II - Adelsbrief für die Fam. Holzing.

199. - 1638, Jan. 2. Gericht Julbach - Gutsverkauf zu Niederlangwat.

200. - 1639, März 21. Stadt S ch onga u - Grundstückverkauf zu Altenstadt.

201. - - Juni 27. Kloster Michaelsberg - Zollner v. Brandt, Belehnung.

202. - 1642, März 22. Kloster Michaelsberg - Zollner v. Brandt, Belehnung.

* 203. - 1644, Juli 15. Reichskammergericht: Protest einer appellierenden Partei.

* 204. - 1645, Febr. 27. K a i 8 er Ferdinand III - Stände des Landes ob d. Enns.

205. - - Aug. 26. Poyss I v. Loifling u. Hausner v. Winbuch Ehevertrag.

206. - 1649, Jan. 8. Gericht Julbach - Bauerngut zu Niederlangwat, Verlassenschaft.

*207. - 1650, Sept. 15. Ka iser Ferdinand III - Adelsbrief für die Fam. Jürgensen $\nabla$. Trachenfels.

208. - - Okt. 28. v. Streitberg zum Greifenstein - Zollner v. Br., Lehen Staffelstein, Drosendorf u. Brunn.

209. - 1652, Juli 10. Regierung Burghausen - Beutellehen Kugelstatt im Gericht Julbach.

210. - 1653, März 7. Gericht Julbach - Kirohenrechnung St. Achaz in Aich.

211. - - Okt. 25. Peisoh v. Hueb, Comes pal. - Wappen der Fam. Satler.

212. - 1656, Okt. 7. V. Stadion-Zollner v. Br., Lehen zu Kattenreuth.

213. - 1657, April 11. Regierung Burghausen - Lehen auf der Kugelstatt.

214. - - Sept. 29. Hochst. Eichstätt - Frb. v. Spirink, Ordination.

215. - 1661, April 19. Gericht A u r bu r g - Die Zimmerleute zu Oberau. dorf, Lebrbrief. 
216. - 1661. Juni 3. v. Trachenfels, Comes pal. - Wappen der Fam. Brettschneider.

217. - 1664, Jan. 30. Ka iser Leopold - Adelsbrief für die Fam. Zwierner v. Klingenfeld.

218. - 1670, Okt. 7. v. Imhof u. Peller zu Nürnberg - Ehevertrag. 219. - 1672, April 22. Herzogtum Neuburg - Die Färber zu Burglengenfeld u. auf dem Nordgau.

220. - - April 27. Herzogtum Neuburg - Zunftordnung der Färber auf dem Nordgau.

221. - - Aug. 12. Gericht Julbach - Verlassenschaft auf dem Bauerngut zu Niederlangwat.

222. - 1673, April 15. Bayern, Kurf. Fordinand Maria - Truppenwerbung.

223. - - Juli 6. Bamberg'sches Kellereigericht Kaulberg - Verehelichungszeugnis.

224. - 16i5, April 8. Papst Clemens X - Pfarrkirche zu Staffelstein.

-225. - 1676, Febr. 12. Ka iser Lepold - Adelsbrief für die Fam. Strauss v. Straussenegg.

226. - - Sept. 4. Gericht Julbach - Verlassenschaft auf dem Mayrgut zu Holzham.

227. - 1678, April 4. Ba yern - Kurfürstl. Verruf nichtbayer. Thalersorten.

228. - - Mai 30. Stadt München - Die Weber von Starnberg u. Miinchen u. das lästige Galgenprivileg.

229. - 1680, Nov. 14. B a y ern - Kurfürstl. Erlass betr. "Infektionspriester" (Seelsorge).

230. - - Nov. 26. Stadt München - Die Färberzunft, Lehrbrief

231. - 1681, Febr. 18. Markt 1 s en - Geburtsbriof.

232. - 1682, Dez. 3. Hochst. Freising - Kurfürstl. Hofkapelle zu München.

233. - - Dez. 15. v.Stadion-Zollner v. Br., Lehen zu Kattenreuth.

234. - 1683, März 16. B a y ern, Kurf. Max Emanuel - Standeserhöhung des Freih. Auer v. Winkel.

235. - 1684, Febr. 28. Hochst. Bamberg - v. Aufsess, Lehen zu Mengeradorf.

236. - 1686, April 3. Paps t Innocenz XI - Pfarrkirche zu Staffelstein.

237. - 1688, März 12. Stadt München - Die Weber von Kranzberg u. München u das lästige Galgenprivileg.

238. - 1695, Febr.22. Sohenk v. Stauffenberg - Zollner v. Br., Lehen zu Staffelstein.

239. - 1696, Febr.20. Gemeinde Frankenhofen - Wasserrecht.

240. - - Juni 22. Hochst. Würzburg - Preise u. Löhne der Handwerker das.

241. - 1699, Juni 27. B a y ern, kurf. Verordnung - Äntz- oder Deichselfuhrwerk.

242. - 1700, Jan. 11. Papst Innocenz XII - St. Anna in Staffelstein. 243. - 1701, April 1. Paps t Clemens XI - Pfarrkirche in Staffelstein. 
244. - 1706. Juni 30. Papst Clemens XI - Kapelle Adelgundenberg bei Staffelstein.

245. - 1707, Juli 6. Papst Clemens XI - St. Anna zu Staffelstein.

246. - 1715. Nov. 22. Bayern, Kurf Max Emanuel - Eigenh. Handschreiben an Graf Seinsheim über Verheiratung Karl Albrechts.

247. - - Dez. 14. Papst Clemens XI - v. Schönborn, Anwartschaft auf ein Episkopat.

- 248. - 1716, Mai 29. Kaiser Karl VI - Ernennung la Marre's zun Feldmarschall-Lieutenant.

249. - 1722, Sept.11. Stadt Ra in - Zunftordnung der Krämer.

* 250. - 1730, Juli 20. Stadt Grieskirchen - Lehr-Abschiedsbrief der Kürschner-Innung.

251. - 1731, Jan. 27. Papst Clemens XII - Pfarrkirche zu Staffelstein.

252. - - Juni 11. v. Grundherr u. v. Winkler - Ehevertrag.

253. - - Juni 11. v. Gruudherr u. v. Winkler - Ehevertrag; Duplikat.

254. - 1732, Dez. 28. Kapuziner-Orden - Fürbitte für Kloster Ettal.

255. - 1736, Juni 1. Prediger-Orden -- Gebetsgemeinschaft.

256. - 1737, Aug. 1. Stadt A ug s burg - Handels-Lehrbrief.

257. - 1740, Aug. 31. Ka is er resp. Kurf. Karl Albrecht - Portrait oiver Kuriosität.

258. - 1741, Aug. 11. Pa p s t Benedikt XIV - Pfarrkirche zu Staffelstein.

259. - 1744, Juli 28. Ka iser Karl VII Albrecht - Französ. Karten. fabrikation.

260. - 1745, Juni 17. Markgraf v. Brandenburg - v. Dobeneck, Rittergut Schlegel.

261. - 1746, Mai 12. Stadt Wasserburg - Lehrbrief eines Handelsmanns.

262. - 1741, April 6. Würz burg-Marienberg - Freikunst der Büchsenmeister u. Feuerwerkerei, Lehrbrief.

* 263. - 1756, Jan. 17. Papst Benedikt XIV - Neujahrswünsche an Clemens Aug., Erabisch. v. Köln, Prinz v. Bayern.

*264. - 1760, März 4. Kaiserl. Mandat - Verruf braunschweig-wolfenb. Münzen.

265. - 1762, März 26. Bayern, Kurf. Max III Jos. - HoflieferantenTitel.

266. -- - Mai 13. Bayer. Akademie der Wissenschaften Mitgliedsernennung.

267. - 1764, Sept. 17. Stadt Wien - Arbeitsattest der Kupferschmiede.

268. - 1765, Dez. 2. Bayer. Staatsschulden.Tilgung - Assekuration auf Namen.

269. - 1767, Aug. 29. Stadt Ofen - Arbeitsattest der Kupferschmiede.

270. - 1769, Mai 24. Burghausen, Pfalz- u. Hofgraf das. - Unoheliche Geburt, Lossprechung.

271. - 1770. Sept. 3. Stadt Wien - Arboitsattest der Floiseher innung. 
272. - 1774, Sept. 6. Markgr. v. Brandenburg-Kulmbach-Ansbach - Erteilung eines Zeitungsprivilegs an Geheimrat Hagen in Bayreuth.

273. - 1776, Dez. 8. Päpstlicher Hof - Passausstellung,

274. - 1777, A pril 28. Papst Pius VI - St. Anna zu Staffelstein.

275. - 1780, Juni 6. Stadt Pressburg - Arbeitsattest der Posamentierzunft.

276. - Mai 31. Stadt Bamberg - Arbeitsattest der Dachdeckerzunft.

277. - 1782, Dez. 31. Brandenburg'scher Hof zu Ansbach - Lehrbrief eines Mundkochs.

*278. - 1786, Febr. 24. Regimentskommando zu Stargard - Militärabschied.

* 279. - 1787, Jan. 3. Preuss. Rittergut Lübtow - Eine Hochzeitseinladung im 18. Jhdt.

280. - - April 28. Papst Pilis VI - Pfarrkirche zu Staffelstein.

281. - 1788, April 13. Markt Marktscborgast - Arbeitsattest der Bäckerzunft.

282. - 1791, Mai 12. Hochst. Ba mberg - Oberleutuants-Patent.

283. - 1793, Juni 24. Stadt Wien - Arbeitsattest der Schönfärber.

284. - - Nov. 13. Stadt München - Seidenzeugfabrikation, Lehrbrief.

285. - - Nov. 25. Stadt Pressburg - Arbeitsattest der Schönfärber.

286. -- 1795, März 11. Kaiser Franz II -- Bischofswahl in Bamberg.

287. - 1796, Dez. 7. Hochst. Regensburg - Freih. v. Aretin'sches Lehen Winkl.

288. - 1798, Aug. 20. Papst Pius VI - Kirche in Hohengüssbach.

289. - 1800, Okt. 8. Kloster Michaelsberg b. Bamberg-St. EgidiusHospitalgut zu Memmelsdorf.

290. - 1801, Juli 22. Hochst. Bamberg - Grossjährigkeitserklärung behufs Gewerbsausiibung.

* 291. - 1808, Sept. 3. Universität Wien - Magisterdiplom aus Chirurgie und Geburtshilfe.

* 292. - 1809, März 6. Universität Wien - Diplom über Auszeichnung in der prakt. Chirurgie.

293. - 1810, Febr. 28. Schlossgut Bernried - Gräfl. Arco'sche Gärtnerei, Lehrbrief.

-294. - 1839, Aug. 6. Universität Wien - Mediz. Doktordiplon. 


\section{Verzeichnis des Inhaltes der Urkunden.}

Die beigegebenen Nummern sind jene des Chronolog. Verzeichnisses, zugleich die der Regesten.

I. Herkunft u. Verbreitung der Urkunden: Territorien (nichtbayerische, ältere u. neuere, geistliche u. weltliche): Brandenburg (Franken) No. $15,55,65,260,272,277$. - Braunsehweig 18,264 - Cleve $39,78,110$, 150. - England (Suffolk) 84. - Fulda 17. - Geldern 36, 39, 110, 131. Hanau - Licbtenberg 92. - Hessen-Darmst. 142. - Italien 137, 273 (vgl. Papst). - Jülich-Berg 29. - Kärnthen u. Tirol 16. - Köln 11, 21, 263. Lïtlich 63. - Magdeburg 2. - Mainz 43. - Meissen 2. - Niederlande $78,122,142,150$. - Österreich (deutsches) 32, 134, 151, 185, 191, 204, 250. Preussen (Rheinlande) 29, 181, (Pommern) 278, 279. - Sachsen 70, 108, 130. - Salzburg 32, 85, 111. - Schwoiz 46, 90. - Tirol 16, 27, 97. Ungarn (deutsches) 162, 269, 275, 285. - Württemberg 34, 98, 162.

A del (hoher $u$. niederer, alter u. neuer, nicht-bayer. u. bayerischer) - Arco 293, Aretin 287, Auer 234, A ufsess 20, 235, Berwang-Eobter 92, Bodenlauben 5, Bogen 4, 6, 8, Camphausen 110, Dobeneck 260, Feilitzsoh 155, Froudenberg 100, Freyberg 59, Grundherr 54, 253, Hartlieb-Walsporn 109, Hausner 205, Hutten 76, Imhof 218, Künsherg 123, 125, Lichtenstein 42, Mägerl 115, la Marre 248, Notbaft 194, Ottingen 196, Paulstorfer 30, Paumgarten 163, 167, Peisch 211. Peller 218, Pollinger 86, Pommersfelden 60, Poyssl 205, Rabenstein 169, 180, Rotenhan 124, 148, Rothkäppel 164, 168, Rudecken 74, Sautter 93, Schönborn 247, Schonebeck 181, Seinsheim 246, Smullings 142, Spirink 150, 189, 214, Stadion 212, 233, Stauffenberg 238, Stein 33, Stieber 165, 177, Streitberg 116, 166, 186, 208, Sturmfeder 142, 150, Trachenfels 216, Ullersdorf 100 , Vetter v. d. L. 149, Wedich 181, Werdenstein 127, Winkler 253, Zollner 20, 44, 53-55, 70, 80, 83, 87, 109, 112-114, $116,124,128-130,148,156,169,176,177,180,186,192,196,201,202,208$, 212. 233, 238, Zwirner 217.

Städ te u. Orte (nicht-bayer.) - Basel 46, Bielefeld 29, Esslingen 98, St. Gallen 90, St. Georgen 185, Grieskirchen 250, Hall i. T. 97, Heckebach 7, Köln 181, Leipzig 106, Linz 191, Lübtow 279, Neustadt (Wien) 134, Ofen 269, Oppenheim 142, Padua 137, Pressburg 275, 285, Ried 115, Rom 273 (s. Papst), Rottweil 34, Salzburg 31, Stargard 278, Trient 16, Ulm 162, Utrecht 78, Wien 267, 271, 283, 291, 292, 294, Zeuenar 142, 150.

Ritterorden - Deutschherrn 15, 17.

II. Territorien in Bayern. - Wittelsbachisohe Herzoge, Kurfürste D, Kaiser $8,22,24,25,38,65,77,135,172,173,222,227,229,241$, 246, 257, 263, 265, 266, 268.

Ne uburg Herzogtum 219, 220. 
Geistliche Territorien - Bamberg 26, 35, 37, 41, 44, 45, 52 , $60,72,73,83,93,107,112.113,123,125,136,138,147,152,165,168.176$. 182, 235, 282, 286, 290. - Eichstätt 95, 214, 247. - Freising 232. - Regensburg 81, 287. - Würzburg 1, 5, 10, 12, 40, 61, 79, 87, 114, 128, 240, 262.

Städte, Märkte, Gerichtsbezirke (ohne die Dörfer, alle rechtsrhein. Kreise vertreten) - Amberg 14i, 148, 161, 164. Aschaffenburg 103, A ugsburg 69, 256, Aurburg 215, Bamberg 20, 23, 28, 31, 41, 48, 51, 68, $71-73$, 106. 129. 223, 276, Bayreuth 272, Berneck 183, Buchloe 154, Burgebrach 91, Burghausen 187, 188, 209, 213, 270, Burglengenfeld 189, 219, 220, Eichstätt 170, Günzburg 67, Hassfurt 40, 94, Herzogenaurach 44, 53, Hohenburg 157, Isen 231, Julbach 199, 206, 209. 210, 213, 221, 226, Kelheim 14, 22, 24, 25, 47, Kitzingen 9, 153, Kranzberg 237, Landsberg a. L. 99, Marktschorgast 281, Memmingen 108, Mühldorf 171, München 49, 57, 66, 191, 121, $132,149,174,175,197,228,230,232,237,259,265,284$, Neuburg a. D. 142, Nördlingen 64, Nürnberg 54, 62, 83, 162, 218, Ochsenfurt 61, 88. Rain 77, 190, 249, Rauhenlechsberg 139, Regensburg 3, 80, Schongau 82, 200, Schwandorf 159, Seefeld 166, Siegenburg 158, Staffelstein 196, 208, 224, 236, 238, 242-245, 251, 258, 274, 280, Starnberg 228, Trostberg 89, Wasserburg 261, Wolfratshausen 195̃, Würzburg 33.

Ritter - Bund der Löwler 74.

Klöster - Bamberg (Jesuitenkolleg) 182, Banz 42, Ebrach 102, Ettal 254, Hl. Grab (Bamberg) 51, Holzkirchen 17, Michaelsberg (Bamberg) 192, 201, 202, 289, Michelfeld 10, Münsterschwarzach 58, Prüfening 19, Reichenbach 75, Rottenbuch 126, Schäftlarn 140, Schwarzach 9, Windberg 4, 6, 8, Zell 1. - Kirchen s. unter IV.

III. Kaiser-Urkk. u. kaiserliche Ausfertigungen (Kais. Ludw. d. B. bis Franz II) - 25, 50, 119, 133, 134, 141, 144, 145, 179, 185, 193, 198, 204, 207, 217, 225, 248, 259, 286.

Papst-Bullen 7, 31, 32, 46, 63. - Breve's 224, 236, 242-245, 247, 251, 258, 263, 274, 280, 288. - Vgl. IV.

Pfalz- u. Hofgrafen (Comites pal.) 117, 160, 163, 167, 211, 216, 270.

IV. Öffentliches Recht. - Regalien etc.: Abgaben- u. Zollfreiheit 6, 16 - Münzwesen 227, 264 - Verkehr 241 - Jagd 134 - Privilegien (s. Städte, Adel, Gewerbe usw.) - Lehen (s. Adel und Güter, weltl. u. kirchliche) - Adels- u. Wappenbriefe, Exemptionen 50, 117, 119, $120,133,144,145,151,160,163,167,179,193,198,207,211,216,217,225-$ Bestallungen 8. Ressorts.

Ressorts. - Haus- u. Hof sachen 246, 257, 259, 265 (Vgl. Bayern, Herzoge etc.). - Politik 38, 65, 74, 84, 246, 272. - Gerichtsurkunden: Dorfger. 46, 118, Landger. 44, 51, 56, 62, 146, 176, 189, Stadtger. 23, 28, 80,83 , Hofger. 45, 71, 85, 228, 237, Reichs-Kammerger. 203, Heimliches Ger. 45 - Kellereiger. (Domkap.) 37, 45, 223 - Gütl. Sprüche 52, 72, 80. - Landesfürstl. Criminale 22. - (Kirchl. Criminale 43). -- Wirtschaftswesen; s. die Urkunden über weltl. u. kirchliche Güter u. Lehen, über 
Zunft- u. Handwerkswesen u. unter V: besonders anschauliche Beispiole in agrar. u. gewerbl. Hinsicht 139, 220, 235, 240, 284, 289. - Unterrichtsu. Gelehrtenwesen 137, 182, 266, 272. 291, 292, 294. - Kultus-u. Kirchenwesen (Bischofswahlen, Kanonikate. Ordination, Pfarreien-, Kirchen-, Benefizien-Errichtung u. -Besetzung. Kirchenverwaltung, Zucht, Einpfarrungen) 4, 5, 9, 14, 19, 26, 28, 32, 34, 46, 47, 57, 63, 78, 81, 103, 210, 214, 232, 247, 286. - Seelsorge, Seelgeräte (Jahrtage), Abläвse 7, 10, 11-14, $21,26.32,34,46,47,102,175,197,224,229,236,242-245,251,258,274$, 280, 285. - Kirchl. Güter - Lehen, Schenkungen, Käufe. Liegenschaftsveränderungen bei verschiedener Besitz- $u$. Bewirtschaftungsart $-1,2$, $4,6,8,10,15,16,17,35,37,39,42,43,46,51,58.60,68,71,75,83,87$, $102,114,126,138,140,165,168,169,182,192,197,201,202,287$. - Klostergründung 2, -Statuten 10, -A uf lösung 46 - Kirchenraub u. -Strafe $43-$ Kirchenbau 57 - Schenkung von Dorf samt Kirche 5. - Orden - Dominikaner 255, Franziskaner 46, Jesuiten 182, Kapuziner 254, Karmeliter 11, 13, 21, Minoriten 12. - Wohltätige Anstalten u. Stiftungen 23, 31, 45, 73, 115, 289; hzgl. 18, Städtestiftung 77. - Krankenpflege u. Seelsorge bei Kontagion 229. - Kriegswesen (Ritter u. Felhden, Werbung, Bestallungen, Lehrling u. Feldmarschall, Auszeichnungen, Motivierung von $\Delta$ dels- u. Wapponbriefen) - 41, 59, 74, 93, 107, 123, 125, 141, $147,152,162,222,248,262,278,282$. - An hang: Städtewesen Reohtsprivilegien, Marktverleihungen s. Städte unter I u. II. - Schutz der Lehrlinge, Gesellen, Meister, Stücklöhne u. -Preise z. B. 220, 240; vgl. V. - Grossjährigkeit behufs Gewerbeausübung 290. - Kunst u. Handwork, Gewerbe, Zünfte u. -Ordnungen, Baumeister 56, 57 - Buchdruck u. Presse 135, 272 - Artillerie-, Büchsenmeister- u. Feuerwerkereiwesen 262 - Seiden-, Samt- u. Brokatfabrikation, Kartenfabrikation in Mưnohen 259, 284 - Zünfte der Bäcker 281, Dachdecker 276, Färber 219, 220, 283, 285, Fleischer 271, Handelsleute 256, 261, Krämer 249, Kupferschmiede 267, 269, Kürschner 250, Posamentierer 275, Weber zu München 228, 237, Zimmerleute zu Oberaudorf u. Salzburg 111, 215.

V. Privatrecbt. - Leibeigenschaft 1 (vgl. Geburtsbriefe). Goburtobriefe (u. a. aus St. Gallen, Hall i. T., Salzburg, Linz, Ochsenfurt, Kitzingen, Berneck, Esslingen, Nördlingen, München) 64, 67, 69, 82, $85,88-90,95-99,108,118,143,153,157,158,166,170,178,183,191,195$, 223. - Legitimation 270. - Standesveränderungen, Immunität, Exemption, Nobilitierung s. Adels- u. W.-Briefe. - Heirats-u. Erbverträge, Verlassenschaften, Vormundschaften, Wittume, Widerlagen u. Morgengaben, Testamente 20,36, 39, 80, 86, 100, 109, 110, 122, 127, 129, $131,142,150,164,176,205,206,218,221,223,226,252,253,278$; vgl. Seelgeräte. - Weltliche Güter (bäuerliche; adelige u. landesfürstl. Lehen u. Güter, dingliche Rechte, Erwerbs-, Besitz- u. Bewirtschaftsgattungen aller Art (vgl. Kirchl. Güter), Schulden u. Zinsen - 3, 5, 18, 20, 27, 30, $33,40,48,49,53,54,56,70,80,86,100,101,104,116,121,124,130,132$, $139,146,148,154,156.159,161,171,174.177,180,186,187-190,194,196$, $199,200,206,208,209,212,213,221,226$; beiläufige Probeu : Grundvermar- 
kung mit Verfahren u. Ger. Urteil 52 - Dingl. Rechte, Baulast, Servitut 49, 79, 91, 239. - Hypothek, Zins u. Leibrente 48. 181 - Staatsschuld, Privatschuld, Schuldeintreibung 106, 155, 260, 268.

VI. Kultur- u. Sittengeschichte (ausser den bezügl. Schlagworten unter $1-$ V) 1, 2, 5, 22, 43, 46, 56, 74, 106, 120, 170, 195, 209, 215, 217, 220, 223, 228, 229. 257, 240, 247, 268, 270, 272, 279.

VII. A u t o gra p hon (meist kaiserl. u. landesfürstl. Namensunterzeichnungen) - Kaiser 119, 120, 133, 134, 141, 144. 145, 151, 179, 185, 193, $188,204,207,217,225,248,259,286$ - Bayer. Herzoge u. Kurf. 38 (Ludwig d. Geb.), 172, 173, 222, 234, 246, 257, 259, 265 - Herzogin zu Sachsen 184 Prinz Eugen 248.

VIII. Kolorierungen, Miniaturen, Ornamente, Initialen, Federzeichnungen, Kupferdruck, Kalligraphio - die Adels- u. Wappenbriefe von 50 an unter IV, sodann 105, 137, 182, 183, 256, 261, 262, 267, 269, $275-277,293$.

IX. Diplome (Entwicklung von Wappen- u. Adels- zum gelehrlen, gewerblichen, Personenstands- u. Ehrendiplom) - s. die Adels- u. W. Briefe u. die Proben 137, 178, 183, 254, 255, 261, 262, 276, 293; s. dagegen die amtliche Kanzlerurkunde 287.

$X$. Verzeichnis der (82) charakteristischsten Urkunden uus I-IX behufs beschleunigter Durchsicht -- 1, 2, 4, 7, 8, 14, 16, 18, 22, 25, $29,31,32,38,43,45,49,53,57,59,61,63,65,70,71,74,77,81,84,102$, $108,105,107,109,111,115,123,129,130,135,137,142,155,162,175,182$, $197,203,206,209,214,215,220-224,227,228,237,239,240,246-248$, $254-256,261,262,266-268,270,272,279,287,292-294$ und einzelne aus den Adels- und Wappenbriefen unter IV. 


\section{Regesten.}

1141.

1a. Friderich von Hoemburc schenkt der Kirche St. Maria und Michaël in Zell') eine gewisse Hildegund samt deren Kinderschaft unter der Bedingung, dass, wenn das älteste Kind ein Knabe, für diesen der Kirche jährlich 5 Denare und im Falle Todes des Knaben das bessere Kleid zu geben seien; wäre das älteste Kind ein Mädchen, so sollen dafür jährlich 3 Denare und im Falle seines Todes das bessere Kleid entrichtet werden. Auch soll Hildegunde keinen anderen Schirmvogt annehmen, als den. ihrer Kirche.

Zeugen: Adelbert, Hartmann, Sigefrid, Adelbero, Lupern, Sigebotho, Hartmann, Herimann, Adalhart, Erenfrid Parrochianus, Everhard. - „Acta 1141 indictione IIII" unter Propst Konrad.

\section{3.}

1b. Odo von Gullichesheim schenkt der Kirche St. Maria und Michaël in Zell den Gothebold samt einem Hofe, wogegen der Kirche von Gothebold 5 Nurnmi, für den Hof von Gothebold und seinen Nachfolgern 2 Nummi jährlich zu entrichten sind; nach dem Tode des Gothebold ist das bessere Gewand zu verabfolgen; er soll keinen anderen Schirmvogt haben als den der Kirche.

Zeugen: Burchard, Erpho, Sigeboth, Herholt, Wirtwin, Herholt, Friderich, Eggeharth, Sigefrit. - „Acta 1143 indictione Vl“ unter Embricho, Bischof von Würzburg. -- Bischöfliches, durchgedrückt gewesenes Siegel abgefallen. - Für 1 b. Orig. - Perg. Doppel-Urkunde. - 32 centm. (Breite) : 42 (Höhe).

1) bei Würzburg. 
* 1157, Januar 24 (1156, Nov. 30).

2. Erzbischof Wichmann von Magdeburg bestätigt die Güterschenkungen, welche Markgraf Konrad (v. Meissen) und seine Gemahlin Markgräfin Liuchardis der Kirche „In Monte Sereno $\left.{ }^{4}, 1\right)$ deren Stifter Konrad ist, neuerdings machten. Der Markgraf erreichte ferner durch schriftliches Ansuchen sowie durch Bischof Anselm und Propst Gerhard als Legaten, bei Papst Eugen, dass, was unter Erzbischof Friedrich sich vollzog, die Kirche zu Nuınec dem Mons serenus überlassen wurde, welche ecclesia Numacensis der Markgraf ebenfalls mit weiteren Gütern ausstattete. Vorstehende Übergabe geschah durch Konrad, seine Söhne Markgrafen Otto und Theodorich, Graf Heinrich sowie Graf Dedo und Fritherich - am Tage des hl. Andreas 1156.

Die in der Stiftung genannten Örtlichkeiten ${ }^{2}$ ) sind: Niubudic, Surtuwic, Triliz, Buzen, Ostrow, Sackestorph, Bauendorph, Ochtmarisdorph, Masel wic, Podelic, Rith, Nebus, Storcow, Drogowic, Waltwic, Gurdenewic, Grabowic, Milniwic, Wellic, Sordowic, Scoldoch, Weldic, Scowic, Catow, Gracher, Salzamund, Uden, Sthitinic, Bucedal, Pellic, Bisinstid, Libichun, Obus, Boim, Rodenic, Thempethorp, Predel, Cebrits, Cozle, Lectwic, Dukelwic, Numec, Pothegrodic, Cestuwic, Alttorp, Rochtendorph, Odelei, Sınalic, Batsec, Gordenewic, Cacre, Mulendorph, Ceprrchow.

Zeugen: Wikerus, Bischof v. Brandenburg; Johannes, Bischof v. Merseburg; Gerung, Bischof v. Meissen; Bertold, Bisch. v. Naumburg; Walo, Bisch. v. Havelberg; Arnold, Abt von Berg; Gerhard, Dompropst; Azzeko, Domdekan; Widold, Propst; Sifrid, Propst v. St. Nikolaus; Otte, Vizedom; Conrad, Propst von St. Maria in Magdeburg; Konrad, Propst von Halle; Lampertus, Propst in „Graciadei“; Fritherich, Propst v. Kecheling; Ernst, Propst v. St. Maurizius; Everwin, Abt v. Burchele; Azzo, Abt v. Bozow. - Adelige u. Freie: Adelbert, Markgraf; Bernhard, Burg-Graf zu Magdeburg und dessen Suhn Burchard; Conrad von Wipper; Gunzelin v. Crozuc und Adalbert șein Sohn; Conrad v. Zpurne und dessen Sohn Bertold; Efik v. Burnenstide; Hoger v. Mannisvelt; Burchard v. Valkeinștein; Walter v.

1) Potersberg, früher Lauterberg bei Halle a. S.

2) Deren Feststellung nach heutiger Benennung wïrde hier auf unverbältnismässige Scbwierigkeiten gestossen seir. 
Arnistid ; Conrad v. Gniekenstein; Udelrich, Castellan v. Witin und seine Söhne Udelrich u. Conrad; Bodo v. Scochwic; Gardolf v. Seburch und dessen Bruder Gero; Baderich, Godescalk, Bertold v. Scips und Marold sein Bruder; Lurf v. Camburg und Lurf sein Sohn; Otto und Bertold sein Bruder. - Ministerialen: Gerhard, Conrad, Heledolf und sein Sohn Everhard, Wernher, Bodo, Volemar, Heremann, Anno, Herebert, Bodo, Frithehelm, Otto, Hoger v. Oztrow und sein Sohn Fridehelm, Ekkehard, Otto, Herimann v. Wetherthe; Wezzelo u. A.

Data Merseburc während des Provinzialconzils (in generali concilio) ... indictione V., VIIII. kal. febr ... presidente ... papa Adriano, regnante $R$. imperatore Friderico.

Siegler: Erzbischof Wichman; Siegel (9 cent.), das auf-, aber nicht durchgedrückt, sondern mit Pergamentstreifen befestigt war, fehlt. - Orig. Perg. - $60: 80$.

\section{3, Mai 29.}

3. Claremia u. Gerdrud, Schwestern, besitzen ein Haus mit Grundstück in der Ackirchestrazze (Bachstrasse zu Regensburg) und ein Gut in Hard; beide vertauschen ihr Besitztum, sodass Claremia mit ihrem Gatten Chuno das Gut, Gerdrud mit ihrem Gatten Gerold das Haus besitzt. Der Besitzwechsel wird durch Heinrich „de Capella“ und Engelbert Anegast vermittelt.

Zeugen : Heinrich de Capella, Rudiger sein Bruder, Rupert Kargel, Ulirich von Wisent, Otto von Wizenburc, Liutwin von Pruneleit, Karol sein Bruder, Rudiger in dem Swale, Liebard von Westerburc, Rapoto, Richter daselbst, Heinr. Pentelinger, sein Bruder, Marquard Schuoer, Pernolt, Sohn Gofrids von Pruneleit, Heinrich Riutär, Liupher von Pruneleit, (llrich Groppel, Liutwin Pochstäche, Otto sein Vetter, Dietmar über der Donau, Wolfram Wurm, Cunze von Sweige, Friedrich Vtingär, Heinr. von Amberch, Chuno von Stoufe, sein Sohn Dietmar, Heinr. Diener, Fridr. Vtingär, Haword in Ackirchstrazze u. A. .. Mit verletztem Siegel der Stadt Regensburg. - Acta 1213, quarto kal. junii.

\section{3, März 25.}

4. Albert Graf von Bogen gibt dem Kloster Windberg, dessen Schirmvogt er ist, zur Sühne grossen Unrechts die Kirche 
in Viehta $\left.{ }^{1}\right)$ und jene zu Schutenhoven in Böhmen mit dem benachbarten Dorf Podmukel zu Besitz.

Zeugen: Die Ministerialen Henrich von Phuolingen, Gebehard Marschal, Cunrad von Nosceber, Henrich von Prule, Gerho von Främrichsberg u. A. - Actum VIII. kl. aprilis 1233. Mit Siegel des Grafen, zur Hälfte erhalten. -- Orig. Perg. $23: 10,5$.

1233, August 8.

5. Hermann, Bischof von Würzburg, nimmt den Grafen Otto von Botenlouben seiner Verdienste wegen in seinen Schutz auf, setzt ihm 100 Mark Silber aus und überlässt ihm auf Lebenszeit (des Grafen) alle bischöfl. Güter bei Frientulbe und um Mahtolshusen ${ }^{2}$ ), die seit Alters zu Tulbe gehören und von dem Sohne des Grafen, Otto dem jüngeren gekauft worden sind.

Siegel des Bischofs und des Grafen abgefallen; letzteres beiliegend. - Datum 1233. VI. idus aug., episcopatus n. VVIlI. Orig. Perg.

\section{3.}

6. Albert, Graf von Bogen (Pogen), schenkt der Kirche St. Maria in Windberg ${ }^{3}$ ) seine Rechte an den Huben in Niedernhermanstorf, ${ }^{4}$ ) welch' letztere der Kirche vom Bischofe von Bamberg sowie von des Grafen Diener Wernher von Weintzdorff und seinem Koch Kalho ebendaselbst überlassen worden sind. Ebenso gestattet der Graf dem Kloster den Transport von Getreide über die Donau nach Bedarf.

Zeugen: Gerhoh von Fremelsperg, Albert von Satlpogen, Heinrich von Alnkoven, Albert von Erlbach, Ulrich von Geltolvingen, Herman, des Grafen Kapellan, Rudolf von Welthenburg. - Dat. Markt Pogen 1233, indictione XII. - Die U'rkunde ist eine Fälschung des 15. Jahrhunderts, wie Schrift, ad hoc gegeschnittenes Siegel, Genealogie u. s. w. zur Genüge erkennen lassen. $-16: 7$.

1) Bez.-Amt Viechtach.

ग) Bez.-A. Hammelburg.

8) Bez-A. Bogen. \) Bez.-A. Straubing. 
7. Ablass zu Gunsten des Cisterzienserinnen-Klosters Hekkebach, 1) Constanzer Diözese, dessen Neubau Meisterin und Konvent zu vollenden nicht die Mittel haben.

Dat. Lateran. II. nonas apr. pont. n. ao. VIII. - Mit päpstl. Bleibulle an rotgelber Seidenschnur. - Orig. Perg. - 32: 26.

$$
\text { 1240, August } 30 \text {. }
$$

8. Otto, Pfalzgraf und Herzog von Bayern, schenkt dem Kloster Windberg (Johannes, Abt) zu seinem und seiner Gemahlin Agnes Seelenheil die Zehenten aus allen Gütern, die ihm von dem Grafen von Bogen zugefallen sind.

Zeugen: Hohold von Nidekke, Alhard von Preisingen, Sifrid von Vrowenberc, Sifrid Asinus; von Clerikern Heinrich, Pıopst, Gottfried, des Herzogs Kapellan, Swiker, sein Notar u. A. - Geschrieben vom herzogl. Notar Ulrich. - Actum Lantshuot 1240, Ill kl. aug. -- Siegel des Herzogs wenig verletzt, das der Herzogin abgefallen. - Orig. Perg. - $26: 18$.

\section{6.}

9. Der Abt von Schwarzach ${ }^{2}$ ) genehmigt auf Bitten Bertholds von Lancheim und seiner Gattin Jutta, dass von ihren Kindern die künftigen zur Hälfte seiner, zur Hälfte der Kizzinger $\left.{ }^{3}\right)$ Kirche anfallen sollen.

Acta 1246. - Reste der Siegel des Abtes und des Konventes. - Orig. Porg.

$$
\text { 1261, April } 13 .
$$

10. J. Bischof von Würzburg bestätigt den Augustinerinnen des Klosters Michelfeld ${ }^{4}$ ) den Wortlaut einer ihnen vom Papst Alexander erteilten Schutz- und Konstitutionsurkunde (deren Datum fehlt), während er selbst ihnen Recht und Verfassung hiemit bestätigt.

Dat. 1261, jdus aprilis, indictione IIII., pontific. n. VIII. Bischöfliches Siegel. - Orig. Perg.

${ }_{1 j}$ Heggbach, württ. O.-A. Biberach. - Abdruck (nach dem 2. Orig. im gräfl. Archiv zu Buxheim) Württ. Urkundenbuch IV, 416-417.

') Bez.-A. Kulmbach. ") Bez.-A. Kitzingen.

4) Bez.-A. Kitzingen.

Archivalische Zeitwolurift. Neue Folgo XII. 


\section{* 1283, August 19.}

11. Sifrid, Erzbischof von Köln und Erzkanzler für Italien bevollmächtigt die Karmeliter seiner Diözese zur Erteilung eines Ablasses von 40 Tagen an alle jene, die ihre Predigten hören.

Dat. Colon. 1283, XIV. kal. septemb. - Erzbischöfl. Siegel. -. Orig. Perg. - 21,5: 9,5 .

\section{4, Dezember 10.}

12. Johannes, Erzbischof von Kappadocien gewährt allen Jenen, welche die Minoriten in Würzburg, die eine Kirche zu Ehren der hl. Jungfrau Maria zu bauen begonnen haben, unterstützen, einen 40 tägigen Ablass, vorbehalten Genehmigung durch den Diözesan-Bischof.

Dat. Wïrzburg 1284, festo s. Melchiadis pap. - Erzbischöfl. Siegel. - Orig. Perg.

$$
\text { * } 1286 .
$$

13. Ablassbrief des Erzbischofs von Riga für alle Jene, welche die Niederlassungen der armen Carmeliter unterstützen.

Dat. Romae 1286, pontific. Honorii pp. ao. 1. - Erzbischisfl. Siegel. - Orig. Perg.

$$
\text { 1297, April } 11 .
$$

14. Ablass, von Bischof Nikolaus v. Regensburg bestätigt, zu Gunsten der Marienkirche zu Kelheim. ")

Datum Romae. - Von den Siegeln der acht bischöfl. Aussteller nur eines erhalten. - Orig. Perg. - $54: 27$.

1297, Mai 3.

15. Herdegen von Grindlach gibt 2 Höfe in Obernzenne, ${ }^{2}$ ) welche zur Zeit die Colonen Konr. Schaber und Hermann Grimme bewirtschaften, dem Burggrafen Friedrich von Nürnberg, von dem er sie zu Lehen hatte, wieder zurück. Die beiden Höfe werden von Burggraf Friedrich den Deutschherrn zu Virnsperch ${ }^{3}$ ) zu Eigentum überwiesen.

Dat. in Kadolspurch 1297 in die inventionis s. (rucis. Siegel des Herdegen fehlt. - Orig. Perg.

1) A. d. Donau. - Bez.-A. gleichen Namens.

2) Bez-A. Uffenheim. s) Bez-A. Ansbach. 
* 1303, Oktober 21.

16. Otto, Herzog von Kärnthen, Graf von Tirol und Schirmherr der Kirchen von Trient und Brixen, gebietet allen seinen Zöllnern, zu ewigem Gedächtnis seines seligen Vaters Meinhard, alle Lebensmittel der Clarissinnen des Kreuzklosters bei Trient wie Wein, Öl, Salz u. s. w. zoll- und abgabenfrei passieren zu lassen.

Dat. apud Griez XXI. die octobris. - Siegel des Herzogs zum grösseren Teile erhalten. - Orig. Perg. - 23: 12.

1305, August 17.

17. Der Propst des Benediktinerklosters Holzkirchen ${ }^{1)}$ der Diözese Würzburg tritt das Patronatsrecht über die Pfarrkirche Nuwenbrunnen, ') derselben Diözese, mit Zustimmung des Stiftes Fulda an die Commende des Deutschordens in Mergentheim ${ }^{2}$ ) ab.

Siegel des Propstes von Holzkirchen und des Abtes von Fulda in Resten anhängend, das des Konventes von Holzkirchen abgefallen. - Dat. XVI. kal. septembris. - Orig. Perg.

\section{* 1350, März 12.}

18. Heinrich, Herzog von Braunschweig, belehnt die Bürger „Heynen van Evessem, Heuninge van Veltstede und Bertolde van Evessem" mit dem 3. Teil von 21/2 T'eil "scepele wetenes moltes" braunschw. Masses, in der molen vor der Nyen $\operatorname{stad}^{\star}$ zu Braunschweig als Mannlehen.

Geg. „dritteynhundert jar in deme vefteghesten jare ${ }^{\text {" an }}$ St. Gregorien Tag. Die Urkunde wurde mehrfach mit 1315 (l) bezeichnet und daher s. Zt. hier fest eingereiht; es dürfte aber Herzog Heinrich II. (1322-1351) in Betracht kommen. - Kunstvolles Siegel, zum grösseren Teile erhalten. — Orig. Perg. — $23: 12$.

1324, Mai 19.

19. Heinrich der Üngerl, Bürger zu Hembaur, ${ }^{3}$ ) welcher 1 \# "gelts" Reg. \& aus der Voytei der Pfarre zu Hohenschambach $\left.{ }^{4}\right)$ seinerzeit von Wernher dem Mayrhover gekauft hat, verkauft dieses wieder an Albrecht, Abt von Prüfening. ${ }^{5}$ ) Mayr-

1) Bez.-A. Marktheidenfeld. 2) Württ. Ob.-A. gleichen Namens.

") Bez.-A. Hemau. 4) Bez.-A. Parsberg. ') Bez.-A. Stadtamhof 
hover bleibt Lehenträger ron Prüfening. Üngerl setzt zu Bürgen Chunr. den Payr und Ruger den Schuster sowie Rappold den Reicholf.

Gesch. an S. Potenzianä Tag. - Mit Siegel der Stadt Hemau. - Orig. Perg.

1325, Januar 5 .

20. Friedrich Zolner, Schultheiss zu Babemberg, $\left.{ }^{1}\right)$ Elsbeth seine Frau, Chunrat, dann Philipp und Albrecht von Aufsess, ihre Eidame, nämlich Gatten ihrer Töchter Elsbeth und Katharina, überlassen ihrem Sohn, Schwager und Bruder Friedrich alle elterliche fahrende Habe samt dem Schultheissenamt zu Babenberch und die Hofunark srechte, wofür Friedrich alle anhängigen Schulden, Seelgeräte u. s. w. zu übernehmen hat. Schultheissenamt und Hofmark sollen veräusserlich sein.

Zeugen: Heinr. Sanpach, Eberhart Zolner, Friedrich dessen Bruder, Hermann und Joh. Zolner, Vettern. - Geg. an dem Obersten Abend. - Siegel des Friedr. Zolner und seiner Eidame Konrad und Philipp abgefallen. - Orig. Perg.

$$
\text { * } 1325 \text {, Juli } 1 \text {. }
$$

21. Heinrich, Erzbischof von Köln, Erzkanzler des Reichs für Italien, hat den Carmelitern, wie es unter den Päpsten Innocenz IV. und Urban IV. geschehen war, in der Kölner Diözese das Predigen und Beichthören gestattet; auf. Beschwerde der Stadtpfarrer won Köln schränkt er jedoch diese Seelsorge ein, für den Fall, dass sonst ein Hindernis entgegenstehe odler kein Mangel an Geistlichen sei.

Datum Gudensberch in octava b. Johannis bapt. - Siegel des Erzbischofs. - Orig. Perg.

1327, Mai 5.

22. Heinrich, Ott u. Heinrich, Herzoge v. Bayern, erhalten von der Stadt Kelheim ${ }^{2}$ ) wegen des Todschlags an dem Vetter des Richters Weichser (v. Weichs) "gänzliche Besserung“ und beauftragen Albert u. Heinrich die Vacharn, Heinr. den Lanquotär,

1) Bamberg in (O.-Franken. - Vgl. No. 113

2) S. No. 14. 
Konr. den Prükklein, Ott den Spinnlär und Heinr. den Wench, denen der Burggraf und Pfleger zu Kelheim und Ulrich der Ekker beizugeben, die Urheber und Täter ausfindig z.u machen, unter sie die Besserung (Sühnegeld) zu verteilen und einen allenfalls Entweichenden am Leben zu strafen, dessen Bussteil aber auf sein Gut zu legen.

Geg. zu Regensburg, Ertag nach Kreuzauffindung. - Die 3 herzogl. Siegel abgefallen. - Orig. Perg. - $23: 16$.

1337, Juni 30.

23. Friedrich Walch, Bürger zu Babenberg, ${ }^{1}$ ) und seine Frau Osterhilt überlassen dem Spital St. Kathrein bei St. Martin zu Babenberg zu Seelgerät ihren Acker, gelegen zwischen Thondan's Acker, der Strasse und bei den Ziegelhöfen, welcher Acker zur Pfarrei St. Martin jährlich 3 Bh zinst als Zehent, mit der Verfügung, dass der Spitalmeister den Stiftern von dem Haus, das am Grasmarkt an der Ecke neben Erhard Schammelsdorfs Haus, jährl. $25 \mathrm{Bh}$ erlegt, wovon man ein ewiges Licht des Nachts in der Krankenstube des Spitals unterhalten und den Rest am Gründonnerstag in derselben Stube den Dürftigen austeilen soll.

Zeugen: Heinr. Liebsperger, Schultheiss. Gundloch Mewer, Cunr. Kezzler, Cunr. Kelner, Kraft Hasefürter, Cunr. Zolner, Hans Eycheinnagel, Heinr. Togkler, Cunr. Kuchenmeister, Braunwart Üsmer am Markt, Brauuw. Goltsmit, Braunw. Karnmermeister, Cunr. Zolner an der Lugbank u. A. - Geg. Mantag nach St. Johans Tag zu sunwenten. - Mit dem Siegel der Stadt. - Orig. Perg.

1338, März 6.

24. Heinrich, Herzog v. Bayern, weist die Stadt Kelheim an, die sie treffende jährliche Steuerquote von $40 \vec{t}$ Reg. \& jährlich bis auf Weiteres an Hilpold von dem Stayne und dessen Erben auszubezahlen.

Geg. Landshut, Freitag n. weissen Sonntag. - Herzogl. Siegel fehlt. - Orig. Perg. - 30,5:12,5. - Siehe No. 22.

1) Wie No. 20 stots Bamberg. 
1345, Jan. 16.

25. Kaiser Ludwig bestätigt und erneuert die der Stadt Kelheim von Herzog Heinrich und anderen seiner Vorfahren erteilten Privilegien.

Geg. zu Landshut, Sonntag vor St. Antonius. - Kais. Siegel fehlt. - Orig. Perg. - 32,5: 19. - S. No. 24.

* 1350 , März 12.

Herzog v. Braunschweig: Lehen der Mühle vor Braunschweig. - Siehe No. 18.

1353, Mai 1.

26. Leopold, Bischof von Bamberg, bestätigt einen unter Papst Innocenz VI. unterm 1. Mai 1353 zu Avignon ergangenen Indulgenzbrief für mehrere Kirchen und Kapellen seiner Diözese (Pfarrkirche zu St. Andreas u. Bartholomeus, Kapellen St. Mauritius, Nikolaus).

Dat. Auinione I die m. maij . . . pont. Innoc. pp. VI ao. I. - Ohne Siegel. - Orig. Perg. -- $71: 57$.

* 1361, Mai 10.

27. Niklau von Flasperch verkauft an Knecht Andre dem Stuchen, Bürger zu Prauneck, ${ }^{1}$ ) die Mann- und Lehenschaft an dem Swaich-Hofe, gelegen in der Touerecken, ${ }^{2}$ ) geheissen ${ }_{n}$ an der Gazzen" um $8 \mathbb{Z}$ Meraner.

Zeugen: Hainr. v. Velturnes, Hainr. der Osterman, Dietereich der Osterman, Hänsle, Herrn Rudolfes Bruder von Taufers, Ulrich der Schreiber u. A. -- Gesch. Mäntages vor S. Pangräzen Tag ze Mitten Maygen. - Mit Siegel des N. Flasperch. Orig. Perg.

1361, September 23.

28. Gerichtsbrief der Stadt Babenberch (Schultheiss Friedrich vom Rotensteine, Ritter), wonach Heinr. Müntzer „unter dem Swibogen" bekennt, sein Erbe wegen Lebensnot verkaufen zu müssen, wozu er Erlaubnis von seinen Erben erhalten habe. Demnach verkaufe er hier $1 \mathbb{t} h$, einen Lammsbauch u. 2 Fast-

1) Bruneok i. Pustertal. ') Taufereck. 
nachthühner jährl. Gült, fällig aus des Dienstmanns Haus, gelegen hinter den Barfüssern und der Judenbadstube, an Heinrich Lochner. zu St. Jakob gesessen; diese jährl. Gült habe Lochner als Seelgerät zu St. Jakob gestiftet. - Das Stadtgericht genehmigt den Verkauf.

Schöffen und Zeugen: Heinrich Kürsener, Cunrat Zolner an den Predigern, Herdegen Toggler, Cunr. Kuchenmeister, Braunwart Kammermeister, Cunr. Strauzz der Toggler, Frz. Goltsmit, Engel Engelhardt, Fritz Üsemer, Cunr. Hasfurter, Cunr. Inegrame, Walther Zolner u. A. - Gesch. Donerstag vor St. Michelstag. - Siegel der Stadt abgefallen. - Orig. Perg.

\section{* 1381, November 12.}

29. Wilhelm von Jülich, Herzog zu Berg etc. erteilt der Stadt Bylevelde ${ }^{1}$ ) ein Privileg hinsichtlich jener Stadteinwohner, welche „wicboldeguit" besitzen.

Geg. „op and. s. Mertins daichs." - Mit dem Siegel des Herzogs. - Orig. Perg. $-28: 13$.

$$
\text { 1391, Jan. } 18 .
$$

30. Hans der Paulstorffer zu dem Teneisperg ${ }^{2}$ ) verkauft seinem Schwager Jörg dem Ettenstaller den Hof zu Haselbach, ${ }^{3}$ ) bebaut von Ulrich Winter, und die Hube, bestanden von Konr. Vetterlein, welche Güter zu Nabeck, ${ }^{3}$ ) das bereits in Besitze des Jörg ist, gehören. - Teidinger: Niklas der Paulstorffer zu Haselbach, Heinr. der Fronperger zu Fronperg. ${ }^{3}$ )

Geg. Mittw. vor St. Pauls Tag. - Die Siegel Niklas d. Paulstorffers u. Heinr. d. Fronpergers fehlen. - Orig. Perg.

\section{6, Juni 22.}

31. Papst Bonifazius (IX) betraut den Dekan von St. Jakob bei Bamberg damit, alle dem Katharinen-Hospital das. entfremdeten Güter wieder zurückzugewinnen.

Dat. Romae . . X kal. julii pont. n. ao. VIII. - Mit Seidenschnur ohne Bulle. - Orig. Perg. - $26: 16$.

1) Bielefeld, preuss. Reg.-Bez. Minden.

3) Tännesberg, Bez.-A. Vohenstrauss. s) Bez.-A. Burglengenfeld. 


\section{* 1400, Dezember 23.}

32. Indulgenzbrief des Papstes Bonifaz (IX) zu Gunsten der Kapelle St. Georg und Katharina zu Salzburg (sita in monte prope Salinam vulgariter monte s. Georgii nuncupato Salzeburg. dioc.).

Dat. Romae .. X. kal. jan. pont. n. ao. XII. - Mit Bleibulle. - Orig. Perg. $-49: 28$.

\section{2, Februar 26.}

33. Hans Ratsam, Centgraf an der Brücke zu Würzburg, Zins-Einnehmer derer , vom Stein" in der Stadt Würzburg, verleiht dem Johannes Jordan, Kaplan des Grafen Rudolph von Wertheim, Domherrn zu Würzburg, und den Nachfolgern des Kaplans gegen jährl. Zins von 6 Bh u. 2 Fastnachthühnern das Haus, gelegen hinter dem Münster, hinter dem Hofe Grindlach, anstossend an Heinz Pflügers und Johann Butteners Häusern, welches Haus früher Cunrad Beyer von Fulda "vom Stein" zu Lehen hatte.

Zeugen: Johannes, Kirchner des Doms zu Würzburg, Merklein Kannengisser, Bürger, Hans Sachs ${ }^{1}$ ) und Meister Örber, beide Büchsenmeister des Bischofs zu Würzburg. - Geg. Sonntag . . Oculi. - Siegel des H. Ratsam teilweise erhalten. Orig. Perg.

$$
\text { * 1405, Mai } 18 .
$$

34. Das Stadtgericht zu Rotwil beurkundet, dass Conrat von Bochingen, ${ }^{2}$ ) Bürger daselbst, zum St. Martins-Altar in der Frauen-Kapelle zu Seelgerät eine jährliche Gült von 14 Viertel Vesen von der Brugg-Wiese zu Bösingen gestiftet hat.

Geg. nächsten Gutentag vor der Kreuzwoche. - Stadtsiegel von Rottweil fehlt. - Orig. Perg.

\section{5, Dez. 22.}

35. Günther von der Kere, Domherr und Oberster Kellner des Doms zu Bamberg, auch Richter des stiftischen Mundatgerichtes das., beurkundet das Schöffen-Urteil, wonach es Conrad

1) Nicht seltener Namo gleichzeitig in Bayern.

') Württ. O.-A. Oberndorf. 
Kamermeister, Bürger zu Bamberg und Dietrich Gundloch, seinem Schwager, gestattet sein soll, Güter, die vorgenannte beide mit Fritz Gundloch, Dietrichs Bruder, gemeinsam haben in der "Mark zu Kreutschach“, zu teilen, jedoch so, dass daraus keinem anderen in der Mark Begüterten Schaden erwächst.

Schöffen: Gunther, Wernher, Clas Swertfege, Hans Voyt, Conr. Wildenstein, Herm. Behaim, Cuntz Brawn, Herm. Anshalm, Heinz Grym, Hans Heyder, Hans Eysenman. - Gesch. Dienstag vor Weihnachten. - Siegel des Gerichts. - Orig. Perg.

* 1408, Dezember 11.

36. Art Sticke von Lichtenhorst verzichtet auf alle Erbschaft an dem Gute, wolches Henrik van Wotthusen von seinem Weibe, früher Gattin Arts van Dünen, innehat, welches Gut im Kirchspiel van Diedem ${ }^{1}$ ) gelegen ist; nähere Erben will Art Sticke von den $24 \mathrm{fl}$ entschädigen, die er (für seinen Verzicht) erhalten hat.

Geg. Dienstag nach Frauen Conceptio. - Siegel des Art Stike abgefallen. - Orig. Perg.

\section{4, Mai 13.}

37. Hans Herdegen und Braun Herdegen, Brüder, Bürger zu Bamberg, geben vor Jorrg v. Schaumberg, Domherrn und Oberstkellner des Doms zu Bamberg als Richter des Kellnereigerichts ihren Zehent zu Neuses ${ }^{2}$ ) ob Schönbrunne, Lehen des Bischofs von Würzburg, auf, da sie den Zehent an Eberhart und Ulrich die Mertzen veräussert haben.

Zeugen: Die Schöffen Herman Beheim, Chuntz Leicht, Chuntz Braun, Herm. Steinenpeck, Heinr. Groz, Albrecht Rörech, Jak. Goltsmid, Endres, ehemals Landschreiber, Hans Amman, Hans Kunig u. A. - Geg. Samstag nach Johannes ante port. Lat. - Mit dem Gerichtssiegel des J. v. Schaumberg; das des H. Herdegen fehlt. - Orig. Perg.

$$
\text { 1427, Juli } 11 .
$$

38. Ludwig, Herzog v. Bayern(-Ingolstadt), erkennt für sich aus Anlass der 'Teilung der niederbayerischen Lande weil.

1) Didam bei Doesburg i. ehemal. Geldern.

2) Oberneuses, Bez.-A. Bamberg II. 
Herzog Johanns v. Holland mit seinen Vettern Ernst. Wilhelm und Heinrich alle seit Kaiser Ludwig erlassenen herzoglichen $\mathrm{Ur}$ kunden, welchen bayer. Landesteil sie betreffen oder wen oder worüber sie rechtsgültig ausgestellt sind, als geltend an.

Gesch. zu Straubing, Freitag vor Margaretha. - Herzog Ludwigs Siegel fehlt. - Mit eigenhändiger Unterschrift (Loys) Ludwigs des Gebarteten. - Orig. Perg. - 43: 20.

* 1430, November 27.

39. W. Lerink, Bürgermeister zu Zytphen und Werner Lerink, Richter zu Doisborich urkunden mit 11 anderen Schiedsleuten über Güter des Klosters Sleenhorst in Mariengräve bei Doisborich. ${ }^{1}$ )

Genannt: Geldern, Zytphen, Zevenar; die v. Smullinks; Herzog Johann v. Cleve, Graf v. d. Mark. - Von den Siegeln der 13 Schiedsleute 10 anhängend. - Orig. Perg.

1432, Juni 4.

40. Johann, Bischof $v$. Würzburg, gestattet der Stadt Hassfurt, ${ }^{8}$ ) an Stelle von 2 Mühlen ${ }_{\text {an }}$ dem See unter der Stadt an der Nassach", die vom See zerstört wurden, eine neue Mühle am Maine zu bauen, und verleiht der Stadt diese Mühle als Zinslehen um denselben Zins wie die früheren beiden Mühlen.

Geg. Mittwoch vor dem hl. Pfingsttage. - Bischöfl. Siegel fehlt. - Orig. Perg. - 31: 20 .

\section{5, Juni $2 \pi$.}

41. Moritz von Lonerstat ${ }^{3}$ ) kündigt der Stadt Bamberg in ihrem Streite mit Bischof Anton von Bamberg den Frieden.

Geg. zu Altenburg Montag nach St. Johannestag Sunwenden. - Siegel des v. Lonerstat abgefallen. - Orig. Pap.

\section{6, Januar 15.}

42. Eberhard, Abt des Benediktinerklosters zu Panz, ${ }^{4}$ ) belehnt Hans, Ritter, sowie Kaspar und Thoma, seine drei Vettern

1) Text im geldrischen alten Dialekt. - S. No. 65, 122, 129.

?) Bez.-A. gleichen Namens.

8) Bez.-A. Höchstadt a. A.

4) Banz, Bez.-A. Staffelstein. 
vom Lichtenstein mit einem Hof, 3 Gütern und 3 Sölden zu "Kesolcz“ (auch "Kesholz“).

Geg. Sonntag vor S. Anton. - Mit Siegel des Abts Eberhard. - Orig. Perg.

* 1437, Dez. 17.

43. Johannes Wertheim "scolasticus, judex et conservator" des Erzstifts Mainz, vom Conzil zu Basel mit der Führung des Prozesses des Klosters Seligenstadt ${ }^{1}$ ) gegen den Burggrafen von Gelnhausen $^{2}$ ) u. Cons. beauftragt, bevollmächtigt auf Grund einer weiteren päpstl. Bulle de do. Basileae VI. jdus nov. 1435 den Herman Rost, Propst von St. Maria ad gradus zu Mainz, die Klagen des Klosters Seligenstadt, vertreten durch dessen Syndikus Joh. Blatz, entgegenzunehmen, worauf dieser feststellt, dass Henne Erpp-Burggraf, Friedr. v. Vechenbach, Gg. Geyling, Henne v. Bunau, Henne Reprecht sen., Friedr. v. Sparle, Wilhelm Forstmeister u. Gg. v. Breydenbach durch Brand und Raub sich an den Gütern des Klosters vergriffen haben. Hierauf schlägt der Propst von St. Maria in den Pfarrkirchen um Gelnhausen das Anathem und die Ehrloserklärung über die Übeltäter an samt Aufforderung, alle Schäden zu ersetzen und innerhalb dreimal 14 Tagen vor seinem Gericht zu erscheinen.

Urkunde, hierüber aufgenommen durch den kais. Notar Joh. Rumelfels v. Vorcheim, mit dessen Handzeichen; sein Siegel abgefallen. - Perg. - 50:65.

\section{9, März 27.}

44. Heinrich von Aufses, Ritter, Landrichter des Stiftes zu Bamberg, sitzt zu Gericht und fällt Urteil zu Gunsten Eberhards Zolner von Nürnberg gegen Bischof Anton zu Bamberg, vertreten durch seinen Kammermeister Heintz Ditmar, wegen Schloss, Stadt, Amt und Gericht Herzogenaurach ${ }^{3}$ ) oder 14,500 fl. Schuld.

Geg. Freitag vor Palmsønntag. - Siegel des Landgerichts fehlt. - Orig. Perg.

1) a. Main, Hessen-D., Kr. Offenbach. ') Preuss. Kr. Kassel.

bez.-A. Höchstadt a. A. 


$$
\text { 1440, Januar } 31 \text {. }
$$

[1425, Febr. 27 u. 1440. Jan. $\bar{i}$.]

45. Eberhard Mertz, Fritz Zolner, Hans Ortlein und Fritz Schick zu Bamberg, „Freischöffen des heimlichen Gerichts", beylaubigen den Wortlaut von zwei Gerichtsurkunden wie folgt: 1425, Febr. 27. - Das Domkellnerei-Gericht zu Bamberg spricht dem Clas Haller, Vormund der Sondersiechen von St. Anton das., 2 Häuser zu, welche auf dem Kaulberg vor dem obersten Bergfried liegen, samt Zugehörungen, welche Häuser von Hans Häusslein den Ält. für sich und seine Geschwister angesprochen worden waren. - Ergangen durch Jörg v. Schaumberg. Domkellner u. Schöffen, unter Gerichtssiegel, Dienstag n. Petrus Cathedra.

1440, Jan. 7. - Das bischöfl. Hofgericht zu Bamberg bestätigt vorstehendes Urteil. Häusslein hatte gegen dasselbe Berufung zum westphäl. Gericht eingelegt und sich zum Bischof v. Bamberg persönlich verfügt. Hierauf erwirkte auch Clas Haller Briefe vom heimlichen Gericht. Das Hofgericht erkennt nun dahin, dass die Appellation des Häusslein an das westphäl. Gerichtswesen ungehörig war und das Urteil von 1425 zu Recht bestehe, weil die Parteien damals zustimmten, es bei dem ersten Urteile zu belassen. - Ergangen unter dem Siegel des Eberhart v. Schaumberg, Hofmeisters des Bischofs Anton v. Bamberg, durch die bischöfl. Räte (Heinr. v. der Tanne, Heinz v. Auf'ses, Eberh. Mertz, Heinz Zolner), Donerstag vor (nach?) dem Oberstag. Geg. Sonntag vor U. L. Fratentag Lichtmess. -- Siegel der 4 Freischöffen. - Orig. Perg.

\section{* 1441, Februar.}

46. Papst Felix V. ordnet zu Basel eine Kommission an, bestehend aus dem Dekan der Domkirche und dem Propst von St. Leonhard das., die Verwaltung des Franziskanerklosters in Basel wiederherzustellen, Inventare über dessen Immobilien und Mobilien zu errichten, die Gefälle einzutragen und richtig zuzuwenden, die Stiftungen festzustellen und wieder einzuführen.

Datum Basileae ... februarii anno . . . 1441. - Bleibulle føhlt. - Die rechte Hälfte der Urkunde fast ganz zerstört. Orig. Perg. $-72: 52$. 


$$
\text { 1444, Jan. } 8 .
$$

47. Die Stadt Kelheim ${ }^{1}$ ) stiftet eine tägliche ewige Messe in der Margaretha-Kapelle über dem Karner (auf dem Kirchhof der Pfarrkirche U. L. Frau) zu Kelheim, wirft einem von ihr zu nennenden, dem Bischof v. Regensburg zu präsentierenden "gelehrten Priester" d. i. Kaplan ein jährl. Einkommen von $10 \mathbb{Z t}$ Ewiggeld aus und bestimmt ein eigenes Benefiziaten-Haus; der Kaplan ist von dem Pfarrer unabhängig, doch hat er an allen Fest-Zeiten den Chor der Pfarrkirche zu besuchen; für jede versäumte Messe sind 4 Reg. \& zu entrichten; ein Tag in der Woche ist messefrei. Bischof Friedrich v. Regensburg und Friedr. Prügelberger, Pfarrer zu Kelheim, haben ihre Einwilligung zur Messstiftung gegeben. - Unter dem Siegel der Stadt geg. an St. Erhardstag.

Hier Vidimus des Generalvikars v. Tannheim, datum Ratisbonae 22. Jan. 1444; dessen Siegel fehlt. - Orig. Perg.

$$
\text { 1447, Febr. } 4 .
$$

48. Claus Krafft zu Gedem ${ }^{\text {) }}$ verkauft um $28 \mathrm{fl}$ rhein. an Anton Sweinfurter u. Sohn zu Bamberg auf ihre Lebzeit $1 / 8$ Fuder guten "fränkischen Wein “, jährlich an ihr Haus zu Bamberg zu liefern; sie sind in allen Fällen schadlos zu halten, wenn auch etwa Fehden zwischen Bischof, Rittern und Stadt die Lieferung unmöglich machten.

Bürgen unter Verpflichtung des Einlagers: Peter Hartmut, Hermann Reinfelt, Thoman Braun, Hans Ferde, zu Gedem. Geg. Samstag nach Frauen Purificationis. - Siegel des Junkers Hans Zollner, Vogts und Konrads Wyner, Pfarrers zu Gedem fehlen. - Orig. Perg. - Urkunde schadhaft.

\section{7, September 7.}

49. Wilhelm Astaler, Bürger zu München, verpflichtet sich, vom $\mathrm{Hofe}$ seines Hauses an der ninteren Schwäbinger"-Gasse zu München, zwischen den Häusern Andre Krückl's u. des Frölich, einen Licht-Einfall zum Haus des Bäckers Leonh. Rösch zu belassen.

Geg. an U. L. Fr. Abend als sie geboren worden. - Mit Siegel des Astaler. -- Orig. Perg.
1) S. No. 14.
2) Gädheim, Bez.-A. Hassfurt. 


\section{- 1447, November 20.-27.}

50. Friedrich, römischer König etc., verleiht dem Claus Creydweiss erblich ein Wappen (weissen Schild mit rotem, an den 4 Enden mit Widerhaken versehenen Kreuz, Helm mit 2 roten ${ }_{\text {"Flug }}$, Helmdecken rot $u$. weiss), welches in Farben ${ }^{1}$ ) in der Urkunde dargestellt ist, wegen seiner Verdienste um Kaiser u. Reich.

Geg. zu ,Wien am Man ... . (unleserlich) Katharinentag ... unsers Reichs im 8. Jare. “ - Königliches Siegel fehlt. - $50: 24$.

$$
\text { 1450, April } 20 .
$$

51. Das Frauenkloster zum $\mathrm{Hl}$. Grab in Bamberg, vertreten durch Hans Münter, klagt vor dem Stadtgerichte das. gegen Konz vom Berge zu Teurstat wegen rückständigen Zinses von 4 Gemachen (Häusern) an der Siechengasse. Nachdem Otto 'Tors die Schuld mit den Häusern kaufen wollte, vom Kaufe aber zurücktrat und Niemand mehr bot, schlägt das Gericht die Häuser dem Kloster, unbeschadet anderer Oberherrlichkeit, zu.

Richter: Burkart von Gnottstat, Schultheiss. - Schöffen: Hans Bernhart, Heinr. Snepff, Heinr. Schultheiss, Fritz Alt. Gesch. Montag vor S. Jorgen Tag. - Siegel des Bamberger Stadtgerichts fehlt. - Orig. Perg.

$$
\text { 1453, Januar } 10 .
$$

52. Stephan Hornung u. Lorenz Haller wählen in ihrem Gränz-Streite um Wald und Äcker bei Obernheide, ${ }^{2}$ ) genannt die Petelweide, ein gütliches Gericht, welches aus Albr. Neunsteter, Landschreiber des Stifts Bamberg als Obmann besteht und aus Hans von Abersfelt und Heinr. Snepff als Schöffen auf Seite Hornungs, aus Kasp. Haller und Ant. Sweinfurter auf Seite Hallers. Sie entscheiden, dass jede Partei 2 Biedermänner bestelle, welche mit dem Statmesser von Bamberg die Petelweide in gleiche Teile, unter Zugrundelegung des bisherigen Bestandes, teilen und neue Marksteine setzen sollen.

Geg. Mitwoch n. St. Eriardtstag. - Siegel des Obmanns u. der 4 Beisitzer nicht mehr vorhanden. -- Orig. Perg.

1) In den später zahlreich folgenden Wappenbriofen wird die Beschreibung der verliehenen Zeichen etc. - in Ansehung der meist geringen Bedeutung der Namen - unterlassen.

1) Bez.-A. Bamberg II. 
1454, Februar 18.

53. Albrecht, Markgraf zu Brandenburg und Burggraf zu Nürnberg, nimmt Jörg Zollner zu Herzogenaurach ${ }^{1}$ ) auf gegenseitige Kündigung als Diener an, mit der Pflicht, mit drei gerüsteten Pferden zu dienen gegen Unterhalt und Futter.

Geg. zu Bamberg, Montag nach S. Valentin. - Mit einem Rest des Siegels Albrechts. - Orig. Perg. - $30: 14$.

1454, Mai 26.

54. Eberhardt Zollner vergleicht sich mit seiner Gegenpartei Steph. und Hans Tetzel, Brüdern, und Ulman Hegnein, deren Schwager, im Streite um Lehengüter dahin, dass Jörg Keyper zu Nürnberg jetzt u. künftig gütlichen Entscheid, dem sich die Parteien fügen wollen, treffen solle. Die Lehen rühren von „der Gruntherr", Peter Zollners sel. Mutter und sind: gr. u. kl. Zehent zu Weinzierl, 4 Güter zu Nyderndorf, 1 Gut zu Elterstorf, 1 Gut in Aspach, 1 Gut zu Ristelbach, 2 Güter zum Malmasshof, 5 Güter zu Getzenreut, 4 Güter zu Ruckerstorf, 1 Mühle zu Maydbach, 3 Güter zu Perpach, 1 Gut zu Schafftenach u. 2 Güter zu Gekelspuch. ${ }^{2}$ )

Geg. Sonntag nach S. Urbans Tag. - Siegel der vier genannten Streitenden abgeschnitten. - Orig. Perg.

\section{6, Februar 1.}

55. Albrecht, Markgraf zu Brandenburg, Burggraf zu Nürnberg, nimmt Eberhard Zolnér ${ }^{3}$ ) samt Kind und Gesind in Schutz und Dienst. bis zu gegenseitigem Aufsagen.

Geg. Sonntag vor U. L. Fr. Lichtmess. - Siegel des Markgr. Albrecht fehlt. - Orig. Perg. - 28,5 : 15,5.

\section{7, Juni 16.}

56. Ott Swencker, Bäcker zu Bamberg, erhält vor dem Stadtgericht daselbst von Anton Sweinfurter und Meister Hans

1) S. No. 44.

') Meist im Bamberg-Nürnberg'schen gelegene Ortschaften.

2) Die "Zollner" in dieser Sammlung mit Urkunden seit 1325 häufig vertreten. Man bal die hambergischen Ritter $Z$. v. Brandt (ein Hof in Bamberg) zu unterscheiden von der Nürnberger Patrizierfamilie. 
Vorcheimer, Steinmetz und z. Zt. Baumeister der Stadt Bamberg, erbbestandsweise das städtische Anwesen des früheren „gemeinen Frauenhauses" mit Hofreit und Garten, vor dem "Sannttor" gelegen links hinab zu den "Meyenbrunen“, gegen jährlichen, an die Stadt zu entrichtenden Zins von $2 \pi$ \& u. 1 Fastnachthuhn.

Zeugen: Hans Bernhart, Heinr. Cammermeister, Andr. Cristan, Heinr. Snepff, Heinr. Schultheis, Hans Breutigam, Konr. Hiltpoltsteiner, Konr. Holltrer, Reichart Heymburg, Clas Eychelberger, Jobst Melber, Konr. Griess u. A. - Schultheis: Jorg v. Gich. - Gesch. Donerstag n. S. Veyts Tag. - Siegel der Stadt Bamberg fehlt.

1458, Oktober 20.

57. Kaspar, Abt zu Tegernsee, ${ }^{1}$ ) bittet den Rat der Stadt München, dass er deren Mitbürger Meister Hans Stainmetz zu einem „Werchman und Paumaister" aufnehme, nachdem der Rat „Unser Frauen einen merklichen Pau tun“ wolle und er sich überzeugen könne, dass Meister Hans für das Kloster einen "trefflichen Pau" vollbracht habe.

Geg. Freitag vor Undecim mill. virg. - Orig. Pap. Siegel rückseits, abgefallen.

$$
\text { 1460, Februar } 21 .
$$

58. Fckard, Abt des Klosters Münster-Schwarzach, ${ }^{2}$ ) verleiht Michael Segnitz, Kellner zu (astel, ${ }^{9}$ ) einen Zehenten zu Feuerbach ${ }^{3}$, gregen jährlichen Zins von 30 \& 11.1 Malter Korn. Orig. Perg.

Geg. Donnerstag vor Petri kath. - Abtei-Siegel fehlt. -

$$
\text { 1461, Januar } 25 .
$$

59. Sigmund v. Fryberg ${ }^{4}$ ) schreibt an seine Frau Grete v. Fryberg zu Remenhofen, dass er mit seinem Vetter Hans v. Fryberg vor "Heststet" gelegt sei mit 200 Pferden und erteilt ihr Ratschläge.

Geg. zu "Heststetten" an S. Pauls Bekehrung. - Datiert mit. 1461. - Orig. Pap. - Als „Brief“ gefaltet u. gesiegelt gewesen.

1) Bez.-A. Miesbach.

') Bez.-A. Kitzingen. ') Bez.-A. Gerolzhofen.

4) S. Kneschke, Adelslex. III. 338. 
1467, Mai 25.

60. .Jörg, Bischof v. Bamberg, belehnt Mertein zu Bomersfoklen, Veit zu Rotenbach und Albrecht zu Reichmansdorf, Truchsesse, mit dem halben 'Teil von Bomersfelden, ${ }^{1}$ ) mit dessen Vorhof, dem Hofe des Hans Model und weiteren 7 Sölden, nachdem Bomersfelden durch Konr. und Barthol. Truchsesse, Ritter, seinerzeit dem Bischof als freies Mannlehen aufgegeben worden ist.

Geg. Bamberg, Montag nach Trinitatis. - Mit Siegel des Bischofs. - Orig. Perg. - 30: 19.

$$
\text { 1469, Mai } 25 .
$$

61. Ludwig vom Myers, Dekan, und das Domkapitel Würzburg setzen in ihrer Stadt Ochsenfurt ${ }^{2}$ ) einen äusseren Rat von 12 Mitgliedern ein, aus jedem der vier Stadtviertel drei, welche unter ihrein eigenen Bürgermeister mit dem inneren Rat und dessen Bürgermeister die z. T. benannten Geschäfte erledigen sollen. $\mathrm{Zu}$ Räten aus dem Oberen Viertel werden ernannt: Clas Feyel, Hans Hag, Hans Retzelt; aus Cling-Viertel: Cuntz Knorr, Hans Leutzenprunner, Cuntz Wild; aus Brücken-Viertel: Peter Fuchs, Hans Ott, Lienh. Achtseinnit; aus dem Ausmesser-Viertel: Fritz Frölich, derzeit Bürgermeister, Hans Steinacker und Cuntz Beringer.

Geg. an St. Urbanstag. - Siegel des Domkapitels fehlt. Orig. Perg.

\section{9, November 29.}

62. Vor dem Stadtgericht zu Nürnberg gibt Heinr. Gastelsdorfer, Bürger zu Nürnberg, ein Erb(-Grundstück) zu Neuses, ${ }^{3}$ ) das einst dem Hans Gruber zu eigen gehörte, diesem wieder zurück, auf alle Forderungen verzichtend.

Schultheiss: Sigm. von Eglofstein; Zeugen: Anton Tucher, Paulus Volkmeyr. - Geg. Mittwoch an S. Endres Abend. Siegel des Gerichts zur Hälfte erhalten. - Orig. Perg.

$$
\text { * 1472, Dez. } 1 .
$$

63. Papst Sixtus befiehlt dem Offizial der Diözese Lüttich, den Johannes Bury in den Besitz der Pfarrei Ainbreleux zu

') Bez-A. Hüchstadt a. A. ') Bez.A. gleichen Namens.

3) Bez.-A. Fürth. 
setzen, nachdem Joh. Poncini, der bisherige Pfarrer, verstorben, und Arnold Hettet infolge der Prozessucht des Heinr. de Maynet zurückgetreten ist. Der Streit un die Pfarrei war dadurch entstanden, dass sowohl Johannes Graf $v$. Salm als der Raugraf Engelbert das Präsentationsrecht ausühten. Nach đurch mehrere Instanzen geführtem Prozess nimmt der Papst auf Grund früherer päpstl. Dekrete das Besetzungsrecht in Anspruch, und befiehlt dem Gen.-Offizial, dem von Joh. (ir. v. Salm präsentierten Joh. Bury die Pfarrei zu übertragen, unter Ausschliessung jeder weiteren Appellation.

Datum Romae apud s. Petrum . kal. dec., pontif. ao. II. — Mit Bleibulle. - Orig. Perg. - 50.5 : 31.

\section{4, Juni 17.}

64. Vor dem Stadtgericht Nördlingen wird dem I.eonh. Gasser, welcher sich in München ansässig machen will, durch Hans Hofmann, Ulrich Tünzel und Haimbrand Schmid, Bürger zu Nördlingen, bezeugt, dass Gasser das. ehelich geboren.

Stadtammann: Thomas von Nening. - Mit dem Gerichtssiegel der Stadt Nördlingen. - Orig. Perg.

\section{5 , Februar 21.}

63. Herzog Albrecht von Bayern richtet an Markgraf Albrecht von Brandenburg ein Schreiben durch Boten, welcher "neue Zeitungen" teils zu berichten teils zu empfangen hat. Herzog Albrecht eröffnet, dass er mit seinem Vetter Herzog Ludwig (v. Niederb.) nicht übereingekommen sei, worüber er ihm bei einem Zusammentreffen Mitteilung machen werde; mit seinem Bruder Herzog Christoph sei er wegen dessen Erbteils gegen den Willen Ludwigs unter der Obmannschaft Herzog Sigmunds verglichen worden, wozu ein Landtag nach Straubing beschieden worden sei; dem Markgrafen wïnscht Albrecht allen Sieg.

Geg. München, Eritag vor Sonntag Oculi. - Siegel rürkseits. - Orig. Pap.

\section{5, März 3.}

66. Ulrich P'äninger, Metzger und Bürger zı München, stiftet 60 s gährl. ewigen Zins ans seinem Hause diss, in der 
St. Peterspfarrei all Anger gelegen zwischen, der Frauen am Anger" und Hans Fünsingers Haus, - zu einem ewigen Ijicht in der Peterskirche, gegenüber dem Tichtelaltar.

Zeugen: Hernuan Rüger, Kellermeister, Hans Petz, Bürger zu München. - Siegel des Ludw. Part, Unterrichters zu München, alogefallen. - Geg. Freitag in den Viertagen angehender Fasten. - Orig. Perg.

1476, April 26 .

67. Die Stadt Günzburg ${ }^{1}$ ) stellt dem Ulrich Holgmann, Bürger zu München, einen an die Krämerzunft der Stadt München gerichteten Geburts- und Leumundsbrief aus.

Geg. Freitag nach St. Jörgen. - Siegel der Stadt Günzburg fehlt. - Orig. Perg.

1479, Januar 23.

68. Johann Lemblein, Chorherr zu St. Jakob bei Bamberg, verkauft seinen Hof das., den er von Joh. Drossendorfer erworben, an Hans Wattendorfer um $90 \mathrm{fl}$. mit der Bedingung, dass letzterer jährl. 2 fl. auf Reparaturen hineinverwende. Der Hof hat 30 , einen Lammsbauch und 2 Fastnachthühner jährlich zu erheben von dem Hause des Fritz von Gleichen an der Badstube ${ }^{z}$ a der Sunnen" zu Bamberg; vom Gesamt-Zins hat der Käufer jährl. 52 s an den Oblayer von St. Jakob zu reichen.

Zeugen: Fritz Merz, Cleriker, Ulrich Peypass, Joh. Fuchs, Vikar von St. Stephan zu Bamberg. - Nolariatsinstrument, errichtet durch Joh. Rosskopf, Notar, nit dessen Signet. Siegel des Joh. Lemblein fehlt.

\section{5, Dezember 31.}

69. Dem Ulrich Guggauer von Augsburg wird durch Sixt Kartter und Michael Sailer, Bürger zu Augsburg, das Zeugnis ehelicher Geburt ausgestellt.

Zeugen der Beurkundung: Thom. Drechsel, Hans Gogel, Bürger zu Augsburg. - Siegel des Jorig Ott, Stadtvogte zu Augsb. fehlt. - Orig. Perg.

1) Bez.-A gleichen Namens. 


$$
\text { 1487, Juli } 30 .
$$

70. Friedrich, Kurfürst zu Sachsen und Herzog Johann. sein Bruder, belehnen .Jorg Gerhart und Michael Zolner Gebrüder zu Bamberg „auf dem Brant ${ }^{4}$ ) erblich mannslehenweise mit einem Drittel der Vogtei über das Dorf Nydern Leyterbach, ${ }^{2}$ ) mit 3 Sölden, einem Fischwasser das. und einem Gü̈tlein zu Eichhach bei Weissman. ${ }^{3}$ )

Geg. Koburg Montag nach .Jakobi. -- Kurf. Friedrichs Siegel fehlt. - Orig. Perg. - 26: 15 .

\section{7 , November 28.}

71. Bischöflich Bamberg'sches Hofgerichtsurteil. Heinrich. Bischof v. Bamberg, lässt Irteil fällen in der Appellationssache des Spitals St. Martin in Bamberg als angeblichen "Mühlherrn" der Steinmühle unter'm Stephansberg gegen den erbberechtigten Steinmüller Heinz Donermüller, welcher die Hälfte der Mühle neu aufgebaut hat und behauptet, dass das Spital als Müh/herr und Mit-Nutzniesser verpflichtet sei, bis zur Hälfte - es soll noch die Wasserseite der Mühle restauriert werden - die Baulasten zu tragen. Unter Bischof Philipp ist bereits wegen des 'Titels Mühlherrschaft durch Dompropst Veit Truchsess erkannt worden. Während Donermüller erklärt, dass er einen Kaufbrief, mit welchem er die Mühle und seine Verpflichtungen antrat, nicht besitze, legt das Spital vier Kundschaftsbriefe aus den Jahren 1411 und 1486 und noch weitere auf, aus denen seine Entlastung hervorgehen soll. Nach deren Verlesung - ihr Wortlaut ist in vorliegendes Urteil aufgenommen - wird erkannt, dass sie zur Beweiserbringung unzureichend sind. Beklagter beruft sich auf die gleichen Verhältnisse bei der Bruder- und bei der Fischmühle und bietet einen Vergleich an. Nun wird den Parteien zu beschwören aufgegeben, dass sie direkt über ihre Verpflichtungen aussagende Urkunden nicht besitzen. Nachdem weitere Briefe sich als zur Sache „undienstlich" erwiesen, wird erkannt, dass Donermäller die ganze Baulast habe, nachdem er das Erbrecht an der Mühle besitzt und 2/3 der Mühlgefälle. Dass der Bischof Mühlherr sei, war früher erkannt worden.

Bischöfliche Räte und Lrteiler: Meister. Joh. Balckmacher,

i) S. No. 55. 2) Unterleiterbach, Bez.-A. Stalfelstein. 9) Weismain, Bez.-A. Lichtenfe]s. 
Dechant zu St. Jakob, Apel rom Lichtenstein, Hans ron Hirsperg Ritter. Mertein von Hohenstein, Heiden genannt, Dr. beid. Rechte, Jïrg von Wiesentau, Albr. von Redwitz, Balth. von Seckendorff, Giïnther vom Brandenstein, Philips von Gutemberg, Mertein und Albr. Stieber und Karl Koslinger unser Kanzler. - Geg. Bamberg am Nittw. nach St. Katharin Tag. -- Mit dem Siegel des Bischofs Heinrich. ... Orig. Perg.-Libell von 7 Folien $4^{0}$.

\section{8, Juni 17.}

72. Gütlicher Spruch des Birhofs Heinrich von Bamberg in dem Zehentstreite des Dorfes Litzendorf, ${ }^{1}$ ) vertreten durch Hans Kun, Schultheiss, Hans Schneider und Erh. Beyer, Dorfmeister, gegen Heinr. Taler, Cnterküster des Doms, Steph. Zobel, Vikar des Frauenaltars bei St. Stephan, und Gg. Zollner am Brant, wodurch der Zehentstreit dahin beigelegt wird, dass der letztgenannten Partei als Zehentinhaberin von jeder Fuder Heu eine Bürde (Arm voll) gebührt, dàss Wiesen, die vorher Äcker waren, als solche, dann umgekehrt als Äcker wieder getreidezehentpflichtig werden, dass Grundstücke mit doppeltem Anbau (Obst neben Getreide und $\mathrm{Heu}$ ) nur einen Zehenten zu entrichten haben usw.

Räle und Urteiler: Eberh. v. Rabenstein, Domherr, Dr. Lorenz 'Thüm, bischöfl. Vikar und Chorherr zu St. Stephan, Meister Joh. Balkmacher, Dechant zu St. Jakob in Bamberg, Dr. Mert. v. Hohenstein, gen. Heyden, Albr. Gross, Gg. v. Wiesentau, Albr. Stieber, Schulteis zu Bamberg, Math. vom Rottenhan, H. Banreicher, Karl Kosslinger, Kanzler. - Geg. Bamberg, Dienstag nach St. Veit. - Bischöfl. Siegel fehlt. - Orig. Perg.

\section{8, Juni 20.}

7:3. Bischof Heinrich v. Bamberg erlässt eine Ordnung für das Sondersiechen-Haus zu St. Anton das., das mit 7 Plätzen besetzt ist, welche Ordnung besonders die Beilegung von Streiligkeiten der Insassen bezweckt. - Geg. Bamberg, Freitag nach St. Veyt unter bischöfl. Siegel.

Beglaubigung unter Bischof Georg v. Bamberg, Samstag nach Lorenz (11. Aug.) 1509; bischöfl. Siegel anhängend. - Orig. Perg.

1) Bez.-A. Bamberg I. 


\section{9 , .Juli 14 .}

74. Lrkunde äber den Bund der bayerischen Ritter vom löwen (Löwler-Bund), bezweckend eine Einigung zur Erhaltung der Freiheiten des Kitterstandes, Abwehr von fürstlichen Eingriffen und Angriffen. Die Satzungen verbreiten sich über Organisation (Hatuptmann, Räte und Verordnete), über Wappenbila und Tracht (Abzeichen), über die Todtenfeiern bei Ableben von Mitgliedern (Mittelpunkt ist. die Frauenkirche zu Neumark t ${ }^{1}$ ) beim Schlosse des Mitgliedes Pfalzgrafon Ottol, über Verfahren bei Klagsachen, ganz besonders bei Ansuchen un Hilfe, über regelmässige und ausserordentliche Versammlungen, 'Tagsatzungen. Geldhilfen, Ausführung der Beschlüsse, Besiegelung usw.

Mitglieder der "Gesellschaft zum Löwen" und Besiegler sind: (in verkürzter Anführung) Seb. Pflug, M. v. Wildenfels, J. r. Degenberg, B. v. Stauff, H. Pflug, H. v. Stauff, Herm. Haybeck, G. Zenger, H. Nothaft, J. v. Stauff, L. v. Murach, J. v. Parsberg, J. v. Judmann, G. v. Waldau, Joh. Paulsdorfer d. Ï. J. Zenger, Joh. Zenger, (r. Nothaft, P. Rainer, Seb. v. Waldau, Albr. v. Murach, Sigm. Satlpoger, Erasm. Paulsdorfer, Dietr. Hofer, J. Nothaft, Wilh. v. Raidenbuch, Paul Leiblfinger, Cr. Rainer, C. Zenger, Wilh. Paulsdorfer, Kasp. Nothaft, Hieron. Nus:berger, M. Warter, J. 'Türlinger, J. Tresswitzer, .J. u. W. Stainer, Ulr. Elsenbeck, ()sw. Gleissentaler. Balth. Berchtoldshofer, Balth. Warberger, Ileinr. Lichtenecker, G. Pleysteiner, J. Mausheimer. Wilh. Schlamersdorfer (an Zahl 46). - Mit noch 37 z. 'T. stark beschädigten Siegeln. - Geg. Eritag nach St. Margareten. (Orig. Perg. - Lrkunde ${ }^{2}$ ) stark gebleicht und (lurch die siegel abgescheuert. $-71: 46$.

1493, Januar 12.

75. Petrus, Abt von Reichenbach, ${ }^{3}$ ) verleiht dem Woltir. Hüttlein zu Eppendorf ${ }^{4}$ ) des Klosters Eigen zu und an Eppendorf und das Odland am Dachelsberg zu Erbrecht um jährliche'n Zins von $1 / 2 \pi /$ t Reg.

Geg. Samstag nach St. Erhard. - Abteisiegel fehlt. Orig. Perg.

1) i. Ob. Pf.; z. Zt. Pfalzgrafensitz. $173-188$.

2) Gedruckt u. a. bei Krenner, Baier. Landtags-Handlungen, X,

s) Bez.-A. Roding. 4) Bez.-A. Passau. 


\section{3, August 14.}

76. Jörg von Hutten und seine Frau Aule verschreiben ihree 'Tochter Magdalena und ihrem Eidam Heinrich Kuchenmister zu Wittum und Heimsteuer die Hälfte alles dessen, was nach dem T'ode Gutten von Rudeckens, der Witwe Friedrichs von Hutten, des Jörgen Bruders, an Reichslehen und Erbschaft ihnen anfallen wird.

Geg. Mittwoch, U. L. Franen Assumpt. Abend. - Die Siegel Jörgs v. Hutten und Fritz Clebess' von Nanlsbach fehlen. - Orig. Perg.

\section{5, Januar 26.}

. 77. Georg, Herzog von Niederbayern, macht für 18 Städte Wohltitigkeitsstiftungen, hier für die Stadt Rain, ${ }^{1}$ ) indem er ihr (näher beschriebene) Erträgnisse im Betrage von jährlich 15) fl. zuwendet, und zwar aus 1 Hube zu Wechtringen in der Tullinger Pfarrei, 1 Hube zu Hagenheim in der Pfarrei Walldorf', 1 Hofe zu Otting in der Pfarrei Gempfing, dem Kloster Scheyern gehörig, 1 Hofe zu Hausen in der Pf. Tulling. Die Stadt Rain hat die Gefälle zu verwalten und um $7 \mathrm{fl}$. rhein. 10) lodene Röcke für kranke oder pressthafte Hausarme machen zII lassen, wofür jeder Beschenkte ein Pater Noster und Ave Maria zu beten hat. Von den übrigen $8 \mathrm{fl}$. hat der Rat am Montag nach Oculi während des Amtes in der Pfarrkirche allen Begehrenden durch die Thïre Brod und zwar Semeln und Röckel je zu 1 \& zu verteilen; übrig bleibendes Brod soll zu gleichen T'eilen an das Spital, an die Sondersiechen und ar. die Hausarmen zu Rain gegeben werden; Art und Zweck der Stiftung soll an jedem Vertejlungstage von der Kanzel verkündet und hiebei für den Stifter gebetet werden. - Was an Zinsen über $15 \mathrm{fl}$. eingeht, ist bis $30 \mathrm{fl}$. zu admassieren, damit in Jahren, welche unter $15 \mathrm{fl}$. zurückbleiben, bis zu dieser Summe daraufgegeben werden kann. Die herzoglichen Pfleger und Amtleute zu Rain haben für und für den Vollzug der Stiftung zu fördern und zu überwachen.

Geg. Landshut Montag nach St. Sebastian. - Herzogl. Siegel fehlt. - Orig. Perg. - $70: 47$.

1) Bez.-A. Neuburg a. D. 


\section{* 1498, Mai 12.}

78. Erteilung einer Generalvollmacht an ... de Apeltorn. einen Litrechter Kleriker, durch Herzog Philipp von Cleve, Grafen v. d. Mark, anlangend ein Canonikat an der Iomkirche zu Utrecht, auf welches zu Gunsten eines Klerikers Heinrich Sinollyngh verzichtet wurde.

Instrument errichtet durch den Notar Johannes G. zu Cleve unterm 12. Mai 1498, mit dem Zeichen des Notars. - Perg.

\section{8, August 14.}

79. Fabian von Liesperg zu Liesperg verkauft an Hans Fortsch, Bürger zu Bamberg, sein "Wasser zu Fayckendorf," 1, Lehen des Bischofs zu Würzburg, welches Wasser hinab his Jörg Leybessers Wasser reicht, um 70 fl. rhein.

Geg. Dienstag nach St. Laurenzius. - Mit dem Siegel des v. Ijiesperg. - Orig. Perg.

\section{9, April 23.}

80. Giitlicher Spruch, ergangen vor dem Schultheissengericht Regensburg durch Sigmund von Rorbach, Ritter, des Reichs Hauptmann, Kämmerer und Rat der Stadt Regensburg. in der Erbschaftsstreitsache zwischen Leonh. Zeller zu Sulzbach nebst seiner Frau Barbara, Tochter des Degenhard (iräfenreuter zu Regensburg, und Achaz Gräfenreuter. Sohn des Degenhard, wegen der Verlassenschaft des Dionys Gräfenreuter, wonach diese dem Achaz Gräfeureuter zuerkannt wird, welcher 120 fl. an Leonhard Zeller zu entrichten hat.

Gesch. Ertag nach Jubilate. - Mit dem Siegel des Sigm. von Rorbach. - Orig. Perg.

\section{9, Dezember 10.}

81. Wilhelm von Raidenbuch zu Stefling, Erbschenk des: Bistums Regensburg und bischöflicher Hofmeister, stiftet zur FilialKirche zu Afeking ${ }^{2}$ ) soviele Güter, Gülten und Zinsen, dass sic durch Lostrennung von der Mutterkirche zu Kelheim zur selbstständigen Pfarrei erhoben werden kann. Das Nominierungsrecht

1) Feigendorf, Bez.-A. Bamberg II.

2) Affecking, Bez.-A. Kelheim. 
bezgsw. jus patronatus behält der Stifter sich und seinen Erben vor. Sebald, Alt des Klosters Heilbronn, hat als Lehenherr und Meister Heiurich Lebentherr als Pfarrer ron Kelheim, Rupprecht, Herzog in Bayern etc., als Bischof ron Regensburg seine Finwilligung gegeben. Dem Pfarrer von Kelheim verbleibt $1 / 3$ des grossen und kleinen Zehents zu Afeking wie bisher und er erhält ron der neuen Pfarrei jährlich $4 \mathrm{H}$. rhein. Entschädigung. Dotation und Erträgnisse der neuen l'farrei bestehen aus einem neuerbauten Pfarrhaus nebst Hofstatt und Stadel bei der Kirche, einem weiteren Hofe zu Afeking, 1/15 des Weinzehents in den Weingärten, Raidenbuch'sche Lehen in Oberkelheim, und meist Barzinsen aus Grundstücken z. B. „des Laberers" zu Afeking etc., anderer zu Ober- und Nieder-Teyrting, Obersall, Taldorf, Gmünd, Veckenpach, Weltenburg und Oberkelheim, besonders aus Häuserzinsen zu Kelheim.

Siegler dieses Stiftungsbriefes sind Friedr. v. Wirsperg und Jörg Nothaft, Regensburger Domherrn. - Geg. Erichtag vor Luziä. -

Hier Bestätigung dieser Stiftung und Transsumpt ihrer Urkunde durch Rupert etc., Bischof von Regensburg, datum Ratisp. die ... decima decembris unter grösserem bischöfl. Siegel, das nicht mehr vorhanden. - Orig. Perg. - 62:62.

$$
\text { 1501, Mai } 24 .
$$

82. Die Stadt Schongau ${ }^{1}$ ) stellt dem .Jörg Zelltmaister zu München Geburtszeugnis aus.

Geg. Montag nach Exaudi. - Mit Siegel der Stadt Schongau. - Orig. Perg.

\section{2, Juni 13.}

83. Von dem Stadtgericht zu Nürnberg lässt Gerhard Zollner, Bürger daselbst, eine Generalvollmacht ausfertigen für seines Bruders Söhne Mathes und Martin Zollner, ${ }^{2}$ ) um, bei seiner persönlichen Verhinderung, nachfolgende Lehenstïcke ${ }^{3}$ ) zu empfangen: Von Bischof Veit von Bamberg 1 Zehent zu Weinzierl, $1 / 2$ Zehent zu Litzendorf; dann 2 Teile Zehent zu Watten-

1) Bez.-A. gleichen Namens.

') S. No. 55. ) meist im Bambergischen gelegen. 
dorf ob Wasserlos, ${ }^{1}$. Zehent zu Dietreichsprum, 1 Dorfzehent zu Prumn bei dem Greyfenstein, 1 \%ehent zu Heuslingen bei dem Zabelstein, $1 / \times$ Zehent zu Niedernlaiterbach, 1/2 Zehent zu Thochentorf unter dem Grerfenstein, 1 Hof zu Hochstet in der Vorstadt, 1 Gut z Boxtorf auf dem P'irg bei Künigsfeld, 1 Gütlein zu Eych bei Lisperg, 6 Acker Holz zu Vorsdorf bei Burg-Ebrach. Sodann rom Domkapitel Bamberg 1 Hof zum Staffelstein in der Vorstadt nebst 5 Sölden, 8 Stiuck Weingärten, Äcker und Wiesen: endlich von dem Ältesten v. Bonntzendorf 1 Gütlein zu Bonntzendorf unter dem Giugel, 1 Zehent zu Gestingshausen, 1 Zehent in Rauschau.

A ussteller: Schultheiss Hans von Weichstorff. Siegel-Zengen: Wolf Haller. Stephan Volkmer. - Geg. Wontag nach Barnabai. - Gerichtssiegel der Stadt Nürnberg fehlt.

$$
\text { * 1502, September. }
$$

84. Fdinund, rechter Erb der Kiron und Königreichs zu Engrenland, zu Suffolck" etc. erlässt Creditiv für den ihm von Freunden zugegebenen Rat Wolfgang Gotzman sowie für seinen Hofmeister Greyffan von Osskirch, wonach diese befugt sind, mit Königen, Kurfürsten, Fürsten geistl. und welttichen Slandes ete. in geheimsten Sachen zu vorhandeln und zu beschliessen; wat Alles „wir Edmund [und] Ritzhardt unser Brtuder" unwaigerlich vollziehen wollen.

Geg. „in der Statt Aucht des Monatstage Septembris."

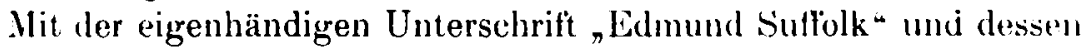
anhängendem grossen Siegel. - Die Urkunde in mangelhafter Form in deutscher Sprache ausgefertigt. - Orig Perg. $35: 20,5$. (Edmund de la Pole ist der zweite Sohn de's Herzogrs von Suffolk und der Elisabeth, Schwester Eduards IV. Er trat als Thronprätendent auf unter König Heinrich VII. [1485-1509]. nachdem schon mehrere Anwartschaften auf den englischen T'hron niedergeschlagen worden waren. Graf Edmund war "der vornehmste Repräsentant der Yorks" und verkehrte mit dem höchsten Adel Englands [1501]. Vom líönige geheim beobachtet, entfloh er mit seinem jüngeren Bruder Richard nach Flandern, wo beide seit 1502 "ein kümmerliches Leben " führten. Auf dem Kontinente wurde Edmund von König Philipp und Kaiser 
Maximilian bei deren Politik hinsichtlich Englands unterstïtzt. Richard befand sich 1505 in Aachen; Edmund wurde $15(16)$ von Lönig Philipl in Namur aufigehoben und an Heinrich nach England ausgeliefert; hier wurde er in Tower gefangen gehalten. Philipp bat um sein Leben; „erst 1509 nach dem Tode Heinirichs ist der Gefangene umgebracht worden.")

\section{* 1506, . Januar 30 .}

85. Von dem erzbischöfl. Hofgericht zu Salzburg wird dem Hans Reiter, bischöfl. fürstl. Büchsenmeister das., bezeugt, dass Benedikt Reiter in München dessen ehelich orzeugter Sohn sei.

Hofrichter: Sebastian von der Alben zu Trübmpach, Ritter, salzb. Erbtruchsess, Landhauptmann und Verweser des Marschallamts. - Zeugen: Kasp. Pannycher, Pfleger zu Staufeneck, Ernst vom Graben zu Sumereck, Gg. Noppinger, Pfleger auf dem Schloss zu Salzburg, Hans Straser, Rat. - Geg. Freitag vor U. L. Fr. Lichtmess. - Mit einem Reste des Siegels des S. v. d. Alben. - Orig. Perg.

\section{6, April 24.}

86. Heimeran Zennger zum Liechtenwald, Domherr und ()fizial des Domstifts zu Regensburg, Mich. Zennger, Christoph (iiesser zu Wyntzer, P'fleger zu Ernfels, und Christoph Plankenfelser zu Schwarzenfeld für seine Ehefrau, Vormünder der Tochter Katharina des Cuntz Pöllinger zu Fronperg, ${ }^{1)}$ verkaufen eine Wiese im Werte von $800 \mathrm{fl}$., 22 'Tagwerk gross an der Naab bei Fronperg, aus der Verlassenschaft des Pöllinger, an dessen Witwe Hedwig, da ihr der Ehegatte $800 \mathrm{fl}$, worunter ihr Heiratgut mit 500 fl., testiert hatte. 800 fl. sind der Witwe erlegt, der Rückkauf der IViese vorbehalten worden.

Siegler: Die fünf erstgenannten Vormünder und Kaspar Plankenfelser zu Treswitz auf der Höch; die Siegel der beiden Zenger anhängend. - Geg. Freitag nach Quasimodogen. -Orig. Perg.

1) Bez.-A. Burglengenfeld. 


$$
1506, \text {. Iuli } 20 \text {. }
$$

87. Lorenz, Bischof von Märzburg, Herzog zu Fanken. belehnt die Briider und Vettern Michel, Mathes, Mertein und Gerhart Zollner, ehem. zu Herzogenaurach mit 1 Zehent zum Arenstein, ${ }^{1}$ ) 1 Zehent zu Birkeich, 1 Zehent zu Mirnhule auf dem liebirge, 1 Zehent zu Horbach bei Wachenrode, ': Zehent zu Hernsdorf, † Gütern zu Neuses bei Burgebrach, 3 Gütern und einer Iühle zı Obernhadmanshach bei Burgebrach, einem Holz im Schafstal bei Kemmern, 1/8 am Fischwasser daselbst und 1 Gut zu Wangerstorf als Mannlehen.

(jeg. Donnerstag nach U. L. Frauen Assumptionis. - Mit einem Rest des bischöfl. Siegels. - Orig. Perg. - $25: 17,5$.

1507, März 9.

88. Die Stadt Ochsenfurt stellt dem Hans Hamer, Bürger zu München, Zeugnis aus, dass er der Sohn des ochsenfurter Bürgers weil. Stephan Hamer ist.

Geg. Dienstag nach Oculi. - Siegel der Sitadt Ochsenfurt abgerissen. - Orig. Perg.

\section{9, Oktoher 8 .}

89. Wilhelm rou Munichau, Pfleger zu 'Trostberge, stellt I'Irich Hueber von Berg (bej St. IVolfgang im Gericht Thostberg), jetzt Bürger in München, ein Zeugnis über eheliche, Geburt aus.

Zeugen: Osw. Geroltinger, Bürger zu 'T'rostberg, Christian Neumair, Bürger zu Altenmarkt, Mich. Hueber von Berg, I,ienh. Prennt von Tuting. - Siegel des Pflegers fehlt. -- Geg. Montag vor Dionysius. - Orig. Perg.

* 1511, August 7.

90. Geburtszeugnis für Ilans Moser, Bürger zu München, ausgestellt von der Stadt St. Gallen.

Geg. Donnerstag vor Laurenzius. - Mit Siegel von St. Gallen. -- Perg.

1) Diese und die nachfolgenden Orlschaften in verschiedenen Bez.Ämtern im ehem. Bamberg'schen gelegen. 


\section{4, März 26.}

91. Die Gemeinde Obernhatmansbach ${ }^{1}$ ) und der Müller in der Erlmühle wählen in ihrem Streite wegen des Wehrs bei letzterer als gütliche Richter Heinz Linhart ron Neuses, Heinz Egen von Unterhatmansbach, Fritz Brem zu Burgebrach, Heinz Popp von Sampach, Ott' Müller von Frensdorf, Hans Müller von Renndorf und Andr. Müller von Gunterdorf, welch' letzterer als Obmann den Spruch verkündet, dass, nachdem sie einen Eichpfahl gesetzt haben, der Müller das Wehr bauen soll „dem Eichpfahl gleich“, dass er das Wehr 18' lang offen lassen muss, doch auch das Wehr verbauen darf; dass ,ein Aufsatz" errichtet werde, soll der Bauern von Oberhatmansbach guter Wille sein. Gesch. Sonntag Laetare. - Siegel des Marktes Burgebrach fehlt. - Orig. Perg.

* 1515, September 13.

92. Anna Echterin, Albrechts von Berwong Witwe, quittiert Philipp Grafen zu Hanau und Lichtenberg über Empfang von $500 \mathrm{fl}$.

Geg. Dornstag nach Nativit. Mariae. - Siegel des Jakob von Cromberg aufgedrückt. - Orig. Pap.

\section{7, April 4.}

93. Georg, Bischof von Bamberg, nimint den Jobst Sautter von der Scherr als Hauptmann über das Fussvolk in seinen ständigen Dienst mit jährlichem Wartgeld von 60 fl., im Dienst 16 fl. monatlichem Sold, Speis' und Futter bei Hof nebst Reisegeld und stellt die Pfichten eines Hauptmanns auf, namentlich darüber, was geheim und im Rat zu behandeln sei. - Geg. unter bischöfl. Sekret an St. Ambrosien Tag.

Revers des J. Sautter desselben Datums, mit seinem aufgedrückten Siegel, Libell von 4 Folien, Pap.

1518, November 6 .

94. Die Geschwister Weber, Bürger zu Hassfurt, welche ihre Erb-Fieischbank im alten Rathaus daselbst um 70 und $10 \mathrm{fl}$.

1) Ober- und Unterharnsbach, Bez.-A. Bamberg II. Vgl. No. 87. 
der Stadt verkauft haben, wie im Buch der Stadthandlungen zı ersehen sei, bestätigen den Empfang der 70 und $10 \mathrm{fl}$.

Geg. Samstag nach Allerheiligen. - Siegel des Junker: Heinz Truchsess, Amtmanns zu Hassfurt, fehlt. -.. (Orig. Perg.

\section{1 j19, März 14.}

93. Eberhart v. Dürham, Landvogt auf St. Wylbolts Berg zu Eichstädt, ${ }^{1}$ ) stellt dem Michael Schmid aus Eittensheim behufs auswärtiger Niederlassung ein Geburtszeugnis aus.

Geg. Montag nach Invocavit. - Mit Siegel des Landrogts. - Orig. Perg.

1523, März 31.

96. Das Dorfgericht zu Zellingen, $\left.{ }^{2}\right)$ Bistums Würzburg. bestätigt dem Michael Weyglein das. die eheliche Abstammung.

Schultheiss Thoman Glöck; Peter Fuller und Hans Gersess Bauermeister. - Geg. Dienstag nach Palmarum. - Mit dem Siegrel des Karl Zolner von Rottenstein zu Zellingen. - Orig. Perg.

1526, Mai 18.

97. Die Stadt Hall im Inntal bestätigt dem Leonh. Aherzhauser zu München, dass er der eheliche Sohn des Martin Aberzhauser, Bürgers und Amtmeisters im Pfannhaus zu Hall, und der Katharina, geb. Sper, daselbst sei.

Geg. wie oben. - Mit verletztem Siegel der Stadt Hall. Orig. Perg.

$$
\text { * 1527, Februar } 7 .
$$

98. Geburtszeugnis seitens der Stadt Esslingen ${ }^{3}$ ) für Endres Karr, genannt Schott, welcher der Sohn des Bürger's Andreas Karr daselbst und der Magdalena, geb. Jud, sei.

Mit Siegel der Stadt Esslingen.

$$
1528 \text {, März } 20 .
$$

99. Die Stadt Landsberg a. Lech ${ }^{4}$ ) fertigt dem Hans Lang, Bürger zu München, Geburtszeugnis aus.

Mit dem Siegel der Stadt. - Orig. Perg.

1) Bischofssitz. 2) Bez.-A. Karlstadt.

3) Wïtt. Oberamt gleichen Namens. ") Bez-A. gluichen Namens. 
1530, Juni 20.

100. Sebastian Spiegl von Ullerstorf zu Waffenbach erïffnet seinem Schwager Adam von Freudenberg zu Freudenberg, Landrichter und Pfleger zu Auerbach (Oberpfalz), das Testament seiner (Spiegl's) Frau, besiegelt von der Stadt Neunarkt, mit welchem sie den Adain v. Freudenberg in die Güter ${ }_{n}$ an Haselbach" nach dem Todesfalle ihres Mannes (Spiegl) erblich einsetzt. Ad. v. Freudenberg gelobt, seinen Schwager in seinem übrigen Besitz zu schützen.

Zeuge: Ludwig v. Eyb. - Geg. Montag nach Corporis Christi. - Mit Siegel des v. Freudenberg und v. Eyb. - Orig. Perg.

1530 , September 30.

101. Hans Arnold, Bierbräuer und Bürger zu München, verkauft an Elsbeth von Kuching, Dienerin des Sigm. Peisser, Hufschmieds, sowie an der ersteren Sohn um 60 fl. einen jährlichen Ewigzins von $3 \mathrm{fl}$. aus seinem Anwesen in München, gelegen in der St. Peters Pfarrei am Anger zwischen den Häusern des V. Päl „Pirmentters“ und des Seb. Truckenstier "Gschlachtgwanters".

Geg. Freitag nach St. Michael. - Siegel des Ewiggeldamtes München fehlt. - Urkunde durchschnitten. - Orig. Perg.

$$
\text { 1531, Januar } 6 .
$$

102. Abt Thomas des Benedik tinerstiftes Fbrach ${ }^{1}$ ) erneuert die Stiftung der Zolner von Bamberg, wonach Friedrich, Schultheiss zu Bamberg, seine Frau Agnes, geb. v. Randisacker, Hans, Georg und Heinr. Zolner auf'm Brandt 1294 zum Kloster Ebrach eine jährliche Gült von 40 Malter Korn und $30 \mathbb{t} h$, fällig aus dem Dorf Suntheim ${ }^{2}$ ) gekauft, dann 1325 die Söhne des Friedrich Zolner den Zehent zu Gremsdorf, ${ }^{3}$ ) Lehen des Grafen Ludwig v. Rineck, hinzugefügt haben, damit jährlich Gottesdienste für die Vorfahren der Zolner und ein Mahl init den Anwesenden der Familie im Kloster gehalten werden.

Geg. am Tag der hl. Drei Könige. -- Siegel des Klosters fehlt. - Orig. Perg.

1) Bez-A. Bumberg II. 2) Mainsontheim, Bez.-A. Kitzingen.

3) Bez.-A. Hüchstadt a. A. 
1532, November 16.

103. Philipp, Kardinal, päpstl. Vizekanzler, Legat für Deutschland, setzt den Valentin Fabri. ständigen Vikar an der Kirche zu St. Peter und Alexander zu Aschaffenburg, ${ }^{1}$ ) nachdem er ihn von allen kirchlichm Zensuren freigesprochen, in den Genuss einer jährlichen l'ension von 12 cioldgulden, welche die Hälfte der Einkünfte sind aus der Vikarie des Lorenz-Altars in der benannten Kirche, auf welche Vikarie vorher Fridericus Moliatoris verzichtet hat.

Datum Mantua XVI. kal. decembris, pontific. Clementis pp. VII. ao. nono. -- Mit dem Siegel des Kardinals. --Orig. Perg. -- 52:34.

1533, Dezember 9.

104. Peter Erhardt von Schlucht verkauft an Georg Orttel, Müller zu Schönlind") seinen Weiher beim Dorf Schlucht") zwischen der Obern- und Untern Loe an der Landstrasse nach Haringloe, um $36 \mathrm{fl}$. und 1/: $\mathrm{fl}$. Loikauf.

Geg. Eritag nach St. Niklas. - Mit dem Siegel des Ott' Zenger zum 'Thanstain und Kolnpach, Landrichters zu Amberg. -- Zeugen Ulr. Nupaur von Crondorf und Georg Graf von der Khottritz. -- Orig. Perg.

$$
\text { * } 1537 .
$$

105. Schriftproben eines Franz Örtl, die dem Inhalte nach wohl eine Beilage bildeten zu einem Ansuchen, an einer Hofkanzlei Verwendung zu finden.

In verschiedenen derzeitigen Schriftarten ausgeführt. - Ein Perg.-Folium.

\section{8, August 16.}

106. Die Stadt Leipzig wendet sich an die Stadt Bamberg mit dem Ersuchen, den 'Thomas Starke, Diener des Merten Mertens, Bürgers zu Leipzig, zu unterstïtzen, welcher (Starke) in Bamberg 633 fl. 14 Gr. 11 s einzutreiben hat für seinen Herrn. Der Schuldner "Hans Glaser von Possen" hat in Bamberg A ktiven stehen, während er dem Mertens die 633 fl. für „6 Säcke Pfeffer" zurückbehielt.

Geg. Freitag nach Assumptionis S. Mariae. - Siegel der Stadt Leipzig rückseits, abgefallen. - Orig. Pap.

1) Bez.-A. gleichen Namens.

2) Schönlind und Schlicht, Bez-A. Amberg. 
1541, Februar 22.

107. Weygand, Bischof von Bamberg, bestellt den Wolf Jud ron Brupperg als Hauptmann des Fussvolks und Diener von Haus aus mit einem jährl. Dienstgeld von $50 \mathrm{fl}$. rhein., ,in unserer Verlegung" mit weiterem monatlichen Doppelsold für einen Knaben und 2 Trabanten, "nit in unserer Verlegung" mit 5 Solden für einen Monat, 3 Solde für den Hauptmann, 2 für Knaben und 2 Trabanten, sowie unter jeglicher Schadloshaltung. Geg. Dienstag an St. Petrus Cathedra unter bischöfl. Sekret.

Revers des W. Jud dess. Datums mit einem Rest seines Siegels. -- Pap. Libell, 6 Fol.

\section{1, Juli 2.}

108. Die Stadt Memmingen stellt ihrem Mitbürger Hans Reuchlin Zeugnis aus, dass sein Sohn Hans der Jüng., welcher sich zu München ansässig machen will, ehelich geboren ist.

Mit Siegel von Memmingen. - Orig. Perg.

$$
\text { 1541, Juli } 29 .
$$

109. Vertrag des Karl Zollner v. Brand zu Bamberg mit Friedrich Hartlieb genannt Walsporn zu Klingenberg etc., Amtmann, resp. mit dessen Tochter Magdalena behufs Ehe. Jungfer Magdalena erhält $300 \mathrm{fl}$. Heiratgut mit, welche Zollner mit ebensoviel nebst $100 \mathrm{fl}$. Morgengabe widerlegt. Es folgen Erbabmachungen, für den Fall, dass Zollner im Tode vorangeht und 1. Kinder hinterlässt, 2. und 3. diese männlich oder weiblich sind, 4. die Mutter von den Kindern zu ziehen und 5. sich wieder zu verheiraten gedenkt; für dieselben Fälle, wenn Magdalena zuerst stürbe.

Teidinger: Lienh. v. Thurn zu Rieperg, Verweser des bamberg'schen Hofmeisteramts; Dr. Gg. Zollner, bamb. Hofrat, Hans Zollner und Hans Zeitler, des Rats zu Bamberg. - Die Siegel der Teidinger und die des Friedr. Hartlieb und Karl Zollner fehlen. - Geg. Freitag nach Innocenz. - Orig. Perg.

* 1541, November 19.

110. „Henrick dir Groef Erfvaicht tot Erklens, ${ }^{1}$ ) Claes Vyge Amptman van Neder Betuwe, Wynolt Hackfort; Johan

1) Preuss. Reg.-Bez. Aachen.

Arohivalieche Zeitschrift. Neue Folge XII. 
Mom, Wernerns Flferdinck und Johan Everwyn, setzen als Verwandte, Freunde und Schiedsleute das Erbe des Cracht van Camphuysen, Drosten zu Berg und der Schulenburg, und seiner Ehefrau .Joffer Beerte auseinander. Unter deren beiden Söhneu Cracht und Gysbert werden eine grosse Anzahl von benannten Gründen, Gütern, Anwesen, Einkünften, auch Kapitalien ausgeteilt. Von Lehensherrn sind vorzüglich genannt die "Fürstenvon Cleve und Geldern, die "Grafen" von Berg; an Orten: Erklens, $\left.{ }^{1}\right)$ Arnhem, Zytphen.

Geg. S. Elisabeth. - Siegler des „Maichgeschit" diefi Schiedsleute und die Erben-Brüder; $5 \mathrm{~S}$. anhängend. - Orig. Perg.

* 1542, September 19.

11. Ernst, konfirmierter Erzbischof von Salzburg. päpstl. Legat, Pfalzgraf bei Rhein, Herzog von Bayern, bestätigt der Zunft und der Bruderschaft der Zinmerleute in Salzburg die von seinem Vorgänger Kardinal Mathaeus ihnen verliehene Ordnung und Satzungen. Folgen die Satzungen.

Geg. Salzburg am Erchtag vor St. Matheus. - Mit dem erzbischöfl. Siegel. - Orig. Perg.-Libell, 6 Folien.

1544 , Dezember 16.

112. Johann, Bischof zu Naturen (in Thrazien, unter der Konstantinopeler Kirche), Suffragan Bischofs Weigand von Bamberg, vidimiert die (oben sub No. 20, 5. Januar 1325 aufgeführte) Urkunde, wonach Friedrich Zollner, Schultheiss zu Bamberg, seinem Sohne Friedrich das Schultheissenamt, die Hofmark aher der Familie überlässt.

Gesch. Dienstag nach Luciä. -- Siegel Bischofs Johamı fehit. - Perg.

1545, Dezember 31.

113. Die Brüder Dr. Georg, Hans, Michael und Heinz Zollner am Brand überreichen dem bischöfl. Bamberg'schen Rat Protestation dagegen, dass sie von den kaiserl. verordneten Obereinnehmern der Türkensteuer bei der Veranlagung zu Bamberg als Bürgerliche und nicht al, idelige behandelt worden seien.

Notariatsinstrument obigen Datums, mit Signet des Notars Heinrich Schwalb zu Coburg. - Perg.

1) Preufs. Keg.-Bez. Aachen. 
1547, September 20.

114. Lorenz Fries ${ }^{1}$ ) und Peter Klarman, würzburg'sche Sekretäre, verkaufen dem Heinrich Zolner auf dem Brandt zu Bamberg um $380 \mathrm{fl}$. mit bischöfl. Bewilligung nachfolgende Lehenstücke, die vor ihnen Gabriel und Pangraz die Haller zu Bamberg innegehabt hatten: 1 Hube zu Mühlhausen ") mit 5 Sölden, ${ }_{1 / 2}$ Tagwerk Wiese daselbst im Babentale, das Holz zu Schefstal. die Weingärten und Reutäcker im Holz, 2 Teile Zehent von letzteren. die Fischweide unterhalb im Main und 1 Acker zu Reundorf als Mannlehen.

Geg. Dienstag nach Exaltat. Crucis. - Die Siegel der beiden Sekretäre fehlen. - Orig. Perg.

\section{* 1548, Oktober 15.}

115. Wolfgang Mägerl zu Wegleuten stiftet testamentarisch für die Hausarmen des Markts Ried ${ }^{3}$ ) $700 \mathrm{fl}$. rhein. baar, welche rom Markte Ried mit Übereinstimmung der Mägerl'schen Fideikommissare und Vormundschaft in Gülten mit dem Zwecke angelegt werden, dass jeweils davon 4 Personen ${ }_{n}$ in die reiche l'fründstube ${ }^{\alpha}$ im Spital aufgenommen und unterhalten werden.

Geg. wie oben. - Mit Siegel des Mark tes Ried. - Orig. Perg.

1549, April 29.

116. Balthasar von Streitberg zum Greifenstein belehnt die Zolner auf dem Branndt (Dr. Georg, kurpfälz. u. Bamb. Rat, Michael und Heinrich, dann Hans Zolner zu Bischofsberg, ferner Friedrich, Martin und Christoph) mit einem Gut zu Staffelstein 4 nebst 2 Sölden, mit einem Gut zu Drosendorf ${ }^{5}$ ) auf dem Gebirg und ${ }^{1 / 2}$ Zehent zu Brun ${ }^{6}$ ) als Mannlehen.

Geg. Montag nach Quasim. - Siegel des v. Streitberg fehlt. - Orig. Perg.

$$
\text { * 1550, Juli } 28 .
$$

117. Joh. Kneller, kais. Rat, Comes palatinus, verleiht den Nikolaus, Paul, Jakob und Hans Lauser Wappen.

Geg. Reichsstadt Weil vor dem Schwarzwald. - Siegel des J. Kneller. - Orig. Perg. - Mit gemaltem Wappen.

1) Der bekannte Würzburger Historiker. ') Bez.-A. Würzburg.

") Ober-Österreich, Innviertel. ") Bez.-A. gleioh Nameus.

5) Bez.-A. Bamberg. ") Bez.-A. Ebermannstadt. 
1550, November 11.

118. Die Gemeinde Eschenau ${ }^{1}$ ) fertigt dem Lorenz Herr Zeugnis aus über eheliche Geburt.

Geg. Dienstag Martini. - Gerichtssiegel des Dorfes Eschenau fehlt. - Orig. Perg.

\section{4, März 16.}

119. Karl V., röm. Kaiser, verleiht dem Philipp Diennst von Spever erblich ein Wappen, in vorliegender Urkunde eingemalt, für die seitens Diennst' ihm und seinem Bruder, dem röm. Könige, geleisteten Dienste „als Kriegsmann ... vor St. Paul, Peron, Turbena, Gendt, Algiera, in Ungarn vor Pest, in Frankreich vor Landersy" und als T'rabant der deutschen Garde der Königin Maria, des Kaisers Sohwester.

Geg. Brüssel. - Kais. Siegel verletzt. -- Orig. Perg. - i4: 43.

* 1555, November 1.

120. Kaiser Karl V. erteilt dem Melchior Schedel für die Verdienste, die sich seine Vorfahren und besonders er selbst seit 12 Jahren im Reichskriegswesen und an der Kanzlei bei Hofe erworben, erbliche Privilegien, insbesondere des freien Niederlassungsrechtes im Reiche, der Befreiung von allen Ortssteuem und -Abgaben, von Einquartierungen und das Privileg der Exemption von allen Gerichten, das Reichshof- und Reichskammergericht ausgenommen. - Die Wahrung dieser Rechte ist sicherzustellen durch den Erzkanzler zu Mainz, den König von Böhmen, Erzherzog zu Österreich, den Erzmarschall des Reichs, die Herzoge von Sachsen usw. - Die Auszeichnungen Schedels als Kriegsmannes geschahen in Spanien, vor St. Desir in Frankreich, Stadt Deurn, im schmalkaldischen Krieg, vor Ingolstadt, in Sachsen und vor Renty und Camerich unter Günther von Schwarzburg und Philipp zu Eberstein.

Geg. zu Brüssel. -- Kais. Siegel fehlt. - Mit faksim. Unterschrift Karls V. - Orig. Perg. - 65: 54 .

1556, Februar 15.

121. Wolfgang Stäml, Bürger zu München, verkauft seinen auf dem Hause der Barbara Merkseisen in der Neuhausergasse

1) Bez.-A. Hassfurt. 
ruhenden Exigzins von $2 \mathrm{H}$. um $40 \mathrm{fl}$. an die Erben des Bernh. Streicher zu Janskirchen.

Gesch. zu München. -- Ewiggeld-Siegel der Stadt München fehlt. - Mart. Gruber Stadtschreiber, Sim. Schaydenreisser, Unterrichter. - Orig. Perg.

* 1556, Juli 26.

122. "Erffinaechgescheyt", Auseinandersetzung der Verlassenschaft des "Martyn van Roshem", vorgenommen durch die Vormundschaft der Kinder des letzteren zwischen diesen und der Mutter "Maria van Voerst".

Gesch. wie oben. - Siegler: 6 Vormünder und Freunde; Siegel 1 und 4 anhängend. - Orig. Perg.

$$
\text { 1560, Februar } 3 .
$$

123. Georg, Bischof zu Bamberg, eingetreten in die "Landsbergisch Schirmseinung“, nimmt für sein Kontingent u. A. den Gg. W. v. Kindsberg zu Weidenberg als Hauptmann zu Fuss auf gegen jährlich $150 \mathrm{fl}$. bei gegenseitiger Kündigung.

Geg. zu Bamberg unter bischőfl. Sekret. - Ungesiegelter Revers, 16. Jhdt., Pap., 4 Folien.

\section{0, Juli 22.}

124. Mathes vom Rotenhann (zu Rentweinstorff) zu Bamberg, belehnt Dr. Georg Zollner, kurpfälz. und batnberg'schen Rat als Lehenträger derer v. Zollner auf dem Brandt mit 4 Sölden zu Mirsbach ${ }^{3}$ ) und 1/3 Zehent ,zum Zuckshutt".

Geg. Montag Maria Magd. - Siegel des v. Rotenhan fehlt. - Orig. Perg.

$$
\text { 1562, Februar } 7 .
$$

125. Revers des Georg Wolf v. Künsberg über Erneuerung seiner Hauptmannsbestallung durch Bischof Veit von Bamberg.

Geg. wie oben. - Mit dem Siegel des v. Künsberg. Orig. Pap., 4 Folien.

1) Mürsbach, Bez.-A. Ebern. 


\section{3, Juni.}

126. Urban, "Propst und Erzdiakon" des Stiftes Raytenpuch, ${ }^{1}$ ) gibt an Urban Faygle, Schmied zu Peuting, 13 und 5 Strang Äcker "im Feld gen Riedt ${ }^{\prime \prime}{ }^{1}$ ) tauschweise gegen eine Wiese.

Geg. Rayttenpuch den .. Juni. - Propsteisiegel abgefallen. Urkunde mangelhaft abgefasst und ausgefertigt. - Orig. P'erg.

\section{3, November 15.}

127. Hans Jakob und Hans Christoph, Gebrüder von Werdenstein zu Eberspach, Erbkämmerer des Stiftes Kempten, sichern der Ursula v. Werdenstein, geb. v. Polanden, Witwe des dritten Bruders Hans Felix v. Werdenstein, die ihr von letzterem bewilligte aber nicht versicherte Widerlage von $1000 \mathrm{fl}$. in der Weise, dass sie der Witwe auf Lebenszeit jährlich $50 \mathrm{fl}$. Rente aus Dorf und Gericht Eberspach, ${ }^{2}$ ) zahlbar zu Berchingen $^{3}$ ) oder Freistättl in der Oberpfalz, zusprechen.

Geg. wie oben.*) - Siegel der Brüder v. Werdenstein abgefallen. - Orig. Perg.

\section{4, August 14.}

128. Friedrich, Bischof von Würzburg und Herzog zu Franken, belehnt die Söhne des Heinr. Zollner auf dem Brandt mit jenen Lehenstiicken, die letzterer von dem weil. bischöfl. Sekretär Lorenz Fries und von Peter Clarman erkauft hat. I)ie Lethenstücke sind: 1 Hube zu Mühlhausen, ${ }^{4}$ 5 Sölden daselbst. 1/2 Tagwerk Wiese daselbst im Babental, das Holz zu Schaftal. die Weingärten und Reutiacker im Holz, 2 Teile Zehent aus diesen, die Fischweide dabei im Main, 1 Acker zu Reundorf.

Bischöfl. Siegel fehlt. - Orig. Perg.

1564, Dezember 24.

129. Notariats-Instrument, betreffend İbergabe eines Testamentes des Dr. Georg Zollner auf'm Brandt, bischöflichen

1) Bez.-A. Schongau.

4) Bez-A. Amberg. ") Bez-A. Beilngries. ") S. No. 114.

*) Wenn die moderne neue Tages-Datierung wie oben, seit dem 16. Jahrh. sich Eingang verschaffend, gebraucht ist, wird sie weggelassen. 
Hofrats und Hofrichters, in seiner Wohmung über der "Apotheke" an den kais. Notar Joh. Ludwig zu Bamberg.

Zeugen: Hieron. Fürst, Heinr. Schrenker, Seb. Hüls, Zach. Klett, Konr. Sturm, Reich. Koster, Erh. Kolb, Bürger etc. zu Banberg. -- Mit Handzeichen des Notars.

Note über Vollzug des Testaments durch Generalvikar Dr. Paulus Neydecker. Actum Bamberg. Dezbr. 1565̃. - -Perg., 2 Folien in stehendem Format.

\section{5.}

130. Joham Friedrich der Mittlere, Herzog zil Sachsen, Landgraf zu 'Thüringen etc.. belehnt die Söhne weil. Heinrich Zollners auf'm Brandt zu Bamberg, sowie deren Vettern mit ;) Giüteh zu Arnstein ${ }^{1}$ ) und 10 Äckern daselbst, wie diese Lehen:liicke vorher der Bamberg'sche Kanzler Dr. Matth. Reuter genoss.

Zeugen: Dr. Christian Bruck, sächs. Kanzler, Dr. Steph. Clodt, Heinr. v. Thun, H. V. v. Obernitz u. A. - Herzogl. Siegel fehlt. - Geg. Grimmenstein, ohne Tagesdatum. - Orig. Perg. $-61: 25$.

\section{* 1570, September 10.}

131. Gerit von Scherpenseel, genannt Palyck, Richter van Veluwen, urkundet in der Erbschafts-Sache der Bely van der Hoenelyck, der Witwe des Otto van der Horst, betr. Auseinandersetzung von Gütern im Amt und Kirchspiel Brenefelt.

Zeugen: Gerit und Lubbert van Ebbenhorst. -- Siegel des Richters anhängend. - Orig. Perg.

1570, November 20.

132. Balthasar Hofsingoltinger, genannt Streicher, zu Augsburg, verkauft seine $2 \mathrm{fl}$. jährl. Ewiggült auf dem Hause der Barb. Merkseisen in der Neuhausergasse zu München ${ }^{2}$ ) an seinen Bruder Bernhard um $40 \mathrm{fl}$.

Geg. zu München. - Siegel des Ewiggeld-Amtes München fohlt. - Orig. Perg.

') Bez.-A. Lichtenfels. - Vgl. No. 87.

') S. No. 121. 
* 1571, Dozember 20.

1333. Kaiser Maximilian II. lässt dem Wolf Thirnhaimer. Einkäufer des Erzherzogs Ferdinand, Bruders des Kaisers, einen Wappenbrief ausstellen.

Mit eigenh. Unterschrift des Kaisers, dessen Siegel fehlt. - Mit kolor. Wappen. - Geg. zu Wien. - Urkunde schlecht erhalten. - Orig. Perg.

* 1573, April 15.

134. Erlass Kaiser Maximilians II. an die Stadt (W.-Neustat, sich den Schutz des Federwild-Geheges um ihre Stadt angelegen sein zu lassen.

Geg. Wien, gez. Maximilian (m. pr.). - Schreiben mit kais. Siegel, Pap.

\section{3, September 18.}

133. Vertrag Herzog Albrechts mit dem herzogl. Buchdrucker Adam Berg zu München, das Werk des Thomas Sury "Von den lieben Heiligen Gottes", das aus dem Lateinischen in's Deutsche übertragen wurde, zu drucken. Verlangt wurde: Alsbaldiger Beginn mit dem 1. Bande; Regal-Papier; korrekter, zierlicher, hübscher Druck nach Gutachten Versoris; 500 Exemplare für den Herzog, der Bogen für 2 \& zu setzen, wofür $500 \mathrm{fl}$. Vorschuss, eventuell $1000 \mathrm{fl}$; Berg haftet mit seinem Vermögen.

Geg. München, unter herzogl. Sekret sowie Siegel des Druckers. - Pap., durch Moder stark beschädigt, 1 Fol.

\section{5, März 20.}

136. Michael Zoller auf'm Brandt zu Bamberg verleiht dem Magister Paul Metzel, Beisitzer des Landgerichtes daselbst, als rechtes Zinslehen den dritten Teil „am Fahr zu Bieschberg $\left.{ }^{4},{ }^{1}\right)$ zu dem ein Haus gehörig, um jährl. $1 \tilde{H}$ \& Zins, $1^{1 / 2}$ Frontag oder dafür 9 \& , und eine Fastnachthenne oder dafür 24 \&s.

Siegel des M. Zoller fehlt. - Orig. Perg.

$$
\text { * 1579, Juli } 5 \text {. }
$$

137. Ferandus Amadi, „aulae caes. Comes palat., Civis originarius, Eques aureatus“, gibt bekannt, dass Paulus Dinsbeck,

1) Bez.-A. Bamberg II. 
Magister der freien Künste, nach bezeugten Studien und erwiesenen Kenntnissen, gemäss der Goldenen Bulle Karls IV. vom 30. Mai 1363, zum Doctor juris utr. in der Residenz zu Padua promoviert wurde.

Actum Patavii. - Eigenhändige Unterschriften: Fer. Amadi, Sperindeo Bettinus (Promotor), Franc. de Santa Cruce (Promotor), Lud. de Tolentino (Promotor), Georg Gregetius (Promotor), Andr. Tintus, notar. pub. Patav. - Kalligraphisches Diplom mit Initialen in Gold. - Orig. Perg. - 64: 44.

\section{9, Oktober 1.}

138. Johann Georg, erwählter etc. Bischof zu Bamberg, belehnt den Hans Rotkeppel zu Schlucht ${ }^{1}$ ) mit dem Mannlehen der Wiese von 6 Tagwerk an der Schmalnohe ${ }^{1}$ ) bei der Furt, die Rotkeppel um $182 \mathrm{fl}$. von U. Schober zum Reissach gekauft hat.

Bischöfl. Sekret fehlt. - Orig. Perg.

1580, März 2.

139. Hans Pongartner auf dem Bürkland, Ger. Rauhenlechsberg, ") verkauft an Bartol. Streitl, Bürger und Kirchenpfleger zu Weilheim, um $350 \mathrm{fl}$. seinen Hof (Haus, Hofreit und Stadel) auf dem Bürkland, ${ }^{2}$ ) genannt der Sperber, wozu 14 Jauch. Acker, ein Anger von 5 Tagw., 8 Tagw. Wiese, alles in Einem Einfang, gehören; dann 15 Tagw. Weide am Lech und 3 Tagw. Wiese in der Krenau.

Siegel des Christoph von Wildenstein zu Wildbach, Pflegers und Kastners zu Rauhenlechsberg, fehlt. - Zeugen: W. Pongartner von Apfeldorf, H. Puchauer, Wirt zu Rauhenlechsberg. - Orig. Perg.

\section{0, Mai 20.}

140. Ludwig, Propst, und Salomon, Prior zu Schäftlarn, ${ }^{3}$ ) verkaufen 1 Jauch. Acker zu Luttenwang, ${ }^{4}$ Ger. Landsberg, im Feld am Hauserberg gelegen, als Eigen an Vigil Hofer zu Urfahrn um $40 \mathrm{fl}$. Orig. Pap.

Siegel der Prälatur sowie des Konvents beigedrückt. -

1) Schliclit und Schmalnohe, Bez.-A. Amberg. ') Bez.-A. Schongau.

3) Bez.-A. Wolfratshausen. () Bez.-A. Bruck. 


$$
\text { * } 1581 \text { A April } 19 .
$$

141. Erlass Kaiser Rudolphs II. an seinen Bruder Erzherzog Ernst, wegen Besetzung der Kommando-Posten zu Canisa und Wigwar ${ }^{1}$, wiederholte Gutachten einzusenden.

Geg. zu Prag, gez. Rudolf (m. pr.). - Schreiben mit kais. Siegel, Pap.

1582, März 18.

142. Heiratsvertrag zwischen Wolf Heinrich Sturmfeder zu Oppenheim, neuburg'schem Kammerjunker, Sohn des Friedr. Sturmfeder zu Oppenheim und der Frau Margaretha, geb. Hürnheim, und Christina Smüllings (Smüllink). Tochter des Gosen Smüllings zu Zeuenar ${ }^{2}$ ) und der Frau Adrian, geb. von Hackfort. Gosen Smüllings gibt seiner Tochter ein Heiratgut ron $1000 \mathrm{fl}$; da er Kriegs halber dieselben nicht baar zu erlegen vermag. so wird eine jährliche Rente von $50 \mathrm{fl}$., zahlbar zu Oppenheim, vereinbart. Zur Vervollständigung des Schmuckes etc. erhält Christina 300 und $150 \mathrm{fl}$. - W. H. Sturmfeder widerlegt das Heiratgut mit der doppelten Summe von $2000 \mathrm{fl}$. und sichert seiner Frau als Wittum den freien Edelmanns-Sitz zu Oppenheim am Rhein. - Die Versicherung der benannten Summen, des Wittums, weitere Bedingungen und Erbzusicherungen im Falle des Todes der Eltern, im Falle kommender oder ausbleibender Kinder $u$. dgl. bilden den folgenden Inhalt des umfangreichen Vertrags.

Siegler: Philipp Ludwig, Pfalzgraf zu Neuburg; W. H. Sturmfeder; Friedr. und Burkhardt Sturmfeder; Enders Fuchs v. Bimbach, Statthalter zu Neuburg, Landrichter zu Graispach etc.; Joh. v. Gemmingen, neub. Jägermeister; Gosen Smülling; H. R. v. Wez Dr., clevischer Kanzler; W. Smülling zu Pölick; Pilgr. v. Heckern, W. v. Büren, Ad. Spüring. - Mit den Siegeln 1--10. - Geg. zu Neuburg a. D. - Orig. Perg. Libell von 14 Folien. $-28: 33$.

$$
1582 \text {, Juni } 24 .
$$

143. Wolf Münch zu Münchdorf und Oberngangkhofen ${ }^{3}$ ) stellt dem Schneider Hans Niedermayr Zeugnis aus über seine

1) Ungarn. ") in Geldern. - Vgl. No. 39, 78, 150.

s) Bez.-A. Landshut. 
auf dem Erbmayrgütel in der Hofmark Münchdorf erfolgte aheliche Geburt.

Geg. zu Obergangkhofen. -- Siegel des W. Münch fehlt. ()rig. Perg.

$$
\text { * 1582, September } 6 .
$$

144. Kaiser Rudolph II. genehmigt IVolf Probst und seinen Vettern Marx, Wilhelm und Martin die Vereinigung ihres Wappens.

Geg. zu Augsburg. - Mit koloriertem Wappen im 'Texte. - Kais. Siegel und Kais. Rudolphs eigenhänd. Unterschrift. Orig. Perg. $-63: 48$.

$$
\text { * 1582, September } 6 .
$$

145. Kaiser Rudolph genehmigt W. Probst d. Ältern und seinen Vettern Dr. Marx, dann Wilh. und Martin Probst, welche bereits unter Kaiser Ferdinand wegen ihrer Dienste in Feldzügen, in der Reichskanzlei usw. Wappen erhalten, die Vereinigung letzterer in Einem Bilde. Dieses der vorliegenden Urkunde in Farben eingefügt.

Geg. zu Augsburg. - Kaiserliches Siegel anzuhängen unterlassen. - Perg.

$$
\text { 1583, März 18.*) }
$$

146. Kunigunde Ratkeppel (Rotkeppel), des lseonh. R. Witwe, zu Schlucht, 1) verkauft ihrem Sohne Hans, Hauptmamn und Vogteivierer zu Schlucht, 1/s eines "Kuchenwagens samt dem Haus und Hof ${ }^{u}$ um $380 \mathrm{fl}$.

Siegel des Schweykart Wambold v. Umstatt, kurpfälz. Rats und Landrichters zu Amberg, abgefallen. - Orig. Perg.

1583, April 23.

147. Martin, erwählter etc. Bischof von Bamberg, bestellt den Nikolaus Stumpf von Cronach zu einem Fussknecht-Hauptmann mit jährlich 50 fl. Besoldung.

Konzept, Pap.

1) S. No. 138.

*) Die Tagesdatierung wurde belassen wie in der Urkunde, d. h. Alter oder Neuer Stil ist vom Benützer der Urkunde zu unterscheiden. S. Grotefend I, 123 . 


$$
\text { 1585, Januar } 10 .
$$

148. Joachim von Rottenhan zu Mershach, Domherr zu Bamberg und Würzburg, belehnt die Brüder Albr. und Gerhard Zollner auf'm Brandt zu Bamberg mit 4 Sölden zu Mirsbach ${ }^{1}$ ) und $1 / 3$ Zehenten zu Zuckshut. ${ }^{2}$ )

Siegel des J. v. Rottenhan fehlt. - Orig. Perg.

\section{5, März 27.}

149. Mathias Meller, Vogt auf der Burg zu Landshut, stellt Adam Vetter von der Lylgen (Gilgen) auf Colubach, bayer. Rat zu München, auftragsgemäss ein Schreiben zu.

Orig. Pap.

$$
\text { * 1585, Juli } 26 .
$$

150. Peter van Aildenborckhum, fürstl. Clevischer Landhofmeister und Amtmann in der Liemers, Ailbert van der Hoeven, Richter etc., nehmen die Teilung der Verlassenschaft des weil. Gosen Smullink (Schmullings) vor $\mathrm{zw}$ ischen dessen Töchtern Christina, Gemahlin des W. H. Sturmfeder, und der Wendel, verheirateten Adrian Spirink.

Siegel des Amtmanns und des Richters fehlen. - Gesch. in (ler Stadt Zeuenhar. ${ }^{3}$ ) - Orig. Perg.

$$
\text { * } 1585 \text {, September } 16 .
$$

131. Ferdinand, Erzherzog zu Österreich, verleiht Mathias: Hanibal und dessen Vettern Hans und Jakol ein erbliches Wappen. Letzteres der Urkunde in Farben eirigefügt.

Geg. zu Inspruck mit Unterschrift des Erzherzogs. -.. Erzherzogl. Siegel abgenommen. - Orig. Perg.

$$
\text { 1587, Januar } 6 .
$$

152. Ernst, Bischof zu Bamberg, nimmt den Lorenz Schmidt von ${ }_{n}$ Heustreu im Amt Neustadt in der Cent" (Saale) gemäss den Artikeln der Kriegsordnung des Landsberger Schirmvereins, auf gegenseitige Kündigung und gegen 100 Thlr. Jahressold zu einem Fussknechthauptmann (über 400 Knechte) an.

Revers des etc. Schmidt mit dessen Siegel. - Orig. Pap.

') Siehe No. 124. ') Bez.-A. Bamberg I.

? Sieho No. 39, 78, 142. 


\section{7, Februar 9.}

153. Die Stadt Kitzingen stellt dem Schneider Jakob Vees zwecks seiner auswärtigen Niederlassung das Zengnis ehelicher Geburt aus.

Mit dem Siegel der Stadt. - Orig. Perg.

1587, September 16.

154. Stoffel Drucher zu Lindenberg ${ }^{1)}$ verkauft $1 / 2$ Jauch. Arcker zu Unterholz um 32 fl. an Jak. Hörrich, Bürger zu Buchloe. ${ }^{1}$ )

Siegel des Seb. Reuter, augsburg'schen Vogts zu Buchloe und Forstmeisters zu Denklingen, fehlt. - Orig. Perg.

* 1588, Febr. 22.

155. Hans Gangolf v. Witzleben zu Höchstedt, Hans Ulrich v. Zedtwitz auf Neuberg, Christoph von Wiesenthau das., Kasp. Thoss auf Breitenfeld, Hauptmann zu Schlewitz, und Christoph v. Waldenfels zu Lichtenberg verbürgen sich für ein Kapital von $4000 \mathrm{fl}$, welches Christoph Heinr. v. Feiltzsch zu Sachsgrün $^{2}$ ) von Christ. v. Rodtschitz, Bamberg'schem Rat, noch ein weiteres Jahr gestundet erhält; als Sicherheit gegen Nichteinhaltung des Termins ist "Einlager mit Ross und Knecht" zu Kulmbach ${ }^{3}$ ) vereinbart.

Die 5 Siegel der Bürgen fehlen. - Geg. an St. Petrus Kathedra. - Orig. Perg.

\section{8, Dezember 31 .}

156. Dietrich von Streitberg zu Burggrub und Greifenstein belehnt Gerhard und Phil. Albrecht die Zollner auf'm Brandt zu Bamberg, Brüder, mit 1 Gütel zu Staffelstein, ${ }^{4}$ ) 2 Sölden und 4 Sölden das., 1 Gütel zu 'Drosendorf und $1 / 2$ Zehent zu Brunn.

Siegel des Lehenherren fehlt. - Orig. Perg.

1589, Januar 8.

157. Christoph Pietinger, Richteramts-Verwalter der Hofmarksherrschaft Hohenburg ${ }^{b}$ ) an der Isar, stellt auf Ansuchen

1) Bez.-A. Kaufbeuren.

2) Sächs. Kr.-Hauptm. Zwickau. ') Bez.-A. gleichen Numens.

†) Siehe No. 116. s) Bez.-A. Tölz. 
der Witwe Kath. Gschwendtler, Müllerin an der Gufl, für ibren Sohn Georg. Bürger und Handelsmann in München, Geburtszeugnis aus.

Gesch. Schloss Hohenburg, am andern Sonntag nach hl. 3 Könige. - Siegel Pietingers abgefallen. - Orig. Perg.

$$
\text { 1590, Juli } 6 .
$$

158. Der Markt Siegenburg ${ }^{1}$ ) bezeugt, dass Hans Holzner daselbst ehelich geborner Sohn des Leonh. Holzner und der Elisabeth, weil. P. Schieftalers Tochter von Kopfsberg, sei.

Siegel des Marktes „Siginburg“. - Orig. Perg.

1592, September 25.

159. Hans Christoph Lerchenfelder, wohnhaft zu Schwandorf, verkauft an Hans Hechsenacker um $45 \mathrm{fl}$. rhein. und 1 Tler. Leihkauf den jährlichen Zins von 4 Viertel Korn, mit dem dieser aus seinem Gut im Dorf Krondorf*) dem Lerchenfelder pflichtig ist.

Siegel des Gg. Teuffl ron Pirkensee, Pflegers zu Schwanlorf, fehlt. - Siegelzeugen Friedr. Mayr des Rats und Gg. Hörman Kuefer, Bürger zu Schwandorf. - Orig. Perg.

$$
\text { * 1593, August } 28 .
$$

160. Paulus Melissus, Comes palat., Eques, Civis Romanus, durch den Pfalzgrafen Ferrandi Amadi, Eques aureatus, in Padua seinerseits zum Pfalzgrafen eruannt, erteilt dem Georg Hofmann aus Krailsheim ${ }^{3}$ ) ein vererbliches Wappen.

Geg. zu Heidelberg unter Siegel des P. Melissus. - Hier durch den kais. Notar Zach. Schaudig unter'm 23. Juni 1/82 vermöge dessen beigedr. Siegels und Signets beglaubigte Copie. - I’erg. - Die Urkunde enthält das schön colorierte Wappen.

$$
\text { 1595, April } 4 .
$$

161. Peter Khämel, Bürger zu Siegenburg, ${ }^{4}$ ) verkauft jein Anwesen (Behausung, Hofstatt und Stadel) zu Abensberg, ${ }^{4}$ )

1) Bez.-A. Kelheim. 2) Bez.-A. Parsberg.

3) Württ. O.-A. gleichen Namens. „ Bez.-A. Kelheim. 
neben dem städtischen Hüthaus gelegen, mit „Fried, Gemäuer, Schar, Trauf, Nagel und Band versehen und umfangen" als freies Eigen an Leonhard Scheuchen-Pflug, Bürger daselbst.

Siegel der Stadt Abensberg fehlt. - Siegelzeugen: Simon Schorner, Casp. Meuchsner. - Orig. Perg.

1595 , Oktober 6.

162. Die Ratsältesten der R.-St. Nürnberg teilen den (ieheimen des Rats der R.-St. Ulm mit, welche Vorhalte der lireisoberst des fränkischen Kreises ihnen wegen unzulänglicher Verpflegung des fränkischen Regiments von 1000 Pferden in Ungarn gemacht hat, und ersuchen Ulm um Mitteilung etwaiger ähnlicher Verhandlungen mit dem schwäbischen Kreis wegen dessen Regiments Fussvolk.

Siegel abgefallen; Orig.-Schreiben auf Pergament.

$$
\text { 1596, Juni } 21 .
$$

163. Maximilian Paungartner von und zu Paungartell, Freiherr zu Hohenschwangau und Erbach, Erbmarschall des Domstifts Augsburg etc., Aulae lateranensis et imperialis consistorii Comes Palatinus, dessen Vorfahre Hans durch Kaiser Karl V. mit dem Rechte der Wappenverleihung begabt worden, erteilt den Brüdern Hans und Urhan Stauer aus Tirol einen Wappenbrief.

Geg. zu Inspruck, mit Unterschrift m. pr. und dem Siegel des M. v. Paungarten. - Orig. Perg.

1595. August 2.

164. Heiratsvertrag zwischen Hans Joachim Rothkäppel zu Schlicht ${ }^{1}$ ) und Margaretha, Tochter des Hans Prunner, Bürgermeisters zu Weiden, ${ }^{2}$ ) wonach Margaretha $300 \mathrm{fl}$. Heiratgut erhält, welchem H. J. Rothkäppel eine Widerlage von $600 \mathrm{fl}$. und eine Morgengabe von $100 \mathrm{fl}$. entgegensetzt. Es folgen nun Vereinbarungen auf den Todesfall des Mannes, für den Erbfall bei vorhandenen und nicht vorhandenen Kindern, hinsichtlich der Sicherung des Wittums der Frau usw.

Beiständer: Christian v. Crailsheim zu Walstorf, Pfleger

1) Siebo No. $146 . \quad$ 2) Bez.-A. Neustadt a. W. N. 
zu Vilseck, $\left.{ }^{1}\right)$ bamberg'scher Rat, Hans Jochim Portner, Helias Portner; Dr. Joh. Kapplpeck, neuburg'scher Rat, W. Haubmer Bürger zu Weiden, Aug. Meier, Stadtschreiber zu Weiden. Siegel der Beiständer fehlen. - Orig. Perg. - 70: 50 .

1599, Mai 11.

165. Johann Phil., erwählter etc. Bischof zu Bamberg, belehnt den Albrecht Stiber zu Buttenheim²) als Lehenträger der Sobhne des Gg. Heinr. Stiber mit nachfolgenden-Lehenstücken: 1 Hof zu Adelsdorf, ?) einer Schenkstatt dahei, den Schafhof, dem Haus zu Attelsdorf, ${ }^{8}$ ) 1 Sölde das., 3 Weihern, 2 Güteln und 5 Güteln zu Adelsdorf, 1 Hof und 2 Sölden ebendaselbst; mit dem Stiber schen Afterlehen eines Fischwassers, 1 Wiese, 2 Äckern, 1 Wiese, 2 Äckern, 1 Acker, $1 /$ Acker. verschiedenen Morgen Äcker usw., deren Lage und Erträgnisse näher verzeichnet sind.

Bischöfl. Sekret fehlt. - Orig. Perg.

1600, Oktober 24.

166. Eustach Freiherr zu Törring und Seefeld etc., bezeugt die eheliche Herkunft des Hans Mezger von 'Tinzelbach, ${ }^{4}$ ) welcher längere Zeit in Venedig gedient hat und erkrankt ist, zwecks Hausierens.

Siegel des Eust. Frh. v. Törring anhängend. - Orig. Perg.

1601, Februar 24.

167. Maximilian Paumgarter von und zu Paumgarten, Freiherr zu Hohenschwangau etc., Comes palatinus, erteilt den Brüdern Kaspar und Math. Grüger zu Aidling ${ }^{5}$ ) in Ober-Bayern einen Wappenbrief.

Geg. zu Innspruck. - Mit dem Paumgarten'schen Siegel. - Orig. Perg.

1) Bez.-A. A mberg.

1) Bez.-A. Bamberg I.

3) Adelsdorf und Attelsdorf, Bez.-A. Höchstadt a. A.

4) Dünzelbach, Bez.-A. Bruck.

s) Bez.-A. Weilheim. 
1601, März 20.

168. Johann Philipp, erwählter Bischof zu Bamberg, helehnt den Hans Joachim Rodtkeppel zu Schlucht ${ }^{1}$ ) mannlehensweise mit der Wiese von 6 Tagw. an der Furt der Schmahlnohe, $\left.{ }^{1}\right)$ 1 Morgen Feld im Beydenstock, 3 hrautgärten, 1 Morgen Acker, 1 kleinen Acker, 2 Tagw. Wiese und 1 Acker, deren Lage näher beschrieben ist.

Bischöfliches Sekret fehlt. - Orig. Porg.

1602, Februar 13.

169. Georg Werner von und zu Rabenstein und Rabeneck belehnt Gerhard Zollner von Brandt zu Bamberg als Lehenträger seiner Vettern Zollner v. Brandt zu Bamberg, Bieschsberg ${ }^{2}$ ) und Bayersdorf ${ }^{3}$ ) mit 40 Tagw. Holz bei Hofen soweit sie durch die früheren Inhaber versteint sind.

Geg. den 13. Februar alten Kalenders. - Siegel des Lehenherrn fehlt. - Orig. Perg.

\section{6, Februar 15.}

170. Die Stadt Eichstätt bezeugt die legitime Geburt des „Jünglings Melchior Conz" mit der Bestätigungsformel, „dass unser gewester Burger weil. Fabian Conz, Schreiner seel. und Margareta sein eheliche Hausfral, welche dieser Zeit noch im Leben und oblsemeltes Melchior Conzen eheleibliche Eltern, des längst abgewichenen 1578. Jars den 10. Monatstag July iren christlichen Kirchgang in Unser Lieben Frauen Pfarrkirchen alhie zu Eystet nach heiliger christlicher Ordnung und Einsatzung offentlich mit einander gehalten und alsda zu Kirchen und Strassen gangen und daselbsten intronisirt worden seien. welche Eheleut nachmals im während ihrer Ehe gutem Geruch und Leumunth obbemelten ihren Sohn Melchior Conz im 1591. Jar den 1. Monatstag Januarij aus unbeflecktem Ehebet ehelichen erzeugt und erworben haben."

Städtisches Siegel fehlt. - Orig. Perg.

1) S. No. 138.

7) Bez.-A. Bamberg IL. ") Bez.-A. Beilngries. 


$$
\text { 1606, April } 11 .
$$

171. Margaretha, Witwe des Kasp. Lynner, Bürgers und Lederers zu Mühldorf, ${ }^{1}$ ) verkauft ihr Haus daselbst in der Innvorstadt an Thoman Fruman, Bürger und Färber zu Mühldorf, unbeschadet 4 Schill. jährl. Ewiggült der Frauenkirche am Platz.

Mit dem Siegel des Virgil Dihneck, salzb. Rats und Richteramts-Verwalters zu Mühldorf. - Orig. Perg.

$$
\text { 1606, Dezember } 30 .
$$

172. Dankschreiben Herzog Ferdinands von Bayern für (wie äusserlich angegeben, rom Ministerresidenten in Rom) erhaltene Glückwünsche.

Di Monaco. -- Mit eigenhändiger Linterschrift Herzog Ferdinands. - Pap., 1 Fol.

$$
\text { 1607, Januar } 3 \text {. }
$$

173. Dankschreiben des Herzogs Wilhelm V. von Bayern für eine Neujahrsgratulation.

Dat. Monachii, mit eigenhändiger Interschrift des Herzogs. - Pap., 1 Fol.

1608, April 9.

174. Hans Fertl, Fuhrmann und Bürger zu München, verkauft der Krämerzunft daselbst einen jährlichen Ewiggeldzins von $2 \frac{1}{2} \mathrm{H}$. aus seinem Anger, gelegen im Graggenauer-Viertel zu München, um $50 \mathrm{fl}$.

Vierer der Krämerzunft: Kaspar Häckl, Roman Glöggl, Hans Hueter, Math. Käppler. - Für das Ewiggeld-Siegel der Stadt München: Dr. Gg. Locher, Stadtschreiber, Mich. Mändl, Unterrichter. -- Siegel fehlt. - Orig. Perg.

$$
\text { 1608, April } 19 .
$$

175. Die Verwalter der Priesterbruderschaft bei St. Peter zu München versprechen, jährlich am St. Nikolaustag für weil. Hans Sedelmair, Bürger, und seine zwei Frauen Seelenamt und Messe halten zu lassen von den $71 / 2 \mathrm{fl}$. Zinsen aus $150 \mathrm{fl}$. Ewiggeld, welches auf dem Hause des Gg. Mayr, Messners auf dem

1) Bez.-A. gleichen Namens. 
ăusseren Gottesacker an der Weitengasse liegt, von H. Sedelmair testamentarisch der genannten Bruderschaft zu berïhrtem Zwecke gestiftet.

Mit dem Siegel der Bruderschaft. - Orig. Perg.

1609, März 20.

176. Lorenz von Guttenberg zu Kirchlauter, Landrichterants-Verweser des kaiserlichen Stifts Bamberg, beurkundet eine Erbverzichts-Erklärung der Elisabeth Sartory, Ehefrau des Hans Sartory, wonach erstere allen Erbansprüchen in Hinsicht ihrer Eltern und Geschwister entsagt, solche aus letztwilligen Verfügungen ausgenommen, nachdem sie von ihren Brüdern, den Zollnern v. Brandt, baar entschädigt worden.

Siegel des kaiserl. Landgerichts fehlt. - Geg. mit Urteil. - Orig. Perg.

\section{9, Mai 7.}

177. Hans Joachim Stieber zu Aisch, bambergischer Rat und Amtmann zu Herzogenaurach, verleiht allen Zollnern von und auf'm Brandt zu Bamberg, zu Bischberg, zu Bayersdorf und Emskirchen als Mannlehen einen halben Zehenten zu Bosenfellen, das Luzen-Gut zu Drosendorf und das Fahr zu Bischberg. ${ }^{1}$ )

Siegel des J. Stieber abgeschnitten. - Orig. Perg.

\section{0, Mai 1.}

178. Reinhard Graf zu Solms, zu Münzenberg otc., kurpfälz. Rat, Landrichter zu Amberg, Pfleger zu Hirschau und Freudenberg, stellt dem Hans Wissgüggel von Gebenbach,2) jetzt zu Nürnberg, nach Verhörung des Kirchenpropsts zu Gebenbach, des Georg Rumpler, Hauptmanns zu Burgstall usw., Zeugnis darüber aus, dass er der eheliche Sohn des Paulus Wissgüggel und der Margaretha, geb. Diez zu Gebenbach, sei.

Siegel des Grafen zu Solms fehlt. - Orig. Perg. Diplomartige Ausfertigung. - $60: 39$.

1) Siehe No. 136.

2) Bez.-A. A mberg. 


\section{0, Juli 22.}

179. Kaiser Rudolph II. verleiht Kilian Reichart, Ammann der Reichsstadt Nördlingen, um seiner und seines Vaters daselbst Verdienste willen den erblichen Reichs-Adelsstand „als andern rechtgebornen Lehens-, Turniergenossen und Edelleut", ferner ein Wappen und ernennt ihn zum Comes palatinus, d. i. Pfalzund Hofgrafen, u. A. mit der Befugnis, (vollzugsweise) Taugliche zu "Notaren, öffentlichen Schreibern und Richtern" zu ernennen, ausserehelich Geborne (ausgenommen Adelige vom Freiherrn aufwärts) zu legitimieren, „Vormünder, Curatoren und Pfleger" zu setzen, "Söhne und Töchter" zu adoptieren, „Unvogtbare" und Minderjährige zu dispensieren, sowie "Infamierte" und Verläumdete zu nerheben“.

Geg. zu Prag. - Mit dem kais. Siegel. - Eigenhändige Unterschrift des Kaisers. - Orig. Perg.-Libell von 10 Folien; auf Fol. 4 das kolorierte Wappen.

\section{1, März 20.}

180. Georg Werner von und zu Rabenstein und Rabeneck belehnt Gerhard Zollner von Brandt zu Bamberg als Ältesten der Familie Zollner mit dem Holzlehen von 40 Tagw. bei Höfen. ${ }^{1}$ )

Siegel des etc. von Rabenstein fehlt. -- Orig. Perg. Die Urkunde deliert und durch Zusätze verändert.

* 1611, April 30.

181. Rudolf von Schonebeck verkauft um ein Kapital von 3500 R.-Tlern an Herman v. Wedich eine Rente von jährlich 210 R.-Tlern, versichert auf dem Broeler- $\mathrm{Hofe}^{2}$ ) des Schonebeck, zahlbar in der Behausung des Wedich zu Köln.

Siegel des v. Schonebeck abgefallen, das zweier Schöffen zu Wegberk anhängend. - Geg. zu Arndt im Bruell auf Broeler Hof. - Orig. Perg.

1612, Februar 22.

182. Johann Godefried, Bischof von Bamberg, beruft zur Förderung des von seinem Vorgänger Bischof Ernst gestifteten Gymnasiums und Alumnats sowie zur Erhaltung und

1) Siehe No. 169 .

9) Preuss. Reg.-Bezirk Köln. 
Ausbreitung des katholischen Glaubens die Jesuiten nach Bamherg, räumt ihnen das Karmelitenkloster nebst Kirche ein, weist ihnen aus der bischöfl. bamberg'schen Hofkammer jälırlich $2000 \mathrm{fl}$. Einkünfte sowie Getreide, Wein und Viktualien an und erklärt sie frei von allen Steuern und Abgaben. Die Gegenstände des Unterrichts durch die Jesuiten setzt der Bischof fest und erklärt die Einwilligung des Domkapitels durch namentliche Aufführung von Propst, Dekan und Kanonikern. Die Stiftungsurkunde ist in einem Exemplar dem General des Jesuiten-Ordens, in einem dem Rektor auszufertigen.

Datum Bamberge. - Siegel des Bischofs und des Kapitels fehlen. - Orig. Perg. - Die Urkunde mit künstlerisch komponierten, kolorierten Randleisten geziert; die Miniaturen stellen die Hl. Jungfrau, Bischöfe, und Insignien derselben dar. - $76: 70$.

\section{3, August 9.}

183. Das Ehe- und Gastgericht der Stadt Berneck ${ }^{1}$ ) bezeugt dem Georg Kretzschmann behufs seiner Niederlassung in Nürnberg, dass er daselbst ao. 1588 aus der durch Pfarrer Thom. Ruer kirchlich eingesegneten Ehe des Joh. Kretzschmann mit Barbara, geb. Heidenreich von Berneck, entsprossen sei.

Siegel der Stadt fehlt. - Orig. Perg. - Kalligraphische, diplomartige Ausstattung. $-64: 45$.

\section{* 1615, Januar 2.}

184. Dorothea Maria, Herzogin zu Sachsen, gratuliert der Kurfürstin Hedwig von Sachsen, geb. Prinzessin von Dänemark, aus Anlass des Jahreswechsels.

Geg. Weimar. - Schreiben mit Siegel und eigenh. Unterschrift. - Pap.

\section{* 1615, Oktober 24.}

185. Die Stadt St. Georgen wird in ihrem Prozesse mit Nikolaus Jelchych zur Urteilseröffnung vor das königliche Tafelgericht geladen.

Datum in arce . . regia Pragensi. - Schreiben mit eigenhändiger Unterschrift des Kaisers Mathias und kais. Siegel. - Pap.

1) Bez.-A. gleichen Namens. 
1621, November 17.

186. Wilhelm v. Streitberg zu Ahorn, Sachsgrün etc. verleiht dem Hans Christoph Zollner von und auf'm Brandt als Ältestem der Familie zu Mannlehen 1 Gütel zu Staffelstein, 2 und 4 Sölden dabei, 1 Gütel zu Drosendorf und $1 / 2$ Zehent zu Brunn. ${ }^{1}$ )

Siegel des W. v. Streitberg fehlt. - Orig. Perg.

1622, Oktober 28.

187. Landesherrlicher bayer. Consens, dass Wolf Strasser das Aigner-Gütel zu Rånzenberg, ${ }^{2}$ ) Pfarrei Kirchberg, Ger. Julbach, bayer. Beutellehen, käuflich an Georg Handtobler abtreten dürfe.

Geg. zu Burghausen. - Bayer. Sekret fehlt. - Orig. Perg.

1624, Juni 26.

188. Die bayer. Regierung zu Burghausen vollzieht die Belehnung des Georg Handtobler mit dem Aigner-Gütel zu Ränzenberg, Ger. Julbach, nachdem W. Strasser mit landesherrlichem Consens dieses an Handtobler verkauft hat.

Geg. zu Burghausen. - Fürstl. bayer. Sekret fehlt. Orig. Perg.

\section{4, November 19.}

189. Lukas Beuerl, Bürger zu Schwandorf, ${ }^{3}$ ) verkauft an Goswin Freiherrn v. Spiring zu Russwick und Sevener auf Fronberg, neuburg'schen Geh. Rat, Oberhofmarschall, Kammerpräsidenten, Landrichter von Graispach und Pfleger zu Monheim, seinen Wald gen. der Hirschbichel, gelegen im Landgericht Burglengenfeld.

Geg. zu Burglengenfeld. - Mit dem Siegel des Joh. Zeller und des Joh. Keyllholz, Kammerrats- und Landrichteramtsverwalters zu Burglengenfeld. - Orig. Perg.

$$
\text { 1625, Juni } 21 .
$$

190. Hans Niggl von Tötting, ${ }^{4}$ ) Ger. Rain, verkauft an Georg Appel, Bierbräuer zu Rain, eine Wiese von 2 Tagw.,

1) Siehe No. $156 . \quad$ 2) Bez.-A. Pfarrkirchen.

3) Bez.-A. Burglongenfeld. ") Bez.-A. Ingolstadt. 
gen. die Graimet-Poigen, zwischen Gämpfing und Tötting gelegen, um $583 \mathrm{fl}$.

Siegel des Pflegers zu Rain, Maxiın. Fugger d. Jüng., Freih. v. Kirchberg und Weissenhorn, fehlt. - Orig. Perg.

$$
\text { *1625, Juli } 18 .
$$

191. Gabriel Löbmacher, Bürger zu Linz, ${ }^{1}$ ) lässt sich von der Stadt Linz ein Verehelichungs-Zeugnis ausstellen, bezw. die eheliche Geburt seiner Kinder bestätigen.

Siegel der Stadt Linz fehlt. - Orig. Pery.

1628, August 17.

192. Veit, Abt des St. Michaels-Klosters auf dem Mönchsberg ob Bamberg, belehut mannlehensweise die Zollner v. Brandt mit 2 Gütern zu Trassdorf (Drosendorf), 1 Sölde, mehreren Weinbergen und grossem und kleinem Zehent daselbst, mit der Vogtei über 1 Hube zu Unterhaidtmersbach ${ }^{2}$ ) und über 3 Sölden zu Bischberg, ${ }^{3}$ ) mit 1 Hof daselbst samt Weinbergen, Äckern, Wiesen, Seen und mit dem Holz zu beiden Seiten und 4 einzelnen Äckern in der Bischberger Mark, endlich mit 1 Wiese auf dem Gemündt zu Viehrit.

Siegel des Abtes fehlt. - Orig. Perg.

$$
\text { 1629, Juni } 15 .
$$

193. Kaiser Ferdinand II. erhebt die Brüder Johann Werner, Johann und Wolf Georg "Frobeni“ mit allen ihren Nachkommen in den erblichen Reichs-Adelsstand nals ob sy von Ihren Vier Ahnen Vatter Mutter und Geschlecht recht Edl geborn Lehens Turniers und Rittermässige Edelleuth währen“ und verleiht ihnen ein Wappen.

Geg. zu Wien unter kais. Siegel. - Hier durch das kais. Landgericht Nürnberg unter'm 19. April beglaubigte und gesiegelte Kopie, Perg-Libell von 9 Folien, das gemalte Wappen auf losem Perg.-Folium inliegend.

1) Ober-Österreich.

2) Siehe No. 91. 's) Siehe No. 136. 
1629, Juni 30.

194. Walburga, Witwe des Georg Schuchpaur zu Scheiblesgrueb, ') übergibt unter Beistand der Vormünder ihrer unmündigen Kinder ihrem ältesten Sohne die Sölde daselbst, ein Erbbestandsgut, ihr Wittum ausgenommen und unbeschadet allen Verpflichtungen gegenüber den Nothaft'schen Hofmarks- und Grundherrn.

Mit dem Siegel des Ernst Heinr. Nothaft v. Wernberg zu Schönaich. - Orig. Perg.

1629 , Oktober 30 .

193. Der Markt Wolfratshausen ${ }^{2}$ ) bestätigt dem Martin Wolfart behufs Niederlassung in München, dass er zu Wolfratshausen ehelich geboren und Niemanden ${ }_{n}$ mit Leibeigenschaft verbunden" sei.

Siegel des Mark tes fehlt. - Orig. Perg.

1630, Mai 14.

196. Ludwig Eberhard Graf zu Öttingen belehnt Pankraz Zollner v. Brandt und seine Familie mannlehensweise mit $1 / 8$ des Zehents zu Staffelstein, ${ }^{3}$ ) welches die Zollner seinerzeit von Gotz von Rotenhan erkauft haben und ferner mit dem sogen. grossen Achtel Staffelsteiner Zehents, welche 2 Achtel von der Grafschaft Öttingen zu Lehen rühren.

Lehen-Sekretsiegel der etc. Öttingen fehlt. - Orig. Perg.

1630, August 3.

197. Dr. Phil. Baumgartner, Hofgerichtsadvokat zu München, verkauft an die Priesterbruderschaft bei St. Peter daselbst um $100 \mathrm{fl}$. einen Ewigzins von jährlich $6 \mathrm{fl}$., der aus der Hinterlassenschaft weil. Dr. Georg Lochers, Stadtschreibers zu München, stammt und auf des Lebzelters Hans Ebersperger Eckanwesen im Tal daselbst am Bächel liegt.

Mit dem Ewiggeldsiegel von München und den Siegeln der Ehegatten Baumgartner. - Orig. Perg.

1) Bez-A. Bogen. ') Bcz.-A. gleichen Namens.

8) Bez.-A. gleichen Namens. 
* 1630, Oktober 18.

198. Kaiser Ferdinand Il. erneuert dem Georg Christoph Holzinger, Hauptmann, welcher unter Kaiser Rudolf bei Gran als Fähnrich sich ausgezeichnet hat und dafür unterm 4. Januar 1605 mit seinem Bruder Christoph geadelt worden ist, dann unter Kaiser Mathias zum 6. Male Fähnrich und zum 3. Male Hauptmann war, auch dem gegenwärtigen Kaiser Kriegsdienste leistete, - Adel und Wappen erblich für alle Nachkommen, befreit ihn mit Angehörigen und Dienerschaft von allen bürgerlichen und örtlichen Abgaben, wo immer sich die Familie niederlasse, erklärt ihre Exemption von allen niederen Gerichten im Reiche und verleiht ihr das Prädikat "von* Holzing.

Geg. zu Regensburg. - Kaiserl. Siegel fehlt. - Mit eigenhändiger Unterschrift Kaiser Ferdinands. - Libell von 10 Perg.Folien; Abbildung des „vermehrten* Wappens auf Fol. 3.

1638, Januar 2.

198. Sigmund Nidernlangwater zu Langwat verkauft an seinen Schwager Hans Aigner am Ränzenberg ${ }^{1}$ ) die Erbgerechtigkeit auf seinem Gut zu Nidernlangwat samt 1/4 Acker, der Kirche St. Achaz in Aich pflichtig, gelegen in der Pfarrei Kirchberg, Ger. Julbach. ${ }^{1}$ )

Siegel des Aug. Paumgartner von Deutenhofen, Pflegers zu Julbach und Mautners zu Braunau, fehlt. - Orig. Perg.

$$
\text { 1639, März } 21 .
$$

200. Die Vormünder der Anna Frischvez verkaufen verschiedene Grundstücke, meist Änger um Altenstadt, um 72 fl. an Georg Herlin daselbst.

Siegel der Stadt Schongau fehlt. - Orig. Perg.

1639, Juni 27.

201. Abt Kaspar von Michaelsberg bei Bamberg erneuert die Belehnung der Familie Zollner mit den Gütern zu Drosendorf, Bischberg ${ }^{2}$ ) etc. voin 17. August 1628.

Siegel des Abtes fehlt. - Orig. Perg.

1) Bez.-A. Pfarrkirchen.

) Siebe No. 177 und 192. 
1642, März 22.

202. Lehenserneuerung wie No. 201. - Ohne Siegel. -.. Orig. Perg.

\section{* 1644 , Juli 15 .}

203. Protest eines gewissen Joachim Jochem aus . . ., oingereicht zum Reichskammergericht, nachdem seine Berufung in seiner Streitsache mit Mantel und Brunings zum thüringisch. Hofgerichte erfolglos war.

Notariatsinstrument, acta Leodii, mit weiteren notariellen Anhängen. - Perg. - Beispiel zunehmender Schrift verwilderung.

\section{* 1645, Februar 27.}

204. Kaiserlicher Erlass an Joh. Reichardt Frhr. von Sprinzenstein auf Neuhaus, Landschaftsverordneten, ${ }^{1}$ ) einen Anschlag von monatlich 1 Reichstaler für jedes Haus auszuschreiben, um die Heeresverpflegung für die Monate Februar bis Mai aufbringen und das seit Magdeburg "merklich ruinierte Fussvolk“ auf 100 Mann per Kompagnie ergänzen zu helfen.

Gesiegeltes Schreiben mit eigenhänd. kais. Unterschrift, Pap.

1645, August 26.

205. Hans Wilh. Poyssl v. Loyfling ${ }^{2}$ ) auf Wolkerstorf sehliesst mit Ursula Sabina Hausner von und zu Winbuch ${ }^{y}$ ) einen Heirats- und Erbvertrag, wonach der Ehemann von Sabina Hausner $1000 \mathrm{fl}$. Heiratgut, letztere von ersterem ebensoviel als Widerlage und $300 \mathrm{fl}$. Morgengabe erhält. Es folgen die Versicherung der $2300 \mathrm{fl}$. auf das Landedelmannsgut Wolkerstorf, ${ }^{4}$ ) die Festsetzung des Wittums und des Erbes der Witwe mit und ohne Kinder, der Verpflichtung des Ehemannes im Falle des Todes der Frau usw.

Zeugen und Siegler: Hans Poyssl, Wilh. Poyssl, Wilh. v. Prandt, Hans Christ. v. Kürnreuth, Wolf Leonh. Teuffel v. Pürkensee. - Gesch. zu Regensburg. - Siegel fehlen. Orig. Perg.-Libell von 4 Folien.

1) Land o. Enns. 2) Bez.-A. Cham.

s) Bez.-A. Burglengenfeld. " Wolfersdorf (?). 
1649, Januar 8.

206. Gerichtlich genehmigte Auseinandersetzung zwischen der Witwe des Hans Nidernlangwater zu Nidernlangwat ${ }^{1}$ ) und ihren Kindern bezw. deren Vormündern hinsichtlich der Kinder väterlichen Erbteils und der rechtlichen Ansprüche der Mutter. Dieser verbleibt die ganze Verlassenschaft, bestehend in $1 / 4$ Acker, pflichtig zu St. Achaz in Aich, Pfarrei Kirchberg, dem dabei bestehenden ganzen Zehenten, dem Haus nebst Baumannsfahrnissen; dagegen verpflichtet sich die Witwe, innerhalb 4 Jahren den Kindern $190 \mathrm{fl}$. baar hinauszugeben oder diese Summe ihnen nach Landesgebrauch zu verzinsen, dem Sohn zur Verheiratung 10 fl., eine Truhe und die Ausfertigung vorzubehalten, ebenso von den zwei Töchtern jeder eine Kuh und ein Bett oder dafür 20 fl., sowie je eine Ausfertigung.

Siegel des Aug. v. Paumgarten zu Hundspain etc., Pflegers zu Julbach und Mautners zu Braunau. - Siegelzeugen: Christoph Supphan und J. S. Schmidt, julbach'sche Pfleggerichts-Prokuratoren in Braunau. - Orig. Pap.

* 1650 , September 15.

207. Kaiser Ferdinand IIl. erhebt Johann Jürgenson in den erblichen Reichs-Ritterstand mit dem Titel v. Trachenfels und dem Rechte der Selbstbeilegung jedes anderen durch Kauf oder Erbschaft von Gütern überkommenden Titels, mit allen dem Adel z. Z. zukommenden Vorrechten, Exemptionen und Steuerbefreiungen, unter Vermehrung des bisher geführten alten Jürgenson'schen Wappens.

Geg. zu Wien unter grossem kais. Siegel. - Hier unterm 12. Juni 1651 durch Dr. Abraham Gerner von Lilienstein, Com. pal. caes., und dessen Siegel beglaubigte Kopie. - Perg.-Libell, Miniaturformat, 19 Folien, auf Fol. 10 und 11 das kolorierte Wappen. - 10,̄̃ : 12,5.

\section{0, Oktober 28.}

208. Dietrich v. Streitberg zum Greiffenstein, Sachsgrïn etc., bamberg'scher Amtmann zu Hollfeld und Weischenfeld, erneuert bei Ableben des Karl v. Streitberg, Obristwacht-

1) Siehe No. 199. 
meisters, seines Vetters, die Belehnung des Ernst Heinrich Zöllner von und auf Brandt, Bischberg etc. mit dem Gütel zu Staffelstein, den 2 und 4 zugehörigen Sölden, dem Gütel zu 1)rosendorf und 1/2 Zehenten zu Brunn. ${ }^{1}$ )

Siegel des Lehenherren fehlt. - Orig. Perg.

\section{2, Juli 10.}

209. Im Namen „Maria Anna's“, der bayer. KurfürstinWit we und Vormünderin, wird durch die Regierung Burghausen der Marg. Obermair, „Untertanin und Gerichtsweib“ im Gericht Julbach ${ }^{2}$ ) der Zehent „auf der Kugelstatt, ${ }^{2}$ ) Pfarrei Kirchdorf, als fürstl. bayer. Beutellehen verliehen, das sie als "getreues Lehenweib" entsprechend zu führen habe.

Fürstl. bayer. Vormundschafts-Sekret fehlt. - Gesch. zu Burghausen. - Orig. Perg.

1653, März 7.

210. Das Pfleggericht Julbach bestätigt, dass Philipp Nidernlangwatter, seit 1652 bei St. Achaz in Aich ${ }^{3}$ ) Zechpropst, den einzuliefernden Rest von $51 \mathrm{fl} .44 \mathrm{kr}$. $1 \mathrm{hl}$. in Gegenwart des Pfarrers und des Gerichtsschreibers „in den Zechschrein“ richtig erlegt hat.

Ohne Unterschrift und Siegel, Pap.

\section{- 1653, Oktober 25.}

211. „Peter Antonius Peisch von Hueb, des Päpstl. Stuhls apostol. Protonotar, kaiserl. Pfalz- und Hofgraf, Casimirs IV., Königs von Polen und Schweden investierter, und der kurfürstl. Durchlaucht in Bayern Hofkaplan“, von Papst Urban VIII. und Kaiser Ferdinand llI. mit dem Privilegium der Wappenverleihung begabt, stellt den Brüdern Thomas Satler, kurfürstl. bayer. „Einlassverwalter und Zehryaden-Gegenschreiber" sowie Balthasar Satler, kurfürstl. Bereiter, Wappen aus.

Das "Protonotars- und Palatinatssiegel“ des etc. Peisch fehlt. - Urkunde und Wappenbild "mit Pracht" ausgestattet. Orig. Perg. $-80: 65$.

1) Siehe No. 186 .

') Bez.-A. Pfarrkirchen. ") Bez.-A. Pfarrkirchen. 
16506, Oktober 7 .

212. Franz Conrad von Stadion, ,von Gottes Gnaden Dompropst “ zu Bamberg, Domkapitular und Oberkustos zu Würzburg, Propst des Ritterstiftes Comburg, Obleyer der Erbobley Gundelsheim, ${ }^{1}$ ) belehnt Ernst Heinrich Zollner von Brandt zu Bischberg und Bamberg mit drei Gütern zu Hartenreuth (Kattenreuth?), von der genannten Obley aus, gemäss altem Brief von Petrus ad vincula 1511.

Siegel des Lehenherrn fehlt. - Orig. Perg.

1657, April 11.

213. Die Lehenstube bei der Regierung Burghausen bestätigt dem Phil. Niderlambeder (Nidernlangwater) den Empfang der Briefgebühr bei seiner Heirat auf das Zehentlehen der Kugelstatt. ${ }^{2}$ )

Ohne weitere Beglaubigung; angefügt eine weitere Quittung vom 31. Januar 1680. - Pap.

\section{7, September 29.}

214. Wilhelm Ludwig, Generalvikar des Bischofs Marquard von Eichstätt, bestätigt dem Wolfgang Franz Ignaz Freih. von Spirink zu Fronberg, Kanonikus und Cantor zu Eichstätt, seine sub dato erfolgte Ordination zum Presbyter.

Siegel des Generalvikars. - Orig. Perg.

$$
\text { 1661, April } 19 .
$$

215. Die Zimmerleute zu Oberaurdorf ${ }^{3}$ ) stellen dem Andreas Rechenauer aus Rechenau, legitimen Sohn des etc., Zeugnis aus über bei Zimmermeister Bartl. Antritter mit Wohlverhalten und Erfolg verbrachte zweijährige Lehrzeit.

Mitmeister: Erasm. Rechenauer zu Äg, Hans Antritter im Reisach, Sebastian Trainer zu Färnberg. - Siegel des H. P. Ridler von Obing und Trostberg, Pflegers und Kastners zu Aurburg, fehlt. - Orig. Perg.

1) Bez.-A. Bamberg I. - Siehe No. 233.

3) Siehe No. 209.

3) Bez.-A. Rosenheim. 
* 1661, Juni 3.

216. Johann von und zu Trachenfels, Reichsritter, kais. Rat, Mitglied der ,fruchtbringenden Gesellschaft " genannt , der Verfechtende $"$, Comes palat., verleiht dem Conrad Bredtschneider, Handelsmann zu Nürnberg, ehemals 10 Jahre in kaiserlichen, sächsischen, bayerischen und holländischen Kriegsdiensten gestanden, erbliches Wappen.

Geg. zu Wien. - Siegel des Ausstellers. -- Orig. Perg.Libell mit 9 Folien. - Mit koloriertem Wappen.

* 1664, Januar 30.

217. Kaiser Leopold verleiht dem kaiserl. Hofzahlamtsverwalter Hans Jakob Zwierner, dessen Grossvater in zwölf ungarischen Feldzügen bis zum Fähnrich aufrückte, bei der Festung Hatwan tödlich verwundet wurde und dessen zwei Söhne die Schlacht bei Lützen mitmachten, den erblichen Reichsritter-Adel mit dem Beinamen v. Klingenfekd sowie ein Wappen.

Geg. zu Regensburg. - Mit eigenhändiger Unterschrift des Kaisers. - Siegel fehlt. - Orig. Perg.-Libell von 10 Folien mit koloriertem Wappen auf Fol. 6.

\section{0, Oktober 7 .}

218. Michael Imhoff, Sohn des Georg Paul, Geh. Rats und Landpflegers der Stadt Nürnberg, und der Helena, dessen Ehefrau, geb. Scheurlin, schliesst mit Maria Christina, Tochter Christoph Pellers und der Maria Magdalena, geb. Tetzel, einen Ehe- und Erbvertrag, wonach Maria Christina 1000 fl. Heiratgut einbringt, welche M. Imhoff mit $1200 \mathrm{fl}$. widerlegt, dem überlebenden Fheteil diese $2200 \mathrm{fl}$. anheimfallen, vorhandene Kinder das übrige Vermögen erhalten, und endlich mangels direkter Erben das Vermögen den nach Nürnberger Recht Berufenen zufallen soll.

Zeugen und Siegler: Friedr. Volkamer, Gabriel Nützel von und zum Sünderspühl, beide des innern geh. Rats zu Nürnberg; deren Siegel fehlen. - Geg. zu Nürnberg. - Orig. Perg. 
1672 , April 22.

219. Philipp Wilhelm, Pfalzgraf etc., verleiht auf Ansuchen den Meister Schwarzfärbern auf dem Nordgau in Landgericht und Stadt Burglengenfeld, in den Pflegämtern und Städten Schwandorf, Velburg und Hembau, in den Pflegämtern und Märkten Regenstauf, Beratzhausen, Laber und Luppurg, sowie in den Märkten Kallmünz und Schmidtmühlen zur Förderung ihrer Handwerksordnung ein Wappen, in dessen hier eingemaltem Bilde sich 8 Farbabteilungen befinden, von denen vier, die Jeinenen " und vier "die wullenen Meisterstücke“ bezeichnen.

Geg. in der Residenzstadt Neuburg a. D. - Herzogl. Siegel in Kapsel. - Orig. Perg. - $79: 31$.

1672, April 27.

220. Philipp Wilhelm, Pfalzgraf etc., verleiht den Schwarzfärbern auf dem Nordgau in den Bezirken und Orten Burglengenfeld, Schwandorf, Velburg, Hemau, Regenstauf, Beratzhausen, Laber, Luppurg, Kallmünz und Schmidtmühlen auf deren Ansuchen eine Zunftordnung nzur Abstellung aller Missbräuche, Stimpler- und Frettereien " (Preis- und Lohndrückereien), in welcher Ordnung die Färber von der „Obrigkeit" geschützt zu werden wünschen - in 39 Artikeln. Kulturgeschichtliches:

Art. 1. - Da nicht an jedem Orte zwei oder mehrere Färber seien, die zu Geschworenen gewählt werden könnten, so sollen zwei aus den gesamten Färber- und Mangmeistern des Nordgaues als Geschworene gewählt werden; Neuaufstellung letzterer nur successive. - Art. 4. An Feiertagen darf nicht gearbeitet werden. - Art. 12. Kein Meister darf Gelegenheit nehmen, das Handwerk mit Schmälerung des Lohns zu verstimpeln. - Art. 14. Redlichen Gesellen ist auf der Wanderung von den Meistern Herberge über Nacht zu geben. - Art. 17. Die Zunft hat verschiedene disziplinäre Strafrechte; gemeine Vorbrechen sind an Richter und Amtmann zu bringen; dem Verbrecher kann das Handwerk entzogen werden. - Art. 18. Kein Geselle darf Werktags ohne das Zeichen des Arbeitsverhältnisses (Schurzes) sich auf der Strasse umtreiben, zu Hochzeits- oder anderen Ehren-Zwecken ausgenommen. - Art. 20. Unehrliche Manipulationen im Handwerke sind zur Kenntnis zu bringen. - 
Art. 22 u. If. Von Erlangung der Meisterschaft, von Gesellen und Lehrlingen. - Art. 25. Der Meisterernennung soll eine "ehrliche Biermalzeit nach Vermögen“ des Ernannten folgen. Art. 27. Wenn ein Geselle oder eines Meisters Sohn eine Meisterin Witwe heiratet, muss or zur Ausübung des Handwerks gleichwohl die Lernjahre usw. zurückgelegt hahen. -- Art. 28. Verheiratete Gesellen sind nur zu fördern, wenn sie bei Weib und Kind wohnen und diese ernähren wollen. - Art. 35. Gesellen und Lehrjungen dürfen bei Krankheit (blosser ${ }_{n}$ Schadhaftigkeit ${ }^{\prime}$ ) nicht weggeschickt werden, sondern sie bekommen die Kost bis zur Wiedergesundung; bei gänzlicher Vermögenslosigkeit solle der Arztlohn der "gemeineu Büchse" entnommen werden. - Art. 36. Ebenso soll Meistern und Gesellen bei unverschuldeter Not aus der Büchse geholfen, auch, im Todesfalle, nach Ermessen der Geschworenen, das Begräbnis den armen Erben aus der Lade ersetzt werden.

Geg. zu Neuburg a. D. --. Regierungssekret in Kapsel. Orig. Perg.-Libell von 8 Folien.

$$
\text { * 1672, August } 12 .
$$

221. Verlassenschafts-Teilungsvertrag zwischen Philipp Nidernlangwater zu N.-Langwat') und dem Vormünder seiner vier Kinder wegen des Muttergutes nach Absterben der Margaretha, Philipp N.'s Ehefrau. Dem Vater verbleibt die ganze Verlassenschaft, d. h. das Bestand-Recht auf Haus und 1/4 Acker zu N-Langwat, pflichtig zu St. Achaz in Aich, und der ganze Zehent auf dem Kuglmayr-Gut zu Kirchdorf, bayer. Zinslehen, während er den Kindern zusammen $100 \mathrm{fl}$. zu gleichen Teilen als Muttergut hinauszubezahlen oder zu verzinsen, jedem Kinde eine sperrbare Truhe auszuhändigen und zur Verheiratung die gebräuchliche Morgensuppe zu reichen hat.

Siegel des Georg Emerling, bayer. Rats, Pflegers und Kastners auf Julbach, Mautners zu Braunau. - Orig. Pap. - Schadhaft.

$$
\text { 1673, April } 15 .
$$

222. Kurfürst Ferdinand Maria ersucht die Reichsstadt Frankfurt, dem bayer. Leutnant Franz Wilhelm v. Fackenhofen

1) Siehe No. 199, 206, 213. 
Aufenthalt daselbst zu gewähren. da Hoffnung bestehe, hier "einige Mannschaft aufzubringen ... und Uns in noch mehrere Kriegs-Verfassung zu stellen“.

Geg. zu München. - Ungesiegelt, doch mit eigenhändiger Unterschrift des Kurlürsten. - Pap.

1673, Juli 6.

223. Das Domkapitel bamberg'sche Kellereigericht Kaulberg fertigt der Witwe Ursula Katharina Geyer Zeugnis aus über ihre am 18. November 1642 erfolgte Verehelichung mit dem Domkapitel'schen Syndikus Johann Geyer und über die eheliche Geburt ihrer aus dieser Ehe entsprossenen vier Kinder.

Geg. zu Bamberg. - Siegel des Kellereigerichts. - Orig. Perg. - Urkunde schadhaft.

\section{5, April 8.}

224. Papst Clemens $X$. gewährt einen Ablass für den Altar der Bruderschaft zurn Hl. Altarsakrament in der Pfarrkirche zu Staffelstein. ${ }^{1}$ )

Breve. - Datum Romae .. sub annulo piscatoris. - Siegel (wie bei den meisten hernach folgenden Breven) abgelost. Orig. Perg. -. $39: 12$.

\section{* 1676, Februar 12.}

225. Kaiser Leopold erneuert dem Georg Christoph Strauss, kaiserl. Münzmeister in Graz, und dessen Bruder Peter Adel und Wappen, wie sie von Kaiser Ferdinand schon Philipp Strauss 1623 verliehen worden waren, und gewährt ihnen den Beinamen von Straussenegg und Breidtegg.

Geg. zu Wien. - Kaiserl. Siegel fehlt. - Orig. Perg.Libell von 10 Folien, mit gemaltem Wappen auf Fol. 6.

\section{6, September 4.}

226. Die Kinder der weil. Maria, gew. Ehewirtin des Stephan Mayr zu Holzham, ${ }^{2}$ ) quittieren ihren Vormündern über Empfang von 120 fl. $43 \mathrm{kr}$. Muttergut und richtige Abrechnung.

Siegel des Daniel Ris, bayer. Rats, Pflegers und Kastners zu Julbach etc. fehlt infolge Beschädigung der Urkunde. - Orig. Pap.

1) Siehe No. 236. ') Bez.-A. Pfarrkirchen. 


\section{8, April 4.}

227. Kurfürstliche Ausschreibung, wonach nur jene Thaler im Kurfürstentum 1 fl. $45 \mathrm{kr}$. gelten, welche Schrott und Korn nach Reichssatzung haben, während Schweizer-, Burgunder- und Holländer-Thaler nur für $1 \mathrm{fl}$. $40 \mathrm{kr}$. gangbar sein, Öttingenund Ansbach'sche Thaler nicht angenommen werden sollen, da sie eventuell in drei Monaten in Verruf erklärt werden.

Geg. zu München. - Kurfürstl. Siegel. -. Unter dem Text die Abbildung der minderwertigen Thaler von Holland, Costanz, Zürch, Bisanz, Genf, Schafhausen, Bern, Geldern und Burgund. - Orig. Pap. - 41:63.

1678, Mai 30.

228. Vergleich, geschlossen vor dem Hofrat zu München, zwischen den Webern im Starnberger Gerichtsbezirk und der Hauptlade der Weber zu München wegen Einbeziehung der ersteren in letztere, wegen Unterhaltung des Hochgerichts (Galgens) im Bezirk Starnberg gegen Kapitalshinterlegung von $100 \mathrm{fl}$. und das Versprechen der Starnberger Weber, dass sie auf Abschaffung der Last dringen, mit Leiter und Strick beim Galgen zu erscheinen. ${ }^{1}$ )

Kurf. Hofratssiegel anhängend. - Orig. Perg. - $57: 24$.

$$
\text { 1680, November } 14 .
$$

229. Kurfürstl. Erlass an den Pfleggerichtsverwalter zu Kirchberg Dr. Joh. Stäbhuber, ,betreffend die Konferenzen der kurfürstl. Beamten mit dem Archidiakon des Ruralkapitels wegen Spendung der Sakramente und Zahlung der Geistlichen zur Zeit einer Kontagion."

Gez. Regierung Landshut. - 1 Fol., Pap., Fragment eines Schreibens, dessen erstes Folium fehlt.

1680, November 26.

230. Georg Schmidt und Caspar Höfor, Bürger und Vierer der Schwarz- und Schönfürber zu München, bestätigen dem Georg Schickholz aus Jettenbach behufs Niederlassung zu

1) Siehe No. 237. 
Berazhausen ${ }^{1}$ ) im Herzogtum Neuburg, dass er drei Jahre (1655-58) bei dem Färber- und Mangmeister Hanz Mörz zu München gelernt hat, freigesprochen wurde und sich seither wohl verhalten hat.

Mit dem Siegel des Dr. Ambr. Sarotory, Hofgerichtsadvokaten, Stadtunterrichters, geschwor. „Siegelherrn und Gastrichters ${ }^{-}$. - Orig. Perg.

\section{1, Februar 18.}

231. Der freising'sche Markt Isen ${ }^{2}$ ) erteilt dem Hans Kollmüller, geboren daselbst, behufs Niederlassung in Kallmünz ein Geburtszeugnis.

Mit dem Siegel des Marktes. - Orig. Perg.

1682, Dezember 3.

232. Albrecht Sigmund, Bischof von Freising und Regensburg, Herzog von Bayern etc., verkündigt zwei Breve des „Obristen Bischofs“ Papst Innocenz' XI. vom 19. Juni und 14. Juli 1682, wonach derselbe auf Ansuchen des Herzogs Maximilian Philipp zu München für den Besuch der kurfürstl. Hof-Kapelle zu Mariä Einpfängnis daselbst usw. einen ewigen Ablass gewährt.

Aufgedrücktes bischöfl. Kanzleisiegel abgefallen. - Mit eigenhändiger Unterschrift des Bischofs. - Orig. Perg. - 59: 55.

\section{2, Dezember 15.}

233. Georg Heinrich v. Stadion, der Stifte Bamberg und Würzburg Domkeller, des Ritterstiftes Comburg Propst, Oberpfarrherr zu Cronach, belehnt als Obleyherr der Erbobley (Gundelsheims) gemäss alten Spruchs von 1511 den Joh. Franz Zollner v. Brandt, Bischberg und Bamberg mit 3 Gütern zu Kattenreuth als "rechtem Lehen, so man Söhnen und Töchtern zu leihen pflegt".

Siegel des v. Stadion fehlt. - Orig. Perg.

1) Bez.-A. Parsberg.

2) Bez.-A. Wasserburg.

) Siehe No. 212. 


\section{3, März 16.}

234. Kurfürst Max Emanuel erhebt das Geschlecht der Auer v. Winkel (Gottfr. Adolf und Christoph Joachim, Gebrüder) in den erblichen Freiherrnstand mit dem weiteren Beinamen v. Rernbach und dem Prädikat ${ }_{n}$ Edel $^{*}$ und erneuert das Auer'sche Wappen.

Geg. zu München unter kurf. Siegel und eigenhänd. kurf. Unterschrift. - Hier unterm 14. Nov. 1684 durch den Regierungsadvokaten und Stadtsyndikus Liz. Balth. Holzhay zu Landshut beglaubigte Kopie. - Perg.-Libell von 7 Folien; auf Fol. 4 das Wappen in künstlerischer Ausführung.

1684, Februar 28.

235. Marguard Sebastian, Bischof zu Bamberg, belehnt Ernst Alexander von Aufsess auf Mengersdorf nebst Familie unter Aufzählung der männlichen Mitglieder mit dem „Sitz zu Mengersdorf" ${ }^{\prime}{ }^{1}$ ) bestehend in diesem, dem "halben Bau" daselbst, der bei 70 Tagw. Feld und 13 Tagw. Wiese dem Hochstift jährlich ca. $50 \mathrm{fl}$. zinst, in 150 Tagw. Holz, 2 Weihern, $T$ weiteren Gütern zu Mengersdorf, 4 Sölden usw. - Die genaue Bezeichnung der Ausmasse der zahlreichen Grundstücke und Anwesen, ihrer Lage, Jnhaber und Erträgnisse verleiht der Urkunde wirtschafts-geschichtlichen Wert.

Mit dem bischöflichen Sekret. - Orig. Perg.

1686, April 3.

236. Papst Innocenz gewährt einen Ablass für den Altar der Sakraments-Bruderschaft in der Pfarrkirche zu Staffelstein zu Gunsten der verstorbenen Bruderschaftsmitglieder. ${ }^{2}$ )

Päpstl. Breve. - Datum Romae . . sub ann. pisc. Orig. Perg.

\section{8, März 12.}

237. Vergleich, abgeschlossen vor dem Hofrat zu München, wonach die Hauptlade der Weber daselbst die Weber des Gerichtsbezirks Kranzberg ${ }^{3}$ ) in ihren Verband aufnimmt, wenn

1) Bez-A. Bayrouth. 2) Siehe No. 224.

s) Bez.-A. Freising. - Siehe No. 228. 
letztere die sogen. Hofgerichtsbürde durch einen auf Grundstücken gesicherten ewigen Zins von jährlich ó fl. abgelöst haben werden. Die Bürde bestand in jedesmaligem Errichten des Galgens zu Göpferzhausen, Dietersheim und Schmiedhausen und im Anlehnen der Leiter bei der Exekution des "Strangulierens".

Gesch. zu München mit dem anhängenden Hofratssiegel. -Orig. Perg. $-61: 35$.

1695, Februar 22.

238. Max Gottfried und Johann Philipp Schenken von Stauffenberg, Brüder, Pfleger der Äınter Wernfels, Spalt und Amberg, belehnen nach Ableben des Bischofs Marqu. Sebastian den Adam Franz Zollner v. Brand auf Bischberg mannlehensweise mit 1 Gut zu Staffelstein, 1 Wiese bei der Herrgottsmühle, mehreren Äckern an der Bamberger Strasse, 2 Sölden, 1 Gütel zu Drosendorf und $1 / 8$ Zehent zu Brunn. 1)

Geg. zu Greifenstein. - Siegel der v. Stauffenberg fehlen. - Orig. Perg.

1696, Februar 20.

289. Die Gemeinde Frankenhofen ${ }^{2}$ ) erhält von Georg Christoph von Kaltenthal auf Osterzell, das Recht, eine Quelle auf dem Grunde des letzteren in ihr Dorf zu leiten und zu nützen und wahrt dem Kaltenthal'schen Beständer sein Angerrecht auf dem Grundstücke, wo die Quelle entspringt.

Siegel des Karl von und zu Werdenstein, Pflegers zu Buchloe, fehlt. - Orig. Perg.

1696, Juni 22.

240. Johann Gottfried, Bischof von Würzburg, erneuert die bischöfliche Taxordnung für , verschiedene Löhne. Arbeiten, Baumaterialien und Feilschaften“, da die „Bauherrn und Haushalter unrechtmässig übernommen . . . und um das Ihrige gebracht werden". Es wird Preis und Qualität festgesetzt für die Artikel der Wagner (58 Artikel), der Schmiede (61 Art.), Sattler, Seiler, Schuster, Rotgerber, Weissgerber, Schlosser, Kupferschmiede, Steinmetzen, Schreiner, Glaser, Hafner, Kannengiesser,

1) Siehe No. 208. 2) Bez.-A. Kaufbeuren. 
Büttner, Schneider, Maurer und Zimmerleute, Dachdecker, Tüncher, Ziegler und Kalkbrenner, Kärner, Totengräber, Leichansager, Altmacher (Flickschuster), Schrödter (Weinverlader), Drechsler und ungenannter Handwerker, Dienstboten. - Von statistischem Interesse.

Geg. zu Würzburg. - Druck, Pap.-Libell von $10 \mathrm{Fol}$. Durch Moder schadhaft.

\section{9!!, Juni 27.}

241. Das nach dem Landtage von 1669 wiederholt verbotene "Äntzgefährte" wird zu Gunsten des „Deichselfuhrwerkes" neuerdings verpönt. Es wird darauf aufmerksam gemacht, dass „der Äntz, worunter nit weniger das Gutschen- und ander dergleichen Gefährt zu verstehen," von den Fuhrleuten gegen die Deichsel ausgetauscht werden kann und letztere oft betrüglich auf der Fahrt nur beim Passieren der Kontrollstellen eingesetzt wird.

Druck, Pap., 2 Folien

$$
\text { 1700, Januar } 11 .
$$

242. Papst Innocenz XII. genehmigt einen vollkommenen Ablass für die Kirche St. Anna zu Staffelstein.

Breve. - I)atum Romae .. sub ann. pisc. - Orig. Perg. $-42: 14,5$.

$$
\text { 1701, April } 1 .
$$

243. Papst Clemens XI. genehmigt einen vollkommenen Ablass für die ['farrkirche St. Kilian zu Staffelstein.

Breve. - Datum Romae . . sub ann. pisc. - Orig. Perg.

$$
\text { 1706, Juni } 30 \text {. }
$$

244. Papst Clemens $X I$. gewährt einen Ablass für die Adelgundenkapelle (Staffelstein).

Breve. - Datun Romae .. sub ann. pisc. - Orig. Perg.

$$
\text { 1707, Juli } 6 \text {. }
$$

245. Ablass Papst Clemens' XI. für die St. Annakapelle zu Staffelstein.

Breve. - Datum Romae .. sub ann. pisc. - Orig. Perg. 
1715, November 22.

246. Kurfürst Max Emannel beauftragt den mit Instruktion auf Mission befindlichen Grafen v. Seinsheim, über die Verheiratung des Kurprinzen sich nicht etwa auszulassen, als hätte er sie zu betreiben, da auch die Instruktion hiervon nichts enthalte; Hinweis auf Merman (Residenten in Wien).

Eigenhändiges Schreiben des Kurfürsten in französischer Sprache. - Pap., $13: 19$.

\section{5, Dezember 14.}

247. Papst Clemens XI. erteilt dem Kardinaldiakon zu Rom, Damian Hugo von Schönborn-Bucheim Dispens von den ihm fehlenden Rechten eines Domkanonikus und gibt ihm die eventuelle Anwartschaft auf den Bischofsitz in Speyer oder Eichstätt.

Breve. - Datum Romae . sub ann. pisc. - Orig. Perg. $-42: 30$.

$$
\text { * 1716, Mai } 29 .
$$

248. Kaiser Karl VI. ernennt den Obristfeldwachtmeister Philipp la Marre zufolge seiner in Ungarn, im Reichs- und im italienischen Kriege erzeigten Fähigkeiten zum FeldmarschallLeutnant.

Geg. zu Wien. - Kaiserl. Siegel. - Mit eigenhändiger Unterschrift des Kaisers und des Prinzen Eugen von Savoyen. - Orig. Pap. - $58: 43$.

\section{2, September 11.}

249. Der kurfürstl. Hofrat zu München lässt der Stadt Rain in 22 Artikeln eine revidierte Krämer-Zunftordnung ausfertigen.

Geg. zu München. - Hofrats-Siegel fehlt. - Orig. Perg.Libell, 10 Folien.

$$
\text { * 1730, Juli } 20 .
$$

250. Die Kürschnermeister der Stadt Grieskirchen ${ }^{1}$ ) stellen denı Innungsmitgliede Jos. Adlmannseder in Riedau behufs Domizilwechsels einen Abschied über Tüchtigkeit und Wohlverhalten aus.

„Siegel des Handwerks". - Orig. Perg.

') Oberösterreich. 


$$
\text { 1731, Januar } 27 .
$$

251. Papst Clemens XII. erneuert den Ablass zu Gunsten der Armen, welcher am Bruderschaftsaltare zum Hl. Altarssakrament in der Pfarrkirche zu Staffelstein abgehalten wird.

Breve. - Datum Romae . . sub ann. pisc. - Rest des Siegels erhalten. - Orig. Perg.

\section{1, Juni 11.}

252. Ehe- und Erbvertrag zwischen Karl Alexander Grundherr von Altenthan 1) und der Maria Barbara Winkler von Mohrenfels, wonach letztere $3000 \mathrm{fl}$. Heiratgut und ausserdem $12000 \mathrm{fl}$. "nach Art der Einshand-Güter", ersterer $1000 \mathrm{fl}$. einbringt. In seinem Todesfalle erhält die Witwe $4000 \mathrm{fl}$. Das Überlebende erbt das gemeinschaftlich Erworbene.

Geg. zu Nürnberg. - Siegel des Joh. Jak. Tucher von Sinmelsdorf und des Christ. Gottl. Scheuerl fehlen. - Orig. Perg.

\section{1, Juni 11.}

253. Duplikat des Ehevertrags unter No. 252. - Ohne Siegel. - Perg.

$$
\text { 1732, Dezember } 28 .
$$

254. F. Hartmann aus Brixen ('Tirol), General des Kapuziner-Ordens, bezieht Abt und Kloster zu Ettal in Erwiderung erwiesener Wohltaten in das Gebet der Kapuziner ein.

Datum Bulsani. -- Papiersiegel (Stampiglie). - Text vorgedruckt, mit Kupferstichumrahmung. - Perg.

$$
\text { 1736, Juni } 1 .
$$

255. Fr. Onuphrius Sutton, Provinzial des Predigerordens für Oberdeutschland, nimmt die Familie des Hofrats Gallus Heinrich Degen ihrer charitativen Tätigkeit wegen in die Gebetsgemeinschaft seines Ordens auf.

Datum Bambergae. - Siegel des Provinzial-Priorats. Text vorgedruckt. - Orig. Pap.

1) Bez.-A. Nürnborg. 


\section{7, August 1.}

256. Franz X. Kentlin, Bürger und Handelsmann zu Augsburg, stellt dem Joh. M. Lanz, Bierbräuers-Sohn aus München, Zeugnis über zurïckgelegte dreijährige Lehrzeit im Kaufmannsgewerbe aus.

Siegel fehlt. - Der kalligraphische Text mit Randleisten in Federzeichnung geziert. - Perg.

\section{0, August 31.}

257. Aus Luneville wird (durch einen gewissen Custen) an den bayerischen Hof zu München berichtet, dass der Kurfürst das Portrait eines merkwürdigen „petit bébé“; welches er unlängst gesehen, sich verschaffen könne. Der Maler habe übrigens das Portrait des Kleinen, gewöhnlich „en houzard“ gemalt, schon an verschiedene Höfe geliefert usw.

A Lunéville. -- Brief in französ. Sprache, Pap.

\section{1, August 11.}

258. Ablass Papst Benedikts XIV. für die Pfarrkirche U. L. Frau zu Staffelstein.

Breve. . Datum Romae .. sub ann. pisc. - Orig. Perg.

1744, Juli 28.

259. Kaiser Karl Albrecht erneuert dem Tobias Fetscher, priv. Hof kartenmacher und Kartensiegel-Verweser, ausschliesslich das Privilegium, französische Karten zu fertigen, wie dies schon $1720 \mathrm{ihm}$ zugestanden worden, dann diese Karten selbst zum Verkauf zu bringen und mit einem "gewissen Petschaft" gegen Mischung mit anderen Karten zu sichern.

Geg. zu Frankfurt a. M. - Mit eigenhänd. Unterschrift des Kaisers. - Grosses kaiserl. Siegel. - Orig. Perg.-Libell, 4 Folien.

1745, Juni 17.

260. Friedrich, Markgraf von Brandenburg, genehmigt, dass der Kammerjunker und Hauptmann Joh. Heinr. v. Dobeneck 
1000 Tler. auf das ihm verliehene Mannlehen Schlegel ${ }^{1}$ ) aufnehme, um mit den Zinsen die Erziehung seiner Tochter Eleonore Auguste zu förlern.

Geg. zu Bayreut. - Siegel fehlt. -... Orig. Perg.

1746, Mai 12.

261. Johann Lorenz Koppleter, Handelsmann zu Wasserburg a. I., stellt dem Lorenz Rott über die bei ihm zurückgelegte Lehrzeit Abgangszeugnis aus.

Mit dem Siegel des Ausstellers. - Perg. - Der kalligraphische Text umrahmt von kunstreich ausgeführten Ornamenten in Federzeichnung; das Kapselsiegel an blauseiduem Band; letzteres in das Pergament dekorativ eingeflochten. $70: 53$.

\section{1, April 6.}

262. Joh. Georg Müller, bischöfl. Stuckhauptmann zu Würzburg, erteilt dem Joh. Lorenz Roth von Würzburg, Stückgiesser, einen Lehr-Entlassbrief aus der „löbl. Frei-Kunst der Büchsenmeister- und Feuerwerkerei und anderen in die Artillerie gehörigen Wissenschaften", nachdem derselbe eine Probe abgelegt zu "sattsanem Vergnügen" Sr. Exz. des Reichsfreiherrn Christ. C. von und zu Bastheim, würzburg. Geh. und Hofkriegsrats, Gen.-Feldzeugmeisters und Obristen über ein Regiment zu Fuss, Kommandanten der Stadt Würzburg auf Feste Marienberg, sowie des Balth. v. Neumann, Artillerieobristen des Fränkischen Kreises, Premiers-Ingenieurs und ersten Architekten zu Würzburg u. A.

Geg. zu Würzburg. - Siegel des Ausstellers und der beiden Zeugen beigedrückt. - Perg. - Text durch Randleisten, mit würzb. Wappen und Kriegsemblemen in Farben geziert. - 80:57.

\section{* 1756, Januar 17.}

26:3. Papst Benedikt XIV. erwidert die Glückwünsche Clemens August's, Erzbischofs und Kurfürsten zu Köln, aus Anlass des Jahreswechsels.

Breve. -- Datum Romae .. sub ann. pisc. - Orig. Perg. $-38: 24,5$.

1) Bez.-A. Hof. 
* 1760, März 4.

264. Kaiserliche Ausschreibung des von Reichswegen erfolgten Verrufes vom Herzog zu Braunschweig-Wolfenbüttel geschlagener minderwertiger Münzen.

Patent, Druck, Pap., mit Abbildung von 16 Münzen. - 62 : 55 .

1762, Мӓгz 26.

265. Dekret, Verleihung des Titels eines Hoffrüchtenhändlers an Jos. Gaugg in München betr.

Mit eigenhändiger Unterschrift des Kurfürsten. - Siegel der Geheimen Kanzlei. - Orig. Pap.

1762, Mai 13.

266. Die kurfürstlich bayer. Akademie der Wissenschaften ernennt den Ignaz Dominikus Schmid zu ihrem ordentlichen Mitgliede.

Dat. Monachii. -- Siegel der Akademie. - Handschriftlich gezeichnet von Eman. Graf v. Törring-Gronsfeld, Sigm. Graf Spreti, Chev. du Buat und P. Ildephons Kennedy Sekretär. Orig. Perg. mit Vordruck. $-35: 27$.

1764, September 17.

267. Die Innung der Kupferschmiede zu Wien stellt dem Gesellen Andreas Häffner aus Forchheim Arbeits- und Aufenthaltsattest aus.

Siegel der Kupferschmiede. -- Text in Kupferstichrahmen, mit der Stadt Wien im Titel. - Pap. - 51:37.

\section{5, Dezember 2.}

268. Die ,churfürstl.-landschaftlich gemeinsame Schuldenabledigungs-Werks-Commission " erteilt den Söhnen des verlebten "churf. Oberhoftaktors Judens Wolfen Wertheimber" eine (gedruckte) "Assekuranz", lautend auf 1848 fl. 3 kr., welche Assekuranz nach vorheriger Anzeige bei der genannten Kommission „cessionsfähig" ist.

Mit den Siegeln der zwei Landschaftskommissäre. - Quittiert von „David Joseph Wertheimber, K. K. Hof-Jud und Churbayer. Hoffaktor". - Pap. Folio. 


$$
\text { 1767, August } 29 .
$$

269. Die Innung der Kupferschmiede zu Ofen stellt dem Gesellen Andreas Häffner aus Forchheim Zeugnis aus über Aufenthalt und Handwerksleistung.

Mit dem Siegel der Kupferschmiede. - Blatt mit Kupferstich-Umrahmung, im Titel die Stadt Ofen. - Pap. - 45: 37.

\section{9, Mai 24.}

270. Joh. Mich. Karl Oberndorfer, kurbayer. Regierungsadvokat zu Burghausen, J. U. Lic., Hofrat in München, Comes palatinus, spricht den vor ihm erschienenen, unehelich geborenen, doch wohl erzogenen Kaspar H., 8jährigen Sohn des Knechtes Michael H. und der ledigen Bauerstochter Theresia M., beide von Mittenberg, von dem Makel der unehelichen Geburt frei, „so dass er durchgehends für ehelich gehalten und zu allen geistlichen und weltlichen Ständen, Ehren etc., Handwerken, auch Erbschaften ..... zugelassen " und ihm seine Geburt ${ }_{n}$ in keinerlei Weise, wie es von Menschen Sinn und Witz erdacht werden könnte, fürgeworfen . . oder fürgerupft" werden könne.

Gesch. zu Burghausen. - Siegel des Ausstellers fehlt. Orig. Perg. $-56: 33$.

1770, September 3.

271. Die Fleischerinnung zu Wien stellt dem Joseph Hardl aus 'Tirschenreut über Aufenthalt und Arbeitnahme zu Wien Zeugnis aus.

Urkunde verdorben. - Perg.

1774, September 6.

272. Das Zeitungsprivilegium des weil. Hof kammer- und Kommerzienrats Brunner zu Bayreuth wird auf dessen Erben, den Geh. Kammerrat Christoph Heinr. Hagen daselbst übertragen, wobei die Brunner'schen Verleihungsurkunden de do. Bayreuth 28. Juni 1754 und 17. Juni 1763, dann deren Erweiterung de do. Ansbach 26. Oktober 1769 in extenso wiederholt werden. Das Privilegium perpetuum (seit 1754) erstreckt sich auf Sammlung öffentlicher Drucknachrichten, auf eine neue französische Zeitung, betitelt „Evenements interessants“, das 
Bayreuter politische und Intelligenzblatt und auf Erlangische

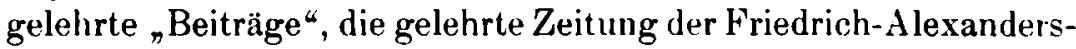
Universität ausgenommen. Das Privileg erstreckt sich auf Druck, Verlag und Postfreiheit. Von den Zeitungen sind Frei-Exemplare an die Mitglieder des markgräfl. Hauses, des Ministeriums und der Regierung zu Bayreuth, an die Archive zu Bayreuth und Plassenburg usw. auszufolgen.

Gesch. zu Bayreuth. - Mit dem Regierungssiegel und der eigenhändigen Unterschrift „Alexander" Mg. B. - Orig. Perg.Libell, 4 Folien. - $33: 37$.

\section{* 1776, Dezember 8.}

273. Kardinal Alessandro Albani, kaiserlich deutscher Plenipotentiär zu Rom, stellt für den bamberger Kanonikus Johann Schott einen Pass aus.

Dato in Roma. - Nach Formular. - Pap.

1777, April 28.

274. Papst Pius VI. gewährt einen Ablass für die St. AnnaKapelle zu Staffelstein.

Breve. - Datum Romae . . sub ann. pisc. - Orig. Perg.

$$
\text { 1780, Juni } 6 .
$$

275. Die Posamentier-Zunft zu Pressburg erteilt dem Joseph Lorenz von Neus(es) Arbeitsattest.

Pap., Druck, mit Darstellung Pressburgs.

1780, Mai 31.

276. Die Dachdeckerzunft zu Bamberg stellt einem Georg Schmitt daselbst Zeugnis über Arbeitnahme aus.

Siegel der Zunft. - Pap., mit Darstellung Bambergs im Titel des Vordrucks.

1782, Dezember 31.

277. Die brandenburg. Mundköche am Hofe zu Ansbach bezeugen dem Joh. Jak. Sicard seine an der Hofküche erhaltene Ausbildung.

Mit 9 Siegeln und Unterschriften, an orster Stelle die des Freih. Friedr. Ludw. v. Nostiz, Oberstküchenmeisters. - Orig. Perg. - 74: 48. 


$$
\text { * 1786, Februar } 24 .
$$

278. Militärabschied für Joh. Eman. Giese aus Stargard.')

Gez. v. Ivernois, Oberst des Gr. v. Schlieben'schen Inf.Regiments zu Stargard. - Pap., vorgedruckt.

$$
\text { * 1787, Januar } 3 .
$$

279. Christian Friedr. Timm ladet seine Jungfer Schwester zu seiner am 11. Januar a. c. stattfindenden Hochzeit mit Jungfer Charl. Soph. Krüger, Tochter des Arrendators auf dem k. Amtsgut Buchholz, ein.

Geg. Lübtow. ${ }^{1}$ ) - Pap., Text vorgedruckt.

$$
\text { 1787, April } 28 .
$$

280. Ablass Papst Pius' VI. für die St. Kilianspfarrkirche zu Staffelstein.

Datum Romae .. sub ann. pisc. -- Orig. Perg.

$$
\text { 1788, April } 13 .
$$

281. Die Bäcker zu Marktschorgast ${ }^{2}$ ) bestätigen dem W. Fr. Kraus aus Steinfeld, dass er während 1 Jahres und 6 Wochen bei ihnen in Arbeit gestanden.

Inmungssiegel. - Pap.

$$
\text { 1791, Mai } 12 .
$$

282. Franz Ludwig, Bischof zu Bamberg und Würzburg. Herzog zu Franken, ernennt den Leutnant im bamberg. InfanterieRegiment Joh. Jak. Bregler zum Oberleutnant.

Mit Unterschrift und Siegel des Bischofs. - Orig. Pap.

1793, Juni 24.

283. Zeugnis für $X$. Maurer aus Plattling ${ }^{3}$ ) über seine Arbeitsleistung bei den Schönfärbern in Wien.

Diplom wie No. 267.

1) Preuss. Reg.-Bezirk Stettin.

2) Bez.-A. - Berneck.

s) Bez.-A. Deggendorf. 
1793, November 13.

284. Ignaz Lang, kurfürstl. und bürgerl. „SeidenzengFabrikant" für Brokat-, Samt-, Ganz- und Halb-Seidenzeuge, bestäligt dem Georg Grässl, Backmeisterssohn aus München, dass er bei ihm 5 Jahre mit Erfolg in Lehre und Arbeit gestanden.

Mit dem Siegel des Stadtunterrichtès Edlen Ladislaus von Strixner, Siegelherrn und Gastrichters. - Orig. Perg.

1793, November 25.

285. Zeugnis für $\mathrm{X}$. Maurer aus Plattling über seine Arbeitsleistung bei den Schönfärbern in Pressburg.

Diplomformular wio No. 275.

1795, März 11.

286. Kaiser Franz II. zeigt dem Domkapitel zu Bamberg (Joh. Jos. Heinr. von Würzburg, Domkapitular) an, dass er zu der am 7. April daselbst stattfindenden Bischofswahl den Grafen v. Schlick, kaiserl. Gesandten zu Mainz, abordnen werde.

Geg. zu Wien. - Mit kaiserl. Siegel. - Eigenhändige Unterschrift des Kaisers. - Orig. Pap.

1796, Dezember 7.

287. Joseph Konrad, Bischof von Freising und Regensburg, Propst zu Berchtesgaden, belehnt den Freil. v. Aretin, Geh. und Oberlandesreg.-Rat, Oberst-Lehenhofskommissär zu München, mit dem adelichen Leheu Winkel im Erdinger Gericht samt dem Sedelhof, mit 2 Teilen Zehents aus 2 Höfen zu Schlegelsreut und dem Gickelsberger Gut zu Strohshofen, zu Irlach usw. - Das Lehen ist Ritter- oder Manuslehen, doch nsuccedieren die ferninae nach Abgang des Mannsstammes, ist feodum promiscuum " von Aretin durch seinen Bevollmächtigten Bernhard Lacense, bischöfl. Lehensekretär zu Regensburg, empfangen.

Geg. zu Regensburg. - Mit bischöfl. Siegel. - Orig. Perg. - Die Urkunde, von Stathalter (Domdechant v. Thurn und Valsassina) und Kanzler gezeichnet, ist bemerkenswert als Beispiel, wie seit längerer Zeit Sprache, Schrift, rechtliche Fassung und Ausfertigung bei amtlichen Schriftstücken allenthalben vernachlässigt wurden. Siehe Einleitung S. 172. 
288. Ablass für die Filialkirche in Hohengüssbach. 1)

Breve. - Dat. Romae .. sub annulo piscatoris. - Orig. Perg. - Seit 1675 (No. 224) in unveränderter Ausfertigungsform.

1800 , Oktober 8.

289. Der Abt von Michaelsberg bei Bamberg verleiht dem Philipp Ulrich, Verwalter des St. Ägidius-Hospitals, des letzteren Anwesen zu Memmelsdorf, ${ }^{1}$ ) bestehend in Hof, Stadel, Baumgarten und Feld, gegen jährliche Gült von 6 Käsen zu Pfingsten, 6 Käsen zu Weihnachten, 6 Eiern zu Ostern, 1 Fastnachthenne, 2 Herbsthühnern; in 12 Tagw. Wiesen (Spitalwiese) gegen jährlich 10 Sunera Korn, 4 Sumera Haber, 2 Fuder Heu; in 1 Wiese von 4 Tagw. (Marschwiese) gegen jährl. $4 \mathrm{~S}$. Korn und 1 Fuder Heu; in 1 Wiese von 4 Tagw. (Steinweg-Wiese) gegen jährl. 1 S. Korn, 1 S. Haber und 1 Fuder Heu. - Statt der 4 Fuder Heu können 20 fl. zum Kloster gegeben werden. Die Grundstücke wurden von Jak. Gebsattel gekauft; sie dürfen nur an einen Bürger oder Baluern weiterverkauft werden.

Mit dem Abtei-Insiegel. - Orig. Pap.

$$
\text { 1801, Juli } 22 .
$$

290. Christoph Franz, Bischof zu Bamberg, erklärt Stephan Förtsch, der von seinem Vetter Pankraz Förtsch zu Höchst a. M. ein Bräuhaus ererbt hat und 23 Jahre zählt, für grossjährig und auf Grund weiterer Zeugnisse über seine „vorzüglich guten wirtschaftlichen Eigenschaften" zur Ausübung des erlernten Braugewerbes zu Bamberg für befähigt.

Geg. zu Bamberg. - Mit Siegel und Unterschrift des Bischofs. - Orig. Perg.

* 1808, September 3 .

291. Die medizinische Fakultät der Universität Wien ernennt den Ant. Holzschuh aus Haimburg in Österreich nach Absolvierung der vorgeschriebenen Studien und erfolgreichst bestandenen Prüfungen zum Magister der Chirurgie und Geburtshilfe mit dem Rechte der Niederlassung als Chirurg.

Mit dem Siegel der Fakultät. -- Orig. Perg.

1) Bez.-A. Bamberg I. 
* 1809, März 6.

292. Die medizin. Fakultät der Universität Wien bezeugt, dass Aut. Holzschuh, Mag. chir., wïhrend zwei .Jahren als Stipendiat an der chirurg. Klinik daselbst öffentlich und mit vollenı Erfolge viele schwierige Operationen ausgeführt habe.

Siegel der Fakultät. -- Orig. Perg.

1810, Februar 28.

293. Franz X. Kellnberger, Kunstgärtner des k. bayer. Kämmerers und Staatsrats Ign. Jos. M. Grafen v. Arco auf Kollnbach etc. zu Bernried ') spricht den bei ihm 3 Jahre in der Lehre der Gärtnerei gestandenen Joh. Nep. Graf aus Oberkellenbach frei.

Der Text der Urkunde erscheint in reicher ornamentaler Umrahmung, bei der hauptsächlich Blumen und Gewächse in guter Ausführung eine Rolle spielen. - Das Siegel des Meisters in Elfenbein-Kapsel an grünem Seidenband, das in den unteren Teil der Perg.-Urkunde vermöge gefälliger ornamentaler Einschnitte sinnreich verschlungen ist. Angebracht sind Sprüche wie:

Ich treibe die Blühe, Wer hätte soviel Frucht

Zu krönen die Mühe. In einem Korn gesucht.

Meine Kunst und Wissenschaft

Braucht Gottes Gnad' und Segen,

Wie Blumen und Gewächs

Floriert durch Sonn' und Regen.

* 1839, August 6.

294. Rektor und Universität Wien verleihen Anton Holzschuh, Mag. chir., Professor am kais. Lyzeum zu Salzburg und I. Chirurgen am St. Johannesspital, unter Dispensation von prakt. und theoret. Prüfungen das Diplom eines Doctors der Chirurgie.

Mit dem grösseren Universitäts-Siegel und den Unterschriften des Rektors (Jak. Ruttenstock), des Präsidenten der medizin. Fakultät (Joh. v. Raimann), des Dekans (Mich. Visranik), des Professors (Sigm. Casp. Fischer) und Notars (Dr. J. Fr. v. Hieber). - Orig. Perg. - $55: 38$.

1) Bez.-A. Weilheim.

Arohivalisohe Zeitschrift. Nene Folge XII. 